\title{
WestVirginiaUniversity
}

THE RESEARCH REPOSITORY @ WVU

Graduate Theses, Dissertations, and Problem Reports

2011

\section{Ash removal from low rank coal}

Deepankar Virendra Sharma

West Virginia University

Follow this and additional works at: https://researchrepository.wvu.edu/etd

\section{Recommended Citation}

Sharma, Deepankar Virendra, "Ash removal from low rank coal" (2011). Graduate Theses, Dissertations, and Problem Reports. 4789.

https://researchrepository.wvu.edu/etd/4789

This Thesis is protected by copyright and/or related rights. It has been brought to you by the The Research Repository @ WVU with permission from the rights-holder(s). You are free to use this Thesis in any way that is permitted by the copyright and related rights legislation that applies to your use. For other uses you must obtain permission from the rights-holder(s) directly, unless additional rights are indicated by a Creative Commons license in the record and/ or on the work itself. This Thesis has been accepted for inclusion in WVU Graduate Theses, Dissertations, and Problem Reports collection by an authorized administrator of The Research Repository @ WVU. For more information, please contact researchrepository@mail.wvu.edu. 


\title{
ASH REMOVAL FROM LOW RANK COAL
}

\section{Deepankar Virendra Sharma}

Thesis submitted to the College of Engineering and Mineral Resources

at West Virginia University

in partial fulfillment of the requirements for the degree of

\author{
Master of Science \\ In \\ Chemical Engineering \\ John W. Zondlo, Ph.D., Chair \\ Elliot B. Kennel, M.S \\ Alfred H. Stiller, Ph.D \\ Department of Chemical Engineering
}

Morgantown, West Virginia

2011

Keywords:

Coal Cleaning, Lignite coal cleaning, Coal preparation Plants

(C) 2011 Deepankar Virendra Sharma 


\section{ABSTRACT \\ Ash removal from low grade coal \\ Deepankar Sharma}

The work presented here is concerned with cleaning of low rank coals such as Texas lignite. As a result, Jewett Texas lignite was cleaned from $28 \%$ ash by weight to $8.5 \%$. In the first part of the thesis, it is proved that conventional cleaning techniques used for bituminous and sub-bituminous having pyritic impurities does not work for cleaning lignite coal because of different coal chemistry and the presence of clay impurities. Hence after trying conventional processes, there was a need for a new technique capable of removing clay from low rank coals.

Micronized coal, obtained from DevourX LLC, proved to be more easily separated than run of mine coal, using a slurry-based technique with an agglomerant to isolate carbon rich particles and a lignin based surfactant. The coal was cleaned from $28 \%$ ash to $9.5 \%$ ash.

This project was sponsored by the Defense Advanced Research Project Agency (DARPA), under subcontract from the University of Texas at Arlington. 


\section{ACKNOWLEDMENT}

First and foremost, I would like to express my deep and sincere gratitude for my research advisor and Committee Chair, Dr. John W Zondlo, for his constant support, guidance and encouragement during the course of this work and without whom this work would not have been possible. I would also like to sincerely thank my committee members, Mr. Elliot B Kennel, for always being accessible and constantly advocating the use of safe practices in the laboratory, and in particular, Dr. Alfred H Stiller, for believing in me and taking time to teach me and answering all my frivolous question. Also for all the 'special' stories that you shared with all of us.

I would also like to extend my appreciation and kudos for my co-workers, in particular, Mr. Anthony Golden, Mr. Benson Njoroge and Mr. Olufemi Olajide for helping me out in the daily laboratory activities. Also, I would like to thank the staff members of the Department of Chemical Engineering, Mr. Liviu Magean and Ms. Gabriela Perhinschi, for doing all the proximate, elemental and ultimate coal analysis

I am extremely thankful and greatly indebted to my parents, Dr. V. K. Sharma and Dr. Asha Sharma for always believing in me. I couldn't have done this work without their support and well wishes. 


\section{Table of contents}

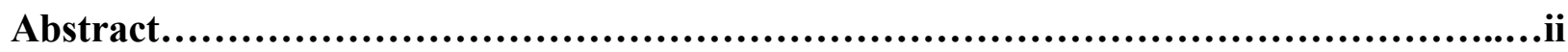

Acknowledgement................................................................................ii

Table of contents.........................................................................................

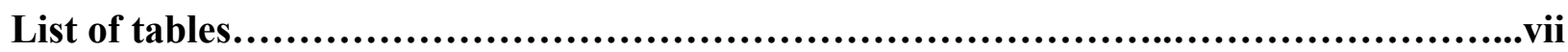

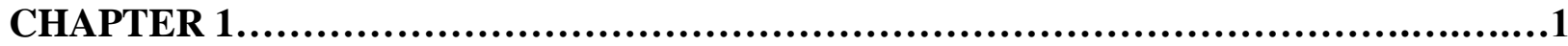

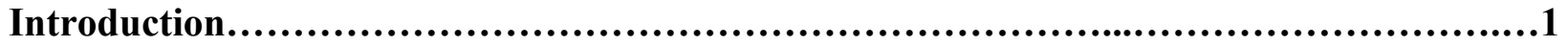

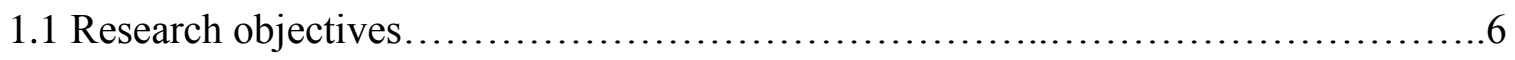

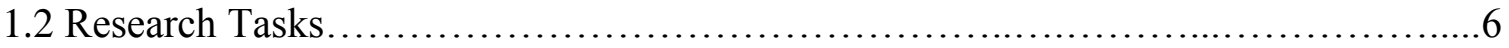

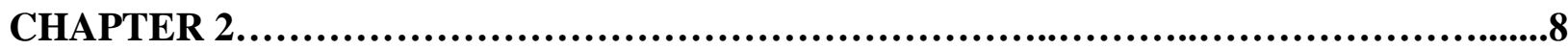

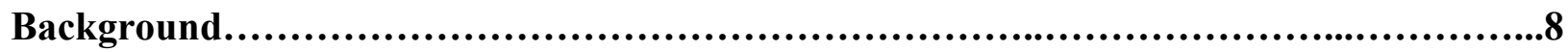

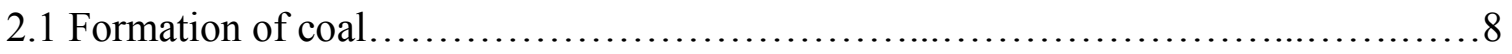

2.1.1 Biochemical phase of coal formation..................................... 8

2.1.2 Geochemical process of coal formation.................................... 9

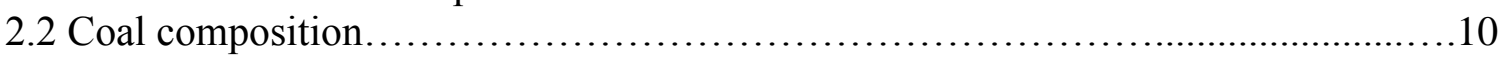

2.3 Proximate and elemental analysis of coal....................................... 10

2.4 Conventional coal cleaning process..............................................

2.5 Coal Cleaning process...........................................................

2.5.1 Enhanced gravity separators for cleaning coal fines.......................14

2.6 Froth Flotation technique.........................................................

2.6.1 Coal Froth Flotation Processes.............................................16

2.6.2 Froth Flotation Cell................................................17

Sulfurous Acid Treatment for Texas Lignite...................................18

2.7 Solvent Extraction of Coal.................................................. 19

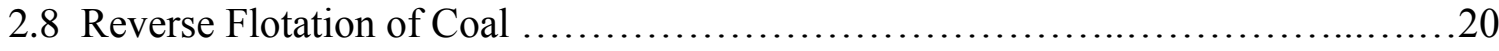

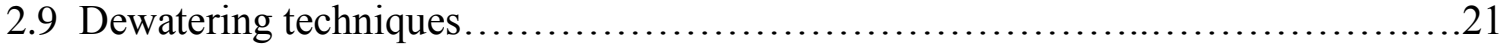

2.9.1 Role of surfactant absorption and study of adsorption

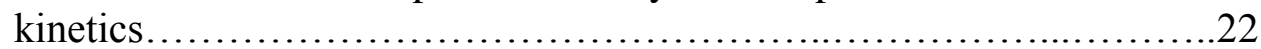

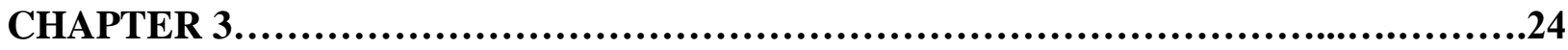

Experiments and Results.........................................................24

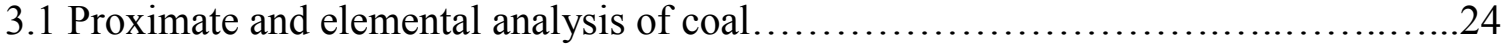

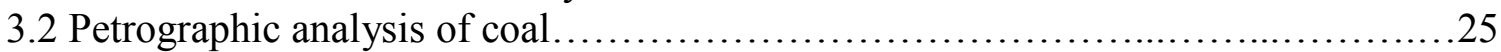




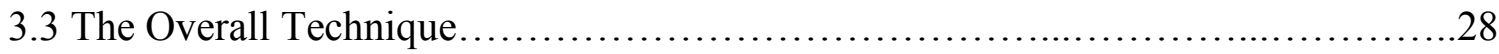

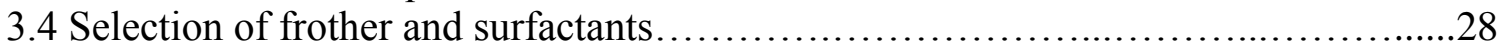

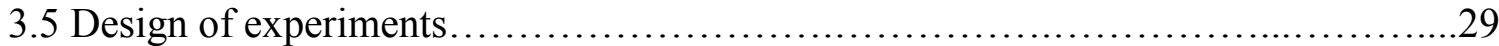

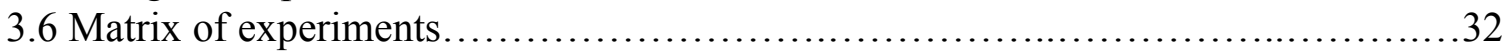

3.6.1 Matrix of the experiments..............................................33

3.6.2 Experimental Data and procedure for the second

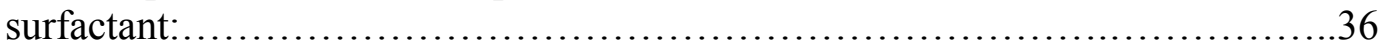

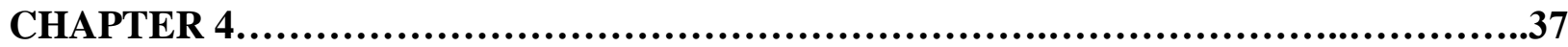

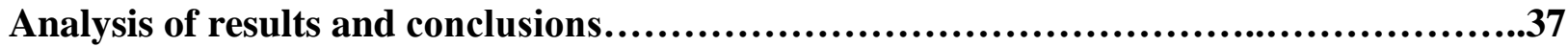

4.1 Results for froth flotation process for DDA and TMAB

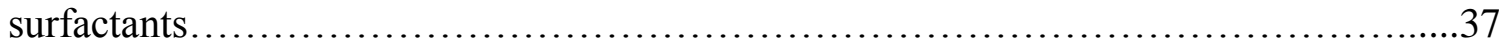

4.2 Analysis of results.......................................................... 41

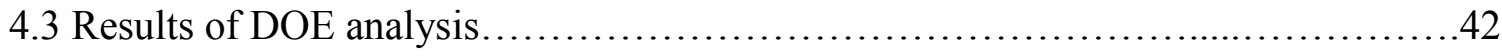

4.4 Conclusions for using conventional cleaning technique for cleaning Texas Jewett

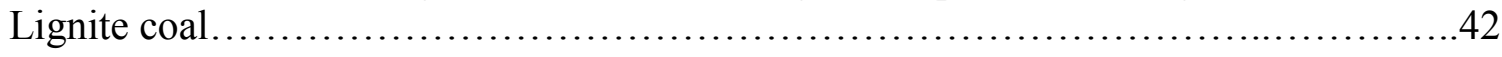

4.5 Non conventional cleaning techniques for cleaning Texas Jewett Lignite............43

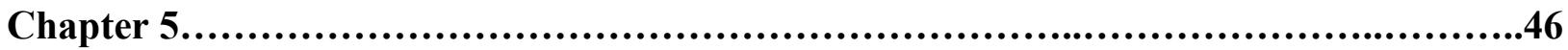

5.1 Cresylic Acid experiments........................................................

5.2 Separations using Particle sizes..............................................54

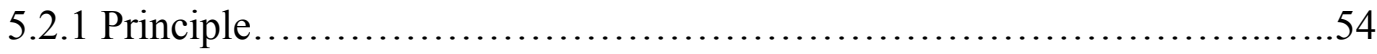

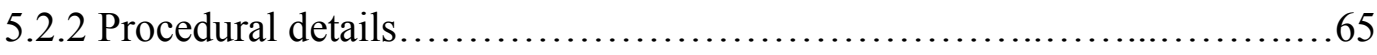

5.3 Comparison between particle size separation method and decantation method.......67

5.4 Refined protocol for the washing of coal...........................................

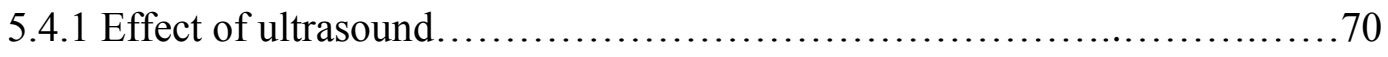

5.5 Incorporation of Float Sink for removing rock ash..............................72

5.5.1 Description of the Revised Protocol for cleaning coal.......................74

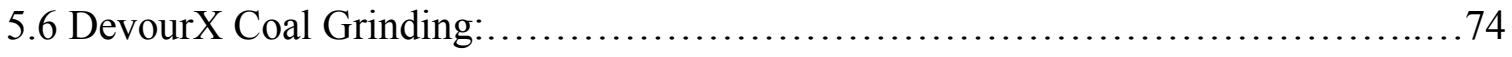

5.7 Cleaning DevourX coals using the process described in figure

5.12

5.7.1 Results for coal cleaning process performed on DevourX

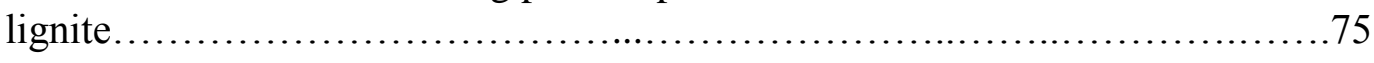




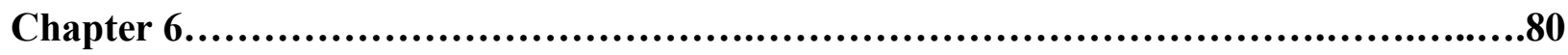

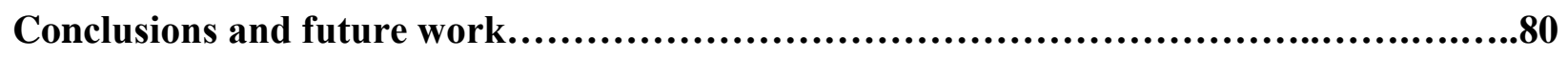

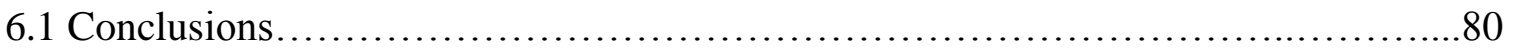

6.3 Recommendations for future work .......................................... 81

References..............................................................................83 


\section{List of Tables}

Table 1.1 ASTM Table for classification of coals ........................................

Table 3.1 Elemental analysis of Jewett Lignite Coal......................................24

Table 3.2 Results for the proximate analysis of Jewett Lignite Coal............................24

Table 3.3 The compositions of the reactive materials......................................26

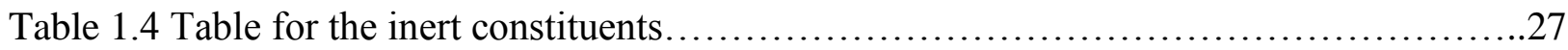

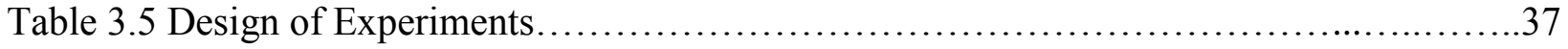

Table 3.6. Design of Experiments Matrix for DDA........................................... 41

Table 3.7 Proximate Analysis Results..................................................42

Table 3.8 Proximate analysis of the samples taken for froth flotation using TMAB as

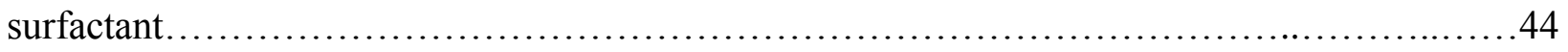

Table 4.1 Results from the calculations done for DDA surfactant............................47

Table 4.2 Results for ash in float and slurry for TMAB surfactant...........................48.

Table 4.3 Proximate analysis of samples for test run of cresylic acid and lignosulphonic salt as

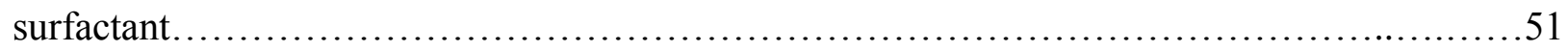

Table 5.1. Results from a Single Pass with Cresylic Acid Washing,

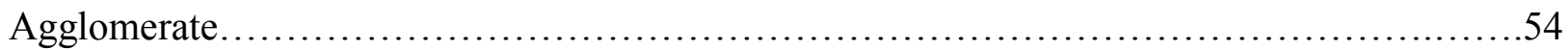

Table 5.2. Results from a Single Pass with Cresylic Acid Washing, Rejects......................54

Table 5.3 Mass and ash balance for decantation process.....................................55

Table 5.4. Results from Second run with Cresylic Acid Washing, Agglomerate..................55

Table 5.5. Results from a Second run with Cresylic Acid Washing, Rejects...................56

Table 5.6 Mass and ash balance for the second run with cresylic acid washing..................56

Table 5.7 Results from a Third Pass with Cresylic Acid Washing, Agglomerate..................57

Table 5.8. Results from a Third Pass with Cresylic Acid Washing, Rejects.......................57

Table 5.9 Mass and Ash balance for third run of Cresylic acid washing......................57

Table 5.10 Data from the experiments done with the cresylic acid protocol....................58 
Table 5.11 Results for Particle size separation method, Agglomerated Coal.

Table 5.12. Results for Particle size separation method, Rejects

Table 5.13 Ash balance and mass balance for the particle size separation method first run. .63

Table 5.14. Results of the Second Pass of particle size separation method first pass, coal.

Table 5.15. Results of the Second Pass of particle size separation method first pass, Rejects.

Table 5.16 Mass and ash balance of second washing using the Particle size separation method. .65

Table 5.17. Results for third pass of Particle size separation method, agglomerates .65

Table 5.18. Results for third pass of Particle size separation method, Rejects. .65

Table 5.19 Mass and ash balance of third washing using the Particle size separation method. .66

Table 5.20 Data from the experiments done with the Particle size separation protocol...........66

Table 5.21 Results of the Control Experiment (CE), Agglomerated Coal.....................71

Table 5.22. Results of the Control Experiment (CE), Rejects.............................71

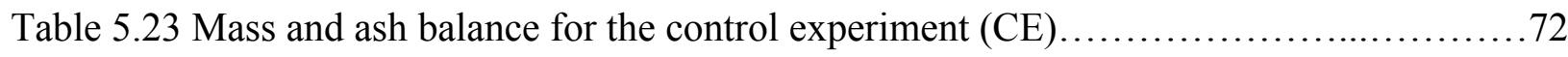

Table 5.24 Results for the Ultrasonic treatment of coal, Agglomerated Coal....................72

Table 5.25. Results for the Ultrasonic Treatment, Rejects..............................72

Table 5.26 Mass and ash balance for the Ultrasound experiment (US) $\ldots \ldots \ldots \ldots \ldots \ldots \ldots \ldots \ldots 72$

Table 5.27. Results with Ultrasonic Treatment, $2^{\text {nd }}$ washing Agglomerated Coal...............73

Table 5.28. Results with Ultrasonic Treatment, Second run, Rejects.........................73 
Table 5.29 mass and ash balance for Ultrasonic Treatment, Second Trial

Table 5.30 Data from the experiments done with the Particle size separation protocol with

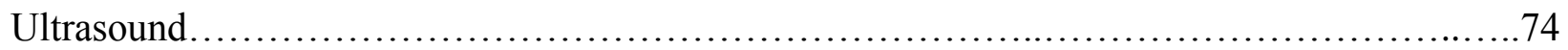

Table 5.31. Results of the 65-100 Mesh coal, Agglomerated Coal............................78

Table 5.32. Results of the 65-100 Mesh coal , Rejects.....................................................78

Table 5.33 Mass and ash balance for cleaning of 65-100 Mesh coal..........................79

Table 5.34. Results float sink performed on coal previously cleaned using the clay removal

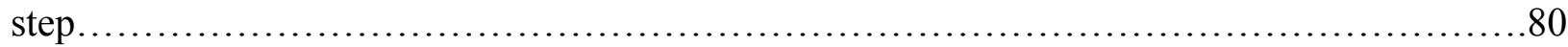

Table 5.35 Results for DevourX coal, cleaned by clay removal process..............................80

Table 5.36 Results for DevourX coal rejects, cleaned by clay removal process..................80

Table 5.37 Results for DevourX coal rejects, cleaned by float sink process....................80

Table 5.38 Results for DevourX coal rejects, cleaned by float sink process.....................81

Table 5.39 Mass Balance for the clay removal step.......................................... 81

Table 5.40 Mass Balance for the float sink step...................................... 82

Table 5.41 Results for SM coal, cleaned by clay removal process..........................82

Table 5.42 Results for SM coal rejects, cleaned by clay removal process....................82

Table 5.43Results orSM coal, cleaned by float sink process.............................84

Table 5.44 Results for SM coal rejects, cleaned by float sink process........................84

Table 5.45 Mass Balance for the clay removal step................................. 84

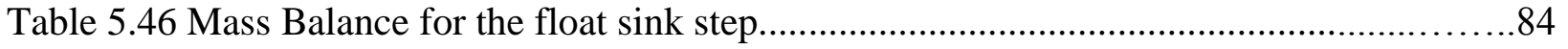




\section{List of Figures:}

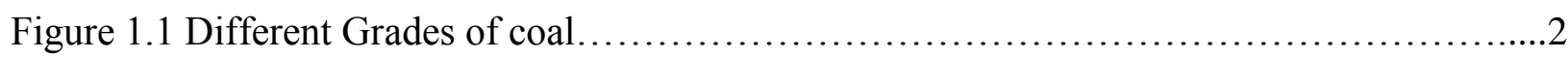

Figure 1.1 LECO Proximate Analyzer............................................ 10

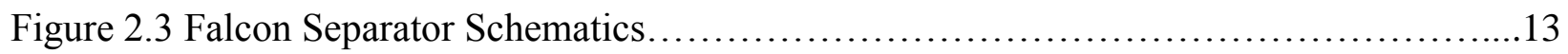

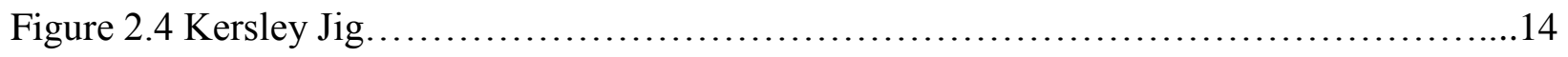

Figure 2.5 Froth Flotation Cell...................................................... 16

Figure 5.1 Protocol for cleaning coal using cresylic acid to agglomerate coal................45

Figure 5.2 Ash $(\%)$ vs Number of experiments......................................

Figure 5.3 Ash (\%) vs Coal recovered cresylic acid agglomeration method....................52

Figure 5.4 Particle size separation protocol for coal cleaning processes.....................53

Figure 5.5 Ash (\%) vs Number of experiments Particle size separation method................59

Figure 5.6 Ash (\%) vs Coal recovered Particle size separation method......................60

Figure 5.7 Particle size separation method vs decantation method.......................61

Figure 5.8 Inclusion of Ultrasound as an additional step to enhance ash removal.............62

Figure 5.9 Ash (\%) vs Number of experiments using Particle size separation method using

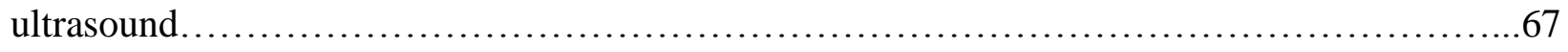

Figure 5.10 Ash (\%) vs coal recovered using Particle size separation method using ultrasound..68

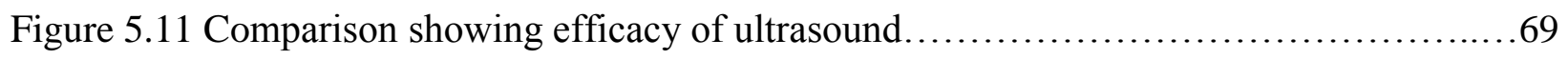

Figure 5.12 Revised protocol developed for coal cleaning $\ldots \ldots \ldots \ldots \ldots \ldots \ldots \ldots \ldots \ldots \ldots \ldots . \ldots 1$

Figure 6.1 Final Process developed for cleaning coal with clay impurities.....................84 


\section{Introduction:}

Carbon based fossil fuels include coal, oil and natural gas. These fossil fuels were formed over millions of years ago due to the decay of dead plant and animal matter under conditions of high pressure and temperature inside the Earth's crust. Fossil fuels, on combustion in the presence of oxygen, produce an enormous amount of energy, and thus, are of great importance in the present-day world. ${ }^{[1,2]}$

Coal, one of the carbon based fuels mentioned above, is a combustible sedimentary rock. It is black or brown in color and is found in layers in the earth's crust called beds. The coal deposits occur as 'seams' interbedded with inorganic sedimentary rocks and are formed by the deposition of organic materials through normal sedimentary processes. The remains of plants that are found in these seams reveal that coal is formed due to the slow decay of the organic matter which is different than the decay in normal environmental conditions because the latter is altered by various chemical and physical agencies. ${ }^{[4,5]}$ The hardness of coal varies with the type of coal. Anthracite is generally harder because it has metamorphosed longer, as it is exposed to elevated temperature and pressure. Coal is composed primarily of carbon along with variable quantities of other elements, chiefly sulfur, hydrogen, oxygen, nitrogen, silicon and a variety of metals like aluminum, iron etc. Coal like other fossil fuels is also a heterogeneous mixture of hydrocarbons and other organic and inorganic impurities such as clays, rock, water etc. This variable nature of coal identifies coal as a rock rather than a mineral. .

Coal derivatives are mostly aromatic compounds, while petroleum and gas derivatives are primarily aliphatic compounds. Advances in materials science over the years provide a definite advantage for the coal-derived compounds over petroleum and gas derivatives because aromatic compounds are the key building blocks for many new high-performance materials such as general engineering plastics, high temperature heat resistant plastics, aromatic resins, liquid crystalline polymers, etc. apart from a variety of carbon-based materials. ${ }^{[6]}$

The USA is the second largest producer of coal in world, second only to China. In the year 2008 the total production of coal in the United States was 1062.9 million tons ${ }^{[7]}$. The most important application of coal in the United States is generating electricity. $44.9 \%$ of the electricity generated in the US in 2009 was by coal-fired power plants. Other uses for coal are gasification, liquefaction and also making other materials of higher commercial value like 
graphite, coke, carbon foam etc. The state of West Virginia produces 15\% of the total production of coal in the USA. ${ }^{[7,8]}$

Coal is characterized in many ways. These characterizations include rank, type, grade, volatiles and caking qualities. Despite numerous ways of classifying coal there is a method set by the American Society for Testing Materials (ASTM). According to the ASTM, coal can be classified into three broad categories or ranks. This classification is made on the carbon content and inorganic content in a sample. This classification is not exact because other factors also change in different coals like the surface chemistry, volatile content and the fixed carbon content of the coal. Figure 1.1 shows the example of coal classification by heating value (hv) and carbon content. Table 1.1 discusses various ranks of coal and their components. 


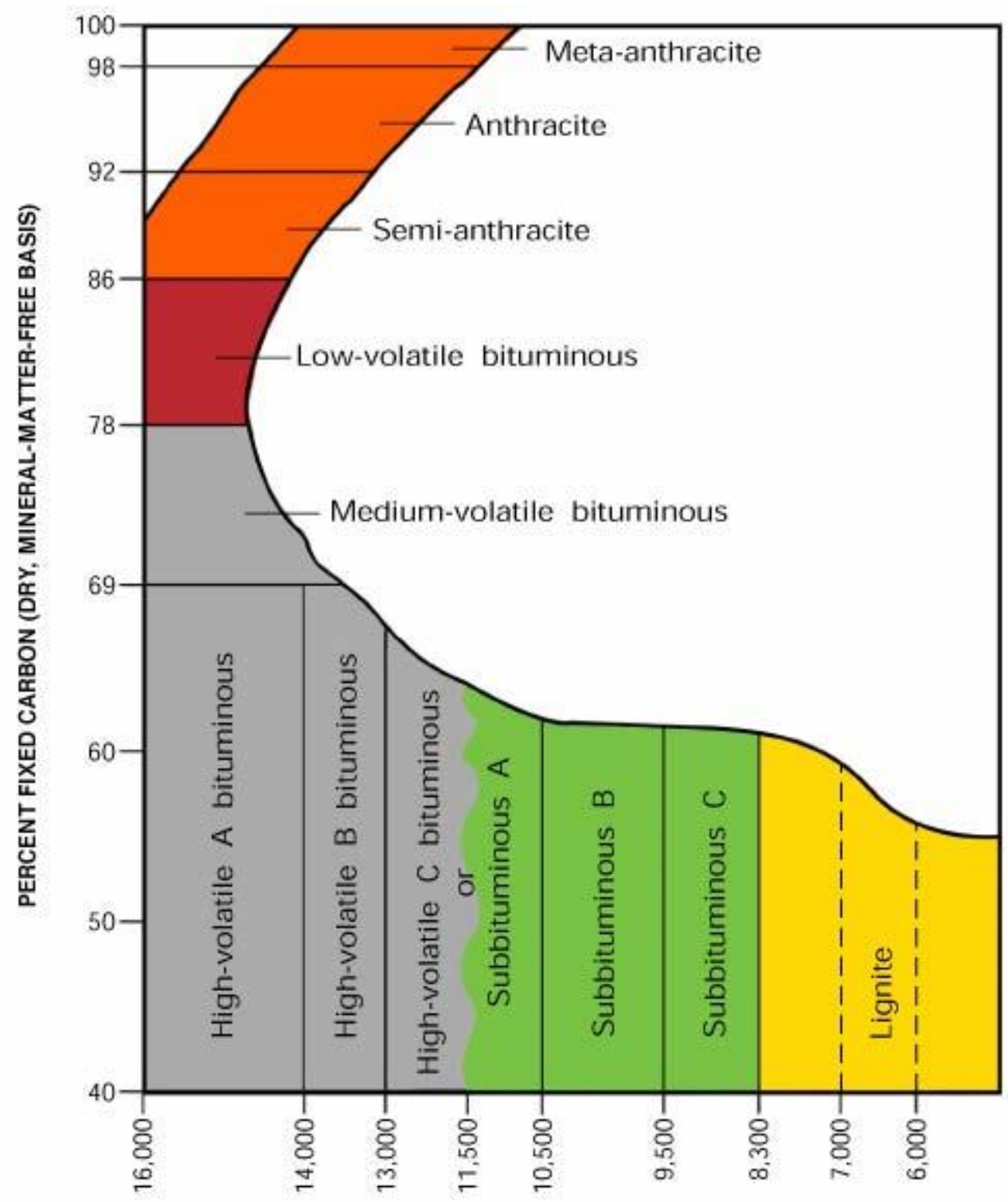

GROSS CALORIFIC VALUE (BTU/LB ON A MOIST, MINERAL-MATTER-FREE BASIS)

Figure 1.1 Different Grades of coal ${ }^{[22]}$

Coal can be broadly classified into different ranks such as lignite, sub-bituminous, bituminous and anthracite. The basic characteristics of these ranks of coal are given below

1) Peat: Peat is considered to be a precursor of coal and has industrial importance as a fuel in some regions, for example, Ireland and Finland. In its dehydrated form, peat is a highly effective absorbent for fuel and oil spills on land and water.

2) Lignite coal: Also referred to as brown coal, it is the lowest rank of coal and used almost exclusively as fuel for electric power generation. 
3) Sub-bituminous coal: Its properties range from those of lignite to those of bituminous coal. It is used primarily as fuel for steam-electric power generation. Additionally, it is an important source of light aromatic hydrocarbons for the chemical synthesis industry.

4) Bituminous coal: It is a dense mineral, black but sometimes dark brown, often with welldefined bands of bright and dull material. Bituminous coal is used primarily as fuel in steam-electric power generation, with substantial quantities also used for heat and power applications in manufacturing and to make coke.

5) Anthracite: This is the highest rank of coal and is a harder, glossy, black coal used primarily for residential and commercial space heating. ${ }^{[3,9,10]}$

Except for physical appearance, different coal ranks also differ in chemical composition, calorific value and percentage of carbon, hydrogen and other elements like sulfur, nitrogen and oxygen. These differences are due to the conditions of coalification that these coals undergo. For example anthracite, since it is metamorphosed for a very long time, has a very high calorific value and also has low hydrogen content. Similarly all the ranks of coal exhibit different chemical and physical properties depending upon the conditions under which they were formed. Properties like chemical composition and calorific values of different ranks of coal are given in Table 1.1.

Table 1.1 ASTM Table for classification of coals ${ }^{[10,12]}$

\begin{tabular}{|c|c|c|c|c|c|c|}
\hline Type of coal & $\begin{array}{c}\text { Volatiles } \\
(\%)\end{array}$ & $\begin{array}{c}\text { Carbon } \\
(\%)\end{array}$ & $\begin{array}{c}\text { Hydrogen } \\
(\%)\end{array}$ & $\begin{array}{c}\text { Oxygen } \\
(\%)\end{array}$ & $\begin{array}{c}\text { Sulfur } \\
(\%)\end{array}$ & $\begin{array}{c}\text { Calorific } \\
\text { Value(KJ/Kg) }\end{array}$ \\
\hline Lignite & $45-65$ & $60-75$ & $5.8-6.0$ & $34-17$ & $0.5-3$ & 28470 \\
\hline $\begin{array}{c}\text { Sub- } \\
\text { Bituminous }\end{array}$ & $28-35$ & $85-87.5$ & $5.6-5.0$ & $7.3-4.5$ & $\sim 1$ & 34960 \\
\hline Bituminous & $14-19$ & $87.5-$ & $4.5-3.2$ & $4.5-3.2$ & $\sim 1$ & 35380 \\
& 89.5 & & & & \\
\hline Anthracite & $7-12$ & $>91.5$ & $<3.75$ & $<2.5$ & $\sim 1$ & 35300 \\
\hline
\end{tabular}

All the fossil fuels that are either mined or pumped out of the ground have some foreign matter like rock, sand, clay, water etc. All the materials that do not contribute to the calorific 
value of a fuel and/or are harmful to the environment can be classified broadly as impurities in the fuel. The above classification is very general; the definition of impurities might differ according to the coal under consideration. ${ }^{[11,12]}$

Ash is the residue composed of the inorganic oxides compounds that remains after burning coal. Coal is a hydrocarbon and any pure hydrocarbon will burn completely without leaving any residue. However, almost no substance is found pure in nature. Coal has impurities which differ according to the terrain, soil chemistry, etc. of the area where it was formed. There are different kind impurities in coal like pyritic rock, sand (oxides of silicon) and clays (aluminum silicates). The methods to remove these impurities vary according to the nature of the impurity. For example pyrites are more dense (have a higher specific gravity) than coal so a gravity separation is effective. If the coal has clay impurities the separation becomes tedious because the specific gravity of clay is very close to that of coal. Furthermore, clay being sticky and small in size, adheres to the coal making a composite particle, so clays cannot be separated by using gravity separation techniques. Therefore for removing clays a different technique must be employed. ${ }^{[9,13]}$

The coal considered in the present research is Texas Jewett Lignite coal. It has $27-28 \%$ ash on a moisture-free basis and the inorganic impurities are mostly clays. The water content in this particular coal is approximately in the range of $30 \%$. The fixed carbon present is $35-36 \%$. As such this is a low grade coal and when run of mine Texas lignite coal is used in a direct combustion system, the energy output is lowered because of the energy losses due to the latent heat of vaporization of water and the specific heat of clay and other impurities. This coal is also highly oxidized which means that the presence of the - COOX (carboxalic group) group is very likely. The major impurity that is present in Texas Jewett lignite coal is clay (aluminum silicates). ${ }^{[14,15]}$

The combustion performance of lignite can be increased if the clay could be separated from the coal. There are many techniques that are used to clean clay from the coal like froth flotation, gravity separations and agglomeration techniques which will be discussed in the following sections. Coal cleaning is also necessary for liquefaction processes to make carbon products. Ash removal is a very important part of coal liquefaction process to make carbon products like binder pitch, coke and graphite. 


\subsection{Research objectives:}

The overall objective of this research is to investigate a process which can be used to effectively de-ash Jewett lignite to improve the combustion performance of lignite by removing the inorganic impurities from the coal which can cause parasitic heat losses. Another reason for ash removal from lignite coal is effectively reducing the amount of waste produced in the system after burning of the lignite. If the aim is to liquefy the lignite coal, removal of clay and other impurities, which do not liquefy is very important. In coal liquefaction the coal is liquefied using a solvent extraction process and made into an extract. There are two ways of removing ash from the extract. First is to centrifuge the extract to get two separate phases one being the solid which did not liquefy and other being the extract. Another method is to pre-treat the coal before liquefaction. This second option has two advantages: first it will decrease the mass flux in the

system and second is that less energy will be required to process the coal and centrifugation can be made less costly.

The development of a process to clean the Jewett Lignite coal is the primary research objective of this research. The main constraints are that the process should be cost effective and also not produce any by-products that are hard to remove and increase the load on the effluent treatment unit. A bench scale operation to clean coal is constructed and tested to check various methods of cleaning coal. Finally an assessment is made to check which process is best suited for the pre-treatment of Texas Jewett Lignite coal.

\subsection{Research Tasks:}

The research objectives defined above are broken into individual tasks for making the work more efficient and complete; these specific tasks are listed below:

1) Perform a detailed survey of the literature and previous work done on the pre-treatment of coal to develop a better understanding of the problem.

2) Test the effectiveness of conventional coal cleaning techniques on Texas Jewett lignite coal.

3) Determine the process variables and understand through experiments the importance and impact of each variable on the result of each experiment. 
4) Develop a bench scale process and try different techniques of cleaning coal and determine the process that is most effective.

5) Develop and test new techniques for cleaning of Texas Jewett lignite coal. 


\section{Background}

The primary objective of this literature review is to study and understand the previous work done by other researchers on cleaning coal and to understand different techniques which are used to solve the problem of removing inorganics from Texas Jewett Lignite. In this section there is a brief discussion of the process of formation of coal and also the different techniques which can be employed to clean coal. Since lignite coal cleaning is not done commercially there are no tested procedures that can be employed for cleaning of lignite. However bituminous and sub-bituminous coals are being commercially cleaned at a very large scale across the world. So the starting point of the literature review are the current commercial technologies that are available. The goal is to understand the available technologies and to see how these technologies can be either used directly or with modifications for lignite coal cleaning.

\subsection{Formation of coal:}

Coal is a solid brittle sedimentary combustible rock. It is found in seams, sandwiched between the layers of the earth's crust. Coal is considered an organic rock, just as rocks are composed of minerals of specific chemistry; coal is composed of different macerals that are organic classifications that have specific chemistry. The macerels of coal are formed by decay of plants and other organic matter over the period of thousands of years. This decay progressed through various chemical and physical stages, and is called coalification. During coalification the percentage of carbon increases in the organic matter and the percentage of other elements such as nitrogen and oxygen decreases. The formation of coal consists of two stages, the biochemical stage and the geochemical stage both of which are described in following section. ${ }^{[3]}$

\subsubsection{Biochemical phase of coal formation:}

The biochemical stage of coalification involves bacteriologically promoted chemical changes in the biological material that mainly consists of algae and plants from swampy areas. These chemical changes lead to the formation of peat. Peat is considered as the starting material for the formation of coal. During this stage, peat beds are formed due to the action of microorganisms such as bacteria and fungi on plants in swampy areas and the subsequent accumulation of the decayed plants and ferns. Hence, the original organic material loses considerable oxygen and hydrogen, thereby increasing the carbon content. As time goes, more 
layers of sediment are formed over the peat beds. The formation of peat represents the end of the biochemical phase of coalification. ${ }^{[3,16]}$

\subsubsection{Geochemical process of coal formation:}

The second stage of coalification is called the Geochemical phase of coal formation and is promoted by physical processes. In this process peat undergoes further transformation because of high pressure and temperature applied by the layers of sediments that are deposited above the peat. This turns peat into coal. The process is very slow so it takes a very long time for the coalification process to be complete. At these intense conditions the hydrogen and oxygen in the organic matter convert to methane and water. This is one of the reasons that methane is called marsh gas. The removal of these elements enriches the carbon content of the coal ${ }^{[12,17,18]}$. Depending on the percentage of carbon, coal is classified into various types or ranks: lignite, bituminous and anthracite in increasing order of carbon content. The first product of the geochemical phase is lignite or brown coal. Lignite contains about $70 \%$ carbon on a moisture and ash-free basis. Bituminous coal is formed from lignite due to the continuous influence of temperature and pressure on the buried plant remains over millions of years. The carbon content in bituminous coal is about $85 \%$. Continued coalification of lignite, to form bituminous and anthracite coal, results in the progressive increase in carbon content. The carbon content in anthracite is about $95 \%$.

\subsection{Coal composition:}

The composition of coal is extremely variable but there are some methods that allow understanding of the micro-structure of coal. The methods range from very general analysis like the Proximate Analysis which determines the percentage of moisture, volatiles, ash and fixed carbon in the coal to more intensive microscopic analysis called pertographic analysis. The petrographic analysis is done to investigate more about the micro-constituents of coal called macerels. These are the building blocks of coal. The results and discussion of the petrographic analysis of Texas lignite coal is presented in section 3.2. For calculating the ash percentage in the coal proximate and ultimate analysis is done, the results of proximate and elemental analysis of Texas Jewett lignite coal are given in section 3.1. 


\subsection{Proximate and elemental analysis of coal:}

Proximate analysis is done for determining the moisture, volatile, ash and fixed carbon content for different materials. The setup show in Figure 2.1 is a proximate analyzer made by LECO (LECO TGA 701). The procedure for calculating all the above mentioned components is listed below. The instrument has a carousel which has a number of crucibles, in this instrument there are 19 crucibles. The carousel is rotated pneumatically and one by one all the crucibles are weighed on the balance beneath the carousel. The samples are filled in the crucible and the oven is heated to different temperatures depending upon the aim of the measurement. The weights are recorded and tabulated from where the final results can be tabulated. The procedure for using the LECO Proximate Analyzer for the proximate analysis of coal is listed below.

1) First the crucibles are filled with sample (here coal) and the top of the oven is closed.

2) Then the oven is heated to $105^{\circ} \mathrm{C}$ in an inert atmosphere to remove all the moisture. The sample is weighed again for calculating the weight loss and the percentage weight loss of the moisture.

3) Next the oven is heated to $750{ }^{\circ} \mathrm{C}$ in an inert atmosphere and kept there for 10 minutes (ASTM guidelines ASTM D5142) for removing all the volatiles from the coal. The weight of crucible is measured again for calculating the weight loss for the percentage loss of moisture.

4) The fourth step is to heat the coal in an oxidizing atmosphere (in presence of oxygen $\left.\left(\mathrm{O}_{2}\right)\right)$ at $900{ }^{\circ} \mathrm{C}$ for complete combustion and the residue is weighed for ash mass and percentage weight.

5) Lastly the combined percentage of moisture, volatiles and ash are subtracted from $100 \%$ for the calculation of fixed carbon.

This method for finding ash percentage in coal is used extensively throughout this work for calculation of ash content in the coal. All the proximate analysis was done in WVU analytical laboratory by Ms. Gabriela Perhinschi. 


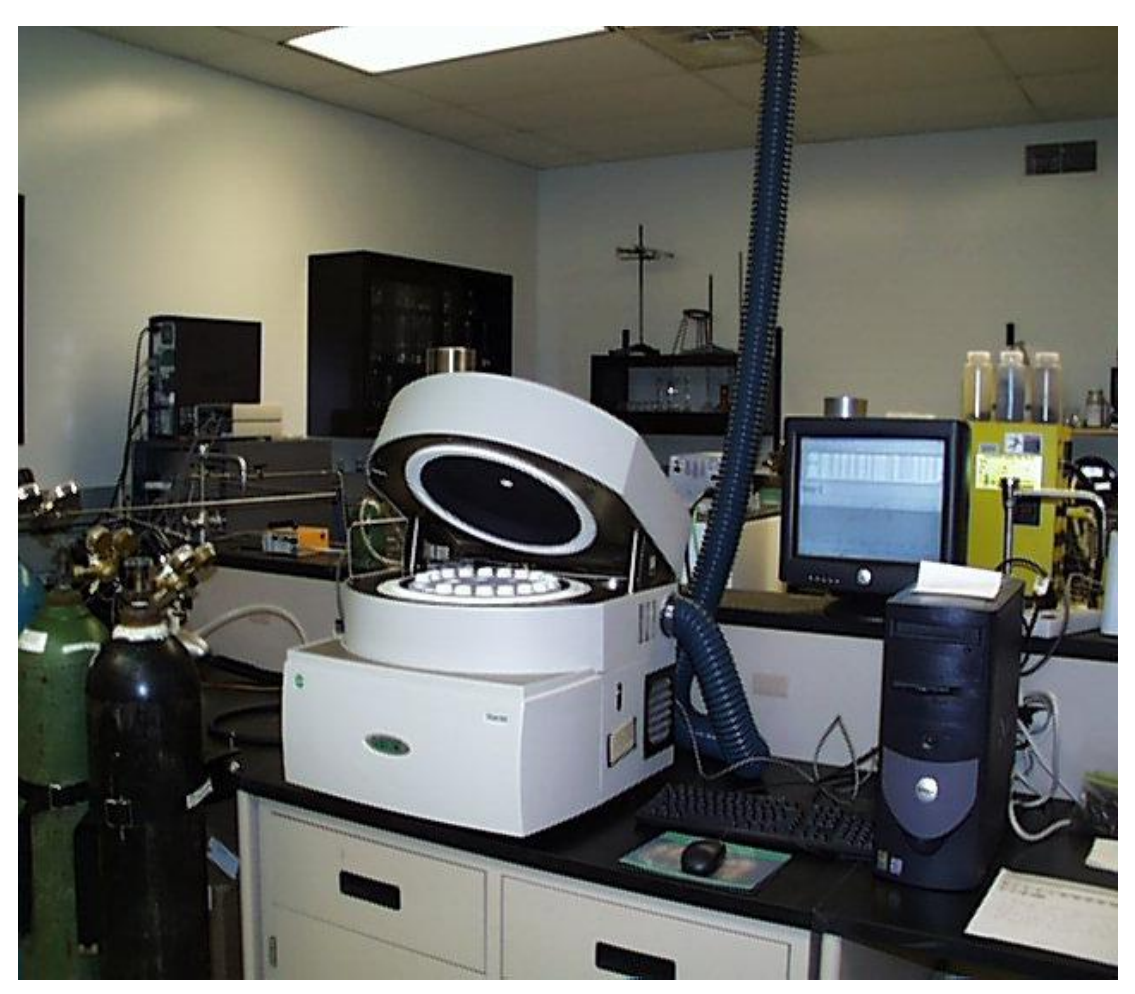

Figure 2.1 LECO Proximate Analyzer.

In the ultimate analysis of a sample the percentage of elements in the sample is determined. In the ultimate analysis of coal the percentage of four major elements, carbon, hydrogen, nitrogen and sulfur is determined. A sample (one gram approx) is burnt in a high temperature furnace $\left(900{ }^{\circ} \mathrm{C}\right)$, all the above mentioned elements form their respective oxides which are gases. These gases are separated in a column and are identified using a detector like a FID (flame ionization detector) or a TCD (thermal conductivity detector), these detectors analyze the flue gases and by concentration of a particular oxide gives the percentage of the respective element as a result.

\subsection{Conventional coal cleaning process:}

Coal cleaning is a process by which impurities such as sulfur, inorganics, and rock are removed from coal to upgrade its value. Coal cleaning processes are categorized as either physical cleaning or chemical cleaning. The mechanical separation of coal from its contaminants using differences in density, is by far the major processes in use today. 
The scheme used in physical coal cleaning processes varies among coal cleaning plants but can generally be divided into four basic phases: initial preparation, fine coal processing, coarse coal processing, and final preparation. A process flow diagram for a typical coal cleaning plant is presented in Figure 2.2.

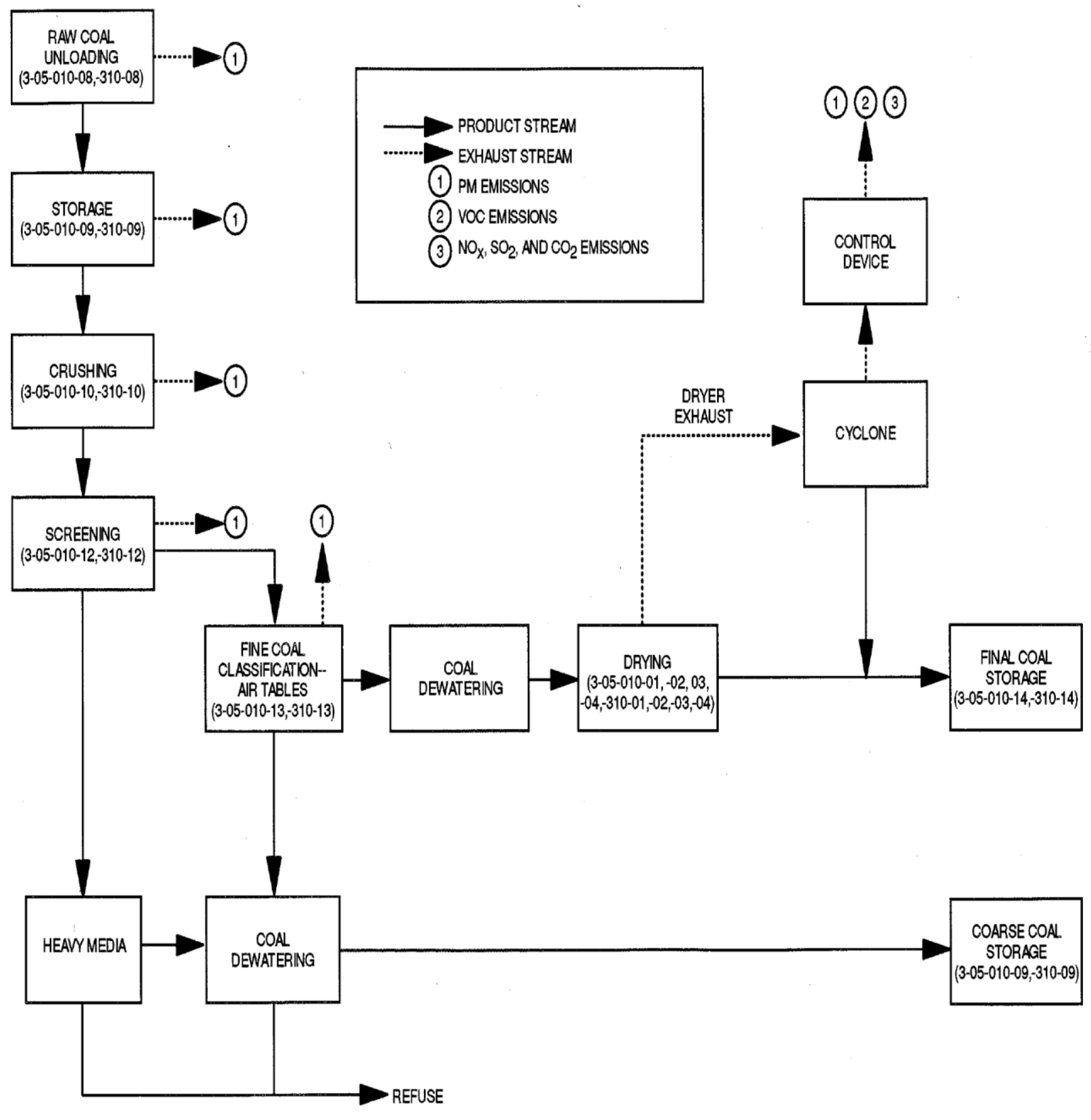

Figure 2.2 Conventional Coal Cleaning Process

In the initial preparation phase of coal cleaning, raw coal is unloaded, stored, conveyed, crushed, and classified by screening into coarse and fine coal fractions. The size fractions are 
then conveyed to their respective cleaning processes. Fine and coarse coal processing use similar processes and equipment to separate the impurities. The major difference is the severity of process variables. The majority of the coal cleaning processes uses upward currents like cyclones or pulses of a fluid such as water to fluidize a bed of crushed coal and impurities. The lighter less dense coal particles rise and are removed from the top of the bed. The heavier more dense impurities are removed from the bottom. Coal cleaned in the wet processes must be dried in the final preparation process.

The final preparation process is used to remove moisture from coal, thereby reducing freezing problems and weight and raising the heating value. The first processing step is dewatering, in which a major portion of the water is removed by the use of equipment like screens, thickeners, and cyclones. Thickeners can be agglomerating agents either for coal or clay. They are used to make coal hydrophobic and reject water. Cyclones are typically used for coal fines and screens are mainly used for coarse coal separation.The second step is normally thermal drying, achieved by any one of three dryer types: fluidized bed, flash, and multilouvered. In the fluidized bed dryer, the coal is suspended and dried above a perforated plate by rising hot gases. In the flash dryer, coal is fed into a stream of hot gases for instantaneous drying. The dried coal and wet gases are both drawn up a drying column and into a cyclone for separation and capturing the coal fines. ${ }^{[40]}$

\subsection{Coal Cleaning process:}

For the separation of two solids there are a number of different techniques that can be used. The simplest technique is to dissolve one solid in a solvent that does not dissolve the second solid. In the Jewett lignite coal the two solids to be separated are inorganic species basically clay and organic species or coal. Inorganics, are the major impurity to be removed from the coal to make it clean. Aluminum silicates will dissolve in solvents like hydrofluoric acid ${ }^{[22]}$. But it has such high reactivity that it will react with coal too and not only this, the disposal of the clays in HF will pose a very big problem because hydrofluoric acid is a hazardous material. So this technique is not viable.

There are a few methods for enhancing gravity separations and the one that may be suited for this research is discussed below. 


\subsubsection{Enhanced gravity separators for cleaning coal fines:}

Gravity separation is a technique used for separating two solids. There are few methods to enhance the gravity force to make the separation of the two solids easier. To enhance the separation based on density difference and efficiency improvements using artificial gravitational fields, many new centrifugal separators have been developed and placed into commercial production in the minerals processing industry. Two of the most well-known of these units are:

\section{Falcon Concentrator:}

The Falcon unit is a centrifugal unit as shown in Figure 2.3. It consists of a smoothsurface truncated cone which rotates at very high speed. Feed slurry is introduced near the bottom of the cone and is accelerated up the cone wall as it rotates at a very high speed by the centrifugal field (up to $300 \mathrm{~g}$ 's). The slurry forms a thin flowing film in which particles are deposited in layers based on differences in density. Light particles on the layer are collected over the top, while heavy particles sliding along the inner surface of the cone are discharged through the cone wall through small reject openings. Falcon units are being used to upgrade a variety of minerals including base sulfides, iron, tin, titanium and gold ores. Pilot-scale units have recently been successfully demonstrated for the upgrading of 28 mesh coal fines. ${ }^{[4]}$

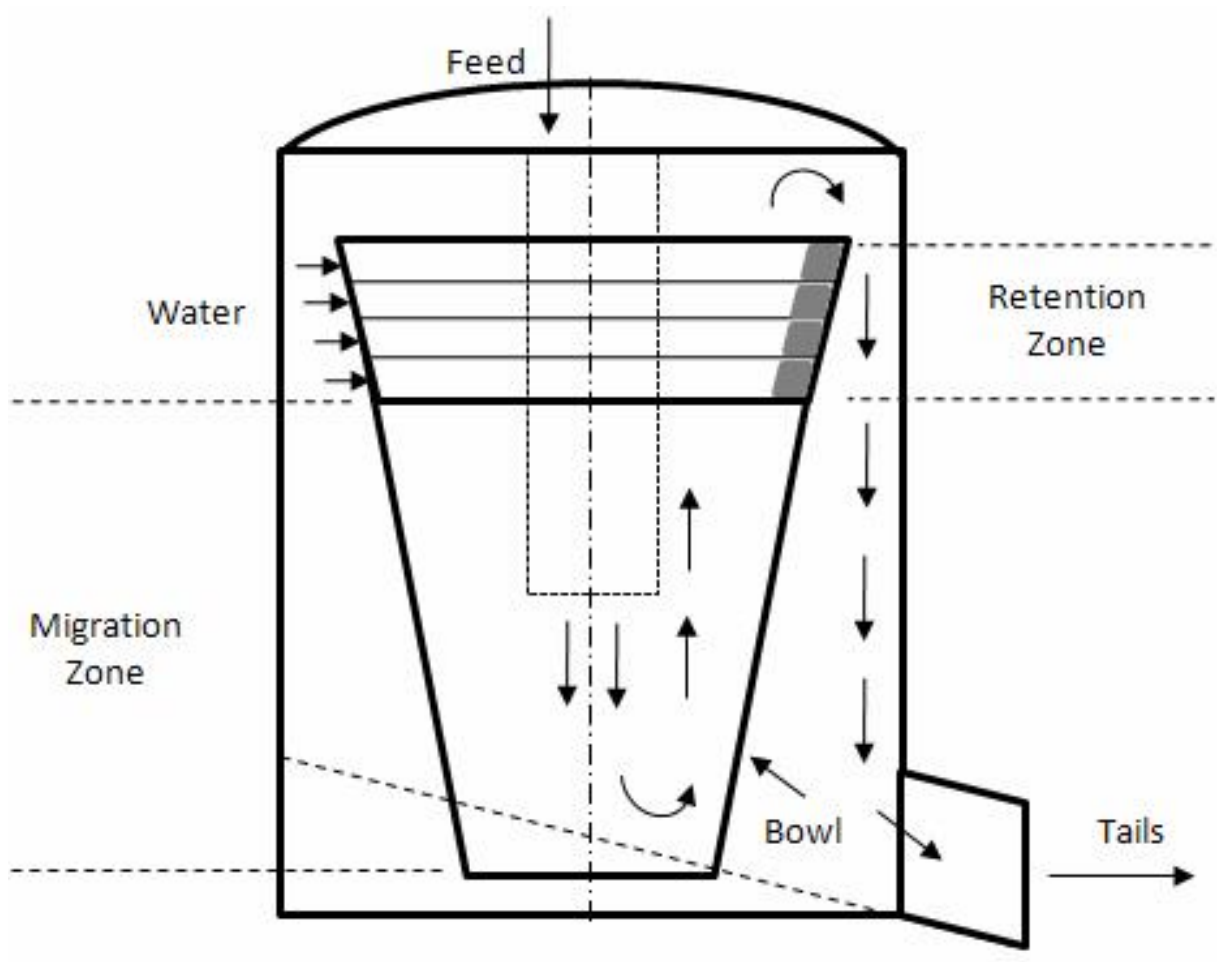

Figure 2.3 Falcon Separator Schematics ${ }^{[23]}$ 


\section{Kelsey Jig:}

The Kelsey jig shown in Figure 2.4 consists of a series of hatches which are rotated about a central feed pipe. The unit is capable of generating centrifugal fields up to $100 \mathrm{~g}$ 's. A cylindrical screen is mounted across the top of each hatch to retain the material. Feed slurry enters the unit through the central feed pipe and flows outward across the screen. Mechanical pulsators located at the end of each hatch create oscillations in the bed that differentially accelerate particles based on differences in density. Low-density particles flow across the screen material and overflow the top of the unit, while high-density particles pass downward through the screen and are discharged through actuated valves. In most cases, the unit forms its own cake from coarser and heavier feed particles. The Kelsey jig has been successfully demonstrated for the concentration of tin, mineral sands, iron ore, gold, lead, manganese and platinum. The need to constantly replenish the screen appears to be the major shortcoming of this particular design. However, narrowly sized clean-coal $(1.2-2 \mathrm{~mm})$ cyclone from coarse spiral products have been successfully used for this purpose.

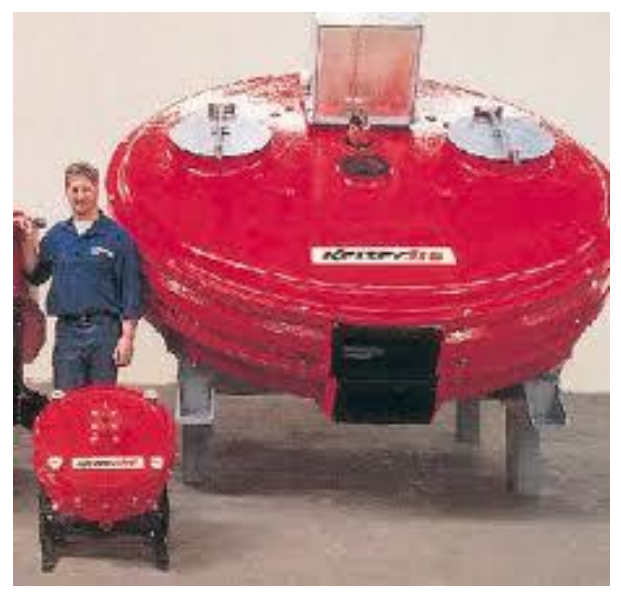

Figure 2.4 Kersley Jig ${ }^{[25]}$

The problem with a centrifugation technique as applied to Texas lignite is that the clay sticks to the coal and with the high percentage of moisture this problem is very difficult to overcome. The particles sizes must be very fine to achieve a very good separation. With this in mind separations using surface chemistry must be discussed using various techniques like froth flotation and agglomeration with chemical agents. ${ }^{[24]}$

Moreover, gravity separation is difficult since the specific gravity of coal and clays are very close. Clays are typically of a specific gravity 1.2 and lignite coals are of a specific gravity 
of $0.9-1.0^{[3,5]}$. Moreover the particle size of clay is 5 microns and the particles get trapped in the cracks of coal. Finally the surface chemistry of the substrates are such that gravity separation is not a very viable process.

There are also other techniques like separating on the basis of surface chemistry of the substances by manipulating the surface charges of the different substances and making it either come into or fall out of the solution. This technique can be done by two ways: one is froth flotation and another is agglomeration. The froth flotation technique is discussed in the coming section.

\subsection{Froth Flotation technique:}

The coal cleaning processes being considered in this section are all based on the principle of separation of substances on the basis of being hydrophobic or hydrophilic. For coals such as Jewett Texas lignite, the major impurity in the coal is clay which is sticky, difficult to dissolve in common solvents, and has about the same specific gravity as coal. The literature suggests a few potential solutions.

\subsubsection{Coal Froth Flotation Processes:}

Froth flotation involves creating a froth to carry less dense coal away from denser ash material. Most such processes are designed for higher rank coals such as bituminous and anthracite. However, some processes have been developed for lignite, though generally not implemented, probably owing to the low commercial market price of lignite (historically below $\$ 15$ per ton, which affords little margin for processing costs). One such lignite-relevant process recommends using ground coal with average dimensions less than 30 mesh $(0.6 \mathrm{~mm})$. In this process coal is made hydrophobic by wetting it with some type of oil and then froth flotation is used to separate coal leaving the impurities in the initial mixture. The coal that comes out with the froth can be collected and dried.

One of the challenges in this technique is to wet coal with oil while not wetting the ash. This can be done with the help of a surfactant. The surfactant wets the coal and not the ash (clay, etc.) and then when oil is added it sticks to the surfactant so only the coal becomes hydrophobic. This process is usually carried out in 5 steps: 
i. Slurry is created with about 2.5 to $10 \%$ weight of solids. The balance is water.

ii. A surfactant is added to make oil stick to coal. Candidate surfactants for this purpose are Shur-Coal 168 (trademark), fatty sulphosuccinic acid and aliphatic carboxalic acid

iii. Oil is added to make the coal hydrophobic. Any kind of oil can be used for this purpose such as motor oil, diesel, kerosene or bunker $\mathrm{C}$ oil. Lignite distillates and cracking products can likely also be considered. If the oil is viscous it can be diluted using light oil.

iv. The frother is added to the solution. The function of the frother is to carry coal with the froth. Among the candidate chemicals that can be used for this process are Dowfroth 1012, heptanol, and octanol. Dowfroth 1012 is an example of an industrial frother; while heptanol and octanol might be useful as model compounds.

v. The floated product is collected, washed and dried.

The above process discussed just describes a technique of carrying out froth flotation. Other variables to this technique are selection of surfactant, frother and agglomerating agents which will be discussed in later sections. ${ }^{[26]}$

\subsubsection{Froth Flotation Cell}

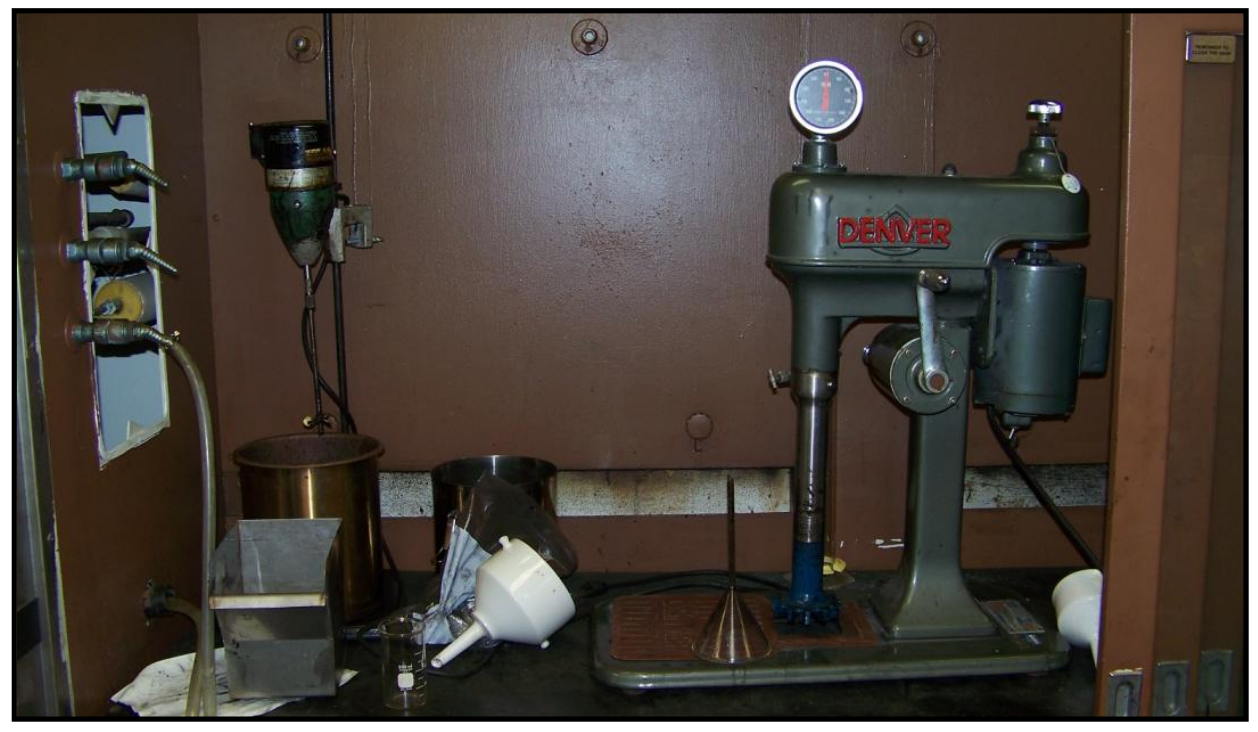

Figure 2.5 Froth Flotation Cell (Denver) 
The froth flotation cell used in these series of experiment is of the Denver Series as shown in Figure 2.5. The maximum RPM that can be achieved by this cell is 3300 RPM. The instrument was manufactured in Denver Colorado by the company Denver Lab. Instruments Ltd.

The construction of this instrument is very simple. The long arm of the instrument is a agitator which is a hollow pipe to allow the air flow for the froth flotation process. The knob on the top right corner adjusts the RPM and the one on the bottom right corner adjusts the air flow rate. The RPM meter is on the left top corner and the handle in the middle adjusts the height of the arm.

A coal slurry is made with water and is introduced into the container of the machine, then the surfactant and oil is added to the slurry and it is agitated. High RPM are preferred because the surfactant is mixed thoroughly with the coal slurry and the surface action of the surfactants is more pronounced. After the mixing step, the frother is added to the slurry and air flow is started by opening the valve on agitator arm of the froth flotation machine. The material that rises with the air bubbles, is collected, dried and sent for proximate analysis.

\subsubsection{Sulfurous Acid Treatment for Texas Lignite}

In a froth flotation process the tendency of a material to rise with the air bubbles i.e. float is called the floatability of a material. Different substances have different surface chemistry and hence variable floatability. The floatability of different materials is quantified and tabulated as a floatability index, which gives each material a numeric value for its floatability. The higher the value of the floatability index, the greater is the ease with which it can float. The floatability average of lignite coal is 12 taking Ceylon Graphite with an index of 100 as standard. The average floatability index for bituminous steam coals was 94 on the same scale, so float sink for separation of lignite is not very effective. The poor floatability of lignite coal was confirmed by Aplan (1976, 1980 and 1988). ${ }^{[27]}$

The contact angle of lignite coals and oil is zero. ${ }^{[14,27]}$ So use of an oily collector does not improve the floatability of lignite coals because of very little adsorption of oil on the lignite surface. Both of these publications (Aplan 1970 and 1988) focused on the surface chemistry of lignite and they predicted that the oxidized carbon contained oxygen mostly as carboxalic groups. This is because of high oxygen content of lignite coals (almost 30\%) and the presence of 
oxygen-containing surface groups. Another important aspect of the presence of these functional groups is that they act as a site for ion exchange for ions like $\mathrm{Na}, \mathrm{Mg}$ and $\mathrm{K}$ and may result in the accumulation of carbonaceous ash. Carbonaceous ash is the inert part of coal which is not reactive. These groups are fusinite and semi-fusinite. These ions that are bonded to the organic portion of coal are inherent ash and are practically impossible to clean using conventional processes. ${ }^{[14]}$ The chemical treatment of coal prior to any separation method is beneficial because if coal is treated with acid all these ions will be dissolved and will come into the aqueous phase. Acids like $\mathrm{HCl}$ and sulfurous acid can be used to dissolve these ions. Sulfuric acid is problematic for this process because it is a very strong oxidizing agent and might oxidize the coal. The use of sulfurous acid is suggested because it is a by-product of sulfur dioxide scrubbing and is very cheap. In a favorable scenario sulfurous acid might be obtained at very low cost from utility plants utilizing sulfur dioxide scrubbers.

Aplan (1970) studied the effects of three different reagents for coal flotation. These reagents were sodium meta silicate, the collector was kerosene and the frother was Methyl Isobutyl Carbinol (MIBC). In studying these effects, the surfactants were tested for high and low concentration values and functions were solved mathematically for lowest percentage of ash. The lowest ash that was achieved was $12.9 \%$. These effects were studied using a three-variable, twolimit factorial method and regression models for the recovery of the combustible matter and the ash content in the combustible matter. The meta-silicate was used to disperse the clay in the slurry and kerosene was used to wet the coal. The frother was used to float the coal with a froth flotation machine. ${ }^{[29,30]}$

Amoco developed a method for increasing the floatability of Texas lignite coal by sulfurous acid treatment, and studied Texas lignite with an ash content of $12.9 \% .{ }^{[14]}$ A sample was pretreated with sulfurous acid prior to separation. Treated coal was subjected to flotation or liquid-liquid extraction for further cleaning. The product obtained from this treatment had $4.4 \%$ ash content with a combustible matter recovery of $95 \%$. In a second stage a coal sample with $3.3 \%$ ash content was treated using mild agglomeration and flotation when a block co-polymer surfactant was added prior to flotation. A clean product of $1.85 \%$ ash was obtained with a combustible matter recovery of over $85 \%$. 


\subsection{Solvent Extraction of Coal:}

This process is based on the solubility of the volatiles and fixed carbon content of the coal in various solvents. There are many solvents that are capable of dissolving coal at various temperatures. Following dissolution the solution can be centrifuged and the suspended ash in the coal will fall out of the system and coal with a very low ash percentage can be obtained. There are many solvents that are capable of dissolving lignite coal like NMP (N-Methyl-2pyrrolidone), heptanes etc. ${ }^{[28]}$

In this method coal is trialed in solvents like heptanes. Coal forms an emulsion with the solvent and can be separated with the organic phase by contacting the solution with water. The impurities are contained in the aqueous phase. Because of the expense of the solvents, this method is not being pursued.

\subsection{Reverse Flotation of Coal}

In this process the ash is floated instead of coal. Dextrein is added to decrease the floatability of coal and then dodecyltrimethyl ammonium chloride (DTAC) is added to float the ash instead of the coal. The problem with this method is DTAC also floats coal along with ash and thus combustible material is lost. The literature reports experiments were done by grinding the coal before floating the inorganic material. This increased the surface area of coal and by extension increased the adsorption of the collector on coal surface. This not only increased the loss of material in the process but also made the process more expensive because a larger quantity of DTAC was required to float the ash. The amount of coal recovered was less than $60 \%$ and the purity of the recovered coal was between $18-20 \%$ ash. ${ }^{[31]}$

By not agitating the slurry to disperse the surfactant, the amount of DTAC can be reduced. Because DTAC also has some affinity towards coal and if agitated the yields after the separation will not be high. The yields can drop down to as low as $54 \%^{[31,32]}$ if the slurry is agitated. To avoid this problem the zero conditioning time method is used. Conditioning time refers typically to the time the slurry is agitated for better application of a surfactant or frother. In this process DTAC is added and simultaneously the froth flotation process is started. This results in less adsorption of the collector on the coal surface and a higher yield of ash in the froth stream. The recovery of the coal by doing the zero conditioning time went up to $65 \%$ but due to 
less agitation the selectivity of the process went down resulting in $20-25 \%$ ash in the recovered material. ${ }^{[32]}$

The second method to lower the amount of DTAC required addition of the collector in parts. The full amount of collector is not added in just one step, but rather two or three parts. The collector can be added either with zero conditioning time or with full conditioning of the slurry. This alteration brought down the concentration of DTAC from $15 \mathrm{gm} / \mathrm{kg}$ of coal to $5 \mathrm{gm} /$ $\mathrm{kg}$ of coal. A addition in parts had no effect on yield or selectivity of the process. ${ }^{[32,33]}$

The third way of reducing the amount of DTAC, is to absorb some other chemical on the coal surface. The chemical that can be added for this task is PAM (Polyacrylamide) which is a quaternary nitrogen compound. It can attach itself easily on the coal surface and this in turn will reduce the amount of collector required for the flotation process and decrease the cost of the process. The function of PAM was to attach itself to the coal and make it sink and thus increase the selectivity of the process because later, when DTAC is added, it will directly attach itself to clay and improve the process. Using PAM to condition the coal first, before the addition of DTAC, did increase the yield of the recovered combustible matter. The yield went up to $80 \%$. The effect on the selectivity was not as good. The ash content in the coal remained at $15 \% .{ }^{\text {[32] }}$

\subsection{Dewatering techniques:}

Water is present in almost all the coals in variable quantities, and since the latent heat of vaporization of water is high, it decreases the heat produced in a combustion system. Therefore it is considered an impurity in the coal. Removal of water can be done by boiling the water by supplying thermal energy, but there are two major problems with this method:

1) Coal is a poor conductor of heat so it is difficult to remove moisture and bulk drying of coal is difficult since heat would not reach to the bulk of coal.

2) Secondly the latent heat of vaporization of water is high so it is not economical to remove water by applying thermal energy.

Due to these reasons water removal from lignite coal is not done and wet coal is burned in a combustion system. This decreases the efficiency of the combustion system and hence increases 
the carbon footprint of the combustion system. There are a few dewatering techniques described in this section that can be investigated for the selection of a process to dewater coal. ${ }^{\text {[3] }}$

\subsubsection{Role of surfactant absorption and study of adsorption kinetics:}

Many surfactants can reduce the moisture content in a coal filter cake during filtering or centrifuging coal. Sodium dodecyl sulphate (SDS) and ammonium dodecyl bromide (ADB) are two surfactants that can be used for this purpose. SDS is an anionic surfactant and ADB is a cationic surfactant.

Another method for dewatering coal is described with the help of a dewatering aid and a clay depressant. The dewatering aid and clay depressant are added prior to the centrifugation of the washed coal. The preferred dewatering aid is an alkylphenolethoxylate surfactant and the coal depressant is sodium hexametaphosphate. The combination of the dewatering aid and the clay depressant also lowers the ash content of the cleaned coal.

The use of coal depressants restores the bed permeability and allows water to drain from the coal. These chemicals for dewatering of clay do not have any detrimental effects on the water treatment process downstream. A very large amount of water is required in the coal water plants. If the water is not clarified and recycled, the process becomes very expensive.

The amount of surfactant needed for the process depends upon the type of coal. It is suggested that the typical amount of surfactant needed is 0.2 to 2.5 pounds per ton of coal. The exact amount of surfactant required for treatment of Texas Lignite coal can be determined by test runs in the lab. The chemicals which were used earlier for aiding dewatering of coal were ionic surfactants like dioctylsulphosuccinate. Non-ionic surfactants like organopolysiloxane were used which would cause foaming in the centrifuge and also lead to foaming in effluent treatment facilities. A small amount of a cationic compound was added to prevent foaming in the centrifuge.

The surfactants currently in use are non ionic surfactants alkylphenolethoxylate. These chemicals are available as Surfonic from Texaco Co. and the Triton series available from Rohm and Haas. The preferred clay depressants are available commercially from Calgon Corp. under the trade name of Calgo. Other clay depressants are also effective. ${ }^{[35]}$ 
The above discussed techniques are available for coal cleaning. Since gravity separation cannot be used for removing the clays, the froth flotation technique is selected for de-ashing the lignite coal. Froth flotation method is a conventional technique used for cleaning bituminous and sub-bituminous coal; lignite coal is not cleaned with this technique. In Chapter 3 a conventional technique such as the froth flotation method is tested on lignite coal and the results are analyzed in Chapter 4. 


\section{Experiments and Results.}

\subsection{Proximate and elemental analysis of coal:}

The elemental analysis and proximate analysis of coal was done by at the WVU analytical laboratory. In this analysis the composition of four elements carbon, nitrogen, hydrogen and sulfur was obtained and the results are shown in Table 3.1 for the Texas Jewett Lignite coal. The proximate analysis of coal was done in LECO Proximate Analyzer and the results are shown in Table 3.2. The method used is ASTM D2013 for sampling and ASTM D5142 ${ }^{[33,38]}$.

Table 3.1 Elemental analysis of Jewett Lignite Coal ${ }^{[15]}$

\begin{tabular}{|c|c|c|c|}
\hline Component & Amount (\%) & Std. deviation & Variance \\
\hline Nitrogen\% & 0 & 0 & 0 \\
\hline Carbon\% & 59.92 & 0.38 & 0.149 \\
\hline Hydrogen\% & 6.92 & 0.04 & 0.002 \\
\hline Sulphur\% & 0.29 & 0.03 & 0.001 \\
\hline
\end{tabular}

Here the amount of sulfur is very low so it is safe to assume that the pyritic ash in the coal is very small. This implies that all the methods to remove pyritic compounds from coal might not work on this particular coal.

Table 3.2 Results for the proximate analysis of Jewett Lignite Coal ${ }^{[15]}$

\begin{tabular}{|c|c|c|c|c|}
\hline Sample number & Moisture (\%) & Volatiles (\%) & Ash (\%) & Fixed Carbon (\%) \\
\hline 1 & 30.46 & 26.46 & 18.56 & 24.53 \\
\hline 2 & 30.53 & 25.74 & 19.29 & 24.44 \\
\hline 3 & 30.07 & 25.59 & 20 & 24.35 \\
\hline 4 & 30.34 & 26.07 & 18.67 & 24.92 \\
\hline 5 & 30.29 & 25.91 & 18.83 & 24.96 \\
\hline 6 & 30.28 & 26.59 & 19.04 & 24.08 \\
\hline Average & 30.32 & 26.06 & 19.06 & 24.55 \\
\hline
\end{tabular}


The proximate analysis of Texas lignite coal is given in the Table 3.2. The moisture content in the coal is high (30.32\%). The volatiles and fixed carbon amounts are typical for a lignite coal. The ash content on a dry basis is $27 \%$ which is very high for use in a liquefaction process. The inert material does not hinder the liquefaction process but this high inorganic content cannot be left in a liquid fuel. So the aim of this research is to bring down the ash content of the coal. The petrographic analysis shows that the inorganic material present in the coal is aluminum silicates (clays).

\subsection{Petrographic analysis of coal:}

Petrographic analysis is a microscopic analysis of this coal observed under a microscope and the constituting macerals are indentified. The pertrographic analysis of Texas Jewett Lignite was done by Daniel P. Gray on February 04, 2009 at Koppers. The coal samples were prepared for petrographic analysis and photographed at $135 \mathrm{X}$ and/or $250 \mathrm{X}$ in air and at $600 \mathrm{X}$ in reflected light oil. The petrographic analysis for lignite coal consists of maceral composition and vitrinite( huminite) reflectance. This method is a point count method which means that in the photographs, points were counted and then percentages of different materials were determined.

A maceral is a component of coal. There are different kinds of macerals which have different properties and consequently have different impact on the nature of coal. The more important types of macerals and their properties are listed below. ${ }^{[20]}$

1) Vitrinite macerals: Vitrinite macerals are derived from the cell wall material (woody tissue) of plants, which are chemically composed of the polymers, cellulose and lignin. The vitrinite group is the most abundant group and commonly makes up 50 to $90 \%$ of most North American coals.

2) Liptinite macerals: The liptinite macerals are derived from the waxy and resinous parts of plants such as spores, cuticles and resins. These are resistant to weathering and make up for about $5-15 \%$ of most North American coals.

3) Inertinite macerals: The inertinite macerals are derived from plant material that has been strongly altered and degraded in the peat stage of coal formation. For example, fossil 
charcoal is the inertinite maceral called fusinite. Other types of inertinite macerals are semifusinite, macrinite and semimacrinite. ${ }^{[3,20]}$

In the petrographic analysis of the Texas lignite coal it was found that the coal has $28.77 \%$ moisture and $21.14 \%$ ash, although the real ash percentage is $28 \%$ on a moisture free basis. The petrographic composition of coal is listed in the Table 3.3 and 3.4. ${ }^{[20]}$

Table 3.3 The compositions of the reactive materials of Texas lignite coal ${ }^{[20]}$

\begin{tabular}{|c|c|}
\hline \multicolumn{2}{|c|}{ Huminite(vitrinite) Macerals } \\
\hline Humocollinite & 20.4 \\
\hline Humotelinite & 15.6 \\
\hline \multicolumn{2}{|c|}{ Humodetrinite } \\
\hline Densinite & 20.0 \\
\hline Atrrinite & 1.2 \\
\hline Exinite & 6.0 \\
\hline Resinite & 1.0 \\
\hline semifusinite & 1.3 \\
\hline Total reactives & $\underline{\mathbf{6 5 . 5}}$ \\
\hline
\end{tabular}


Table 3.4 Table for the inert constituents of Texas lignite coal

\begin{tabular}{|c|c|}
\hline Semifusinite & 2.5 \\
\hline \multicolumn{2}{|c|}{ Micrinite (total 8.4) } \\
\hline Micrinite & 2.4 \\
\hline Macrinite & 0.6 \\
\hline Inertinite & 5.4 \\
\hline Fusinite & 4.6 \\
\hline \multicolumn{2}{|c|}{$\underline{\text { Mineral matter(total 19.0) }}$} \\
\hline Clay & 6.2 \\
\hline Shale & 3.2 \\
\hline Carbon Shale & 3.6 \\
\hline Quartz & 1.4 \\
\hline Carbonate & 0.8 \\
\hline Pyrite & 0.4 \\
\hline Bone Coal & 2.8 \\
\hline Total Inerts & 34.5 \\
\hline Mean-Max Ro in oil, \% & 0.35 \\
\hline
\end{tabular}

These tables deal with all of the reactive and inert substances, but for this research inert material is of more concern, especially the mineral matter because in cleaning coal, the objective is to free the coal of the inert material and thereby upgrade it. 


\subsection{The Benefication Technique:}

The process that is to be tested on Texas lignite coal is froth flotation and this technique is well-established for bituminous and sub-bituminous coal. The efficacy of this process can be judged by looking at two variables: first the yield of the cleaned material out with respect to the total material input and secondly the selectivity of the process which means how much material can be made of a given quality, i.e. a given amount of inorganic content in the clean coal.

The overall technique employed here consists of five steps which were explained in the previous chapter. These include making the coal slurry, mixing of the surfactant, and then mixing oil followed by froth flotation and finally drying and weighing of the product. The chemicals are specific in their effect on the coal and the experiments will test how effective the chemicals are in enhancing the cleaning of the coal. The basic principle behind the overall technique is to manipulate the surface chemistry of the coal to make it hydrophobic and froth the coal out of the solution, leaving behind the clay in the slurry. This involves wetting the coal with the oil so that it becomes hydrophobic and repels water. Thus when it is frothed it foams up and a separation of coal and clay is achieved.

Lignite coal being oxidized on the surface does not adhere well to oil like bituminous coal. The carboxylic groups present at the surface do not allow wetting of the coal particles by oil. To overcome this problem the coal is treated with a surfactant to alter the surface chemistry in such a way that oil adheres to the coal surface. Every surfactant has a different set of properties so the selection of surfactant is a very important task before conducting the experiments.

\subsection{Selection of frother and surfactants:}

The selection of the frother is the final step in determining all the chemicals needed for the proper operation of the froth flotation process. The frother that is selected for this process is Zinkan Shur Coal 168, provided by Zinkan Corp. The surfactant is an isobutanol-based compound that is used to float coal in industry.

Two surfactants were selected to carry out the froth flotation technique namely DDA (dodecylamince) and TMAB (Trimethyl ammonium bromide). Both these surfactants are used for 
cleaning sub-bituminous coal in a froth flotation system. Since the objective is to test the efficacy of this conventional cleaning technique on lignite coal, these surfactants were selected to carry out froth flotation on Texas Jewett lignite. Both these surfactants are cationic hence the froth flotation was carried out in acidic $\mathrm{pH}$ since cationic surfactants are most mobile in acidic $\mathrm{pH}$.

\subsection{Design of experiments:}

The design of experiments is a way for analyzing the effect of two or more factors on a process. By conducting a series of experiments to collect data, the data points are used to obtain a mathematical correlation that will determine the significance of a particular variable on the desired result. This process uses the collected data points, and solves the multi-variable equations and gets a coherent mathematical function. The input variables are set by the experimenter. The responses are noted and solved using an equation solver to get a mathematical function by which any response can be predicted by changing the input variables and solving the corresponding equations.

The method to be used in this problem is a factorial experimental design in which input variables are selected and assigned a high and a low value indicated in the Table 3.5 shown below. 
Table 3.5 Design of Experiments

\begin{tabular}{|c|c|c|c|c|c|}
\hline Sr. No. & $\begin{array}{l}\text { Variable } 1 \\
\mathrm{Hi}=1 / \mathrm{lo}=0\end{array}$ & $\begin{array}{l}\text { Variable } 2 \\
\mathrm{Hi}=1 / \mathrm{lo}=0\end{array}$ & $\begin{array}{l}\text { Variable } 3 \\
\mathrm{Hi}=1 / \mathrm{lo}=0\end{array}$ & $\begin{array}{l}\text { Variable } 4 \\
\mathrm{Hi}=1 / \mathrm{lo}=0\end{array}$ & Response \\
\hline 1 & 0 & 0 & 0 & 0 & \\
\hline 2 & 0 & 0 & 0 & 1 & \\
\hline 3 & 0 & 0 & 1 & 0 & \\
\hline 4 & 0 & 0 & 1 & 1 & \\
\hline 5 & 0 & 1 & 0 & 0 & \\
\hline 6 & 0 & 1 & 0 & 1 & \\
\hline 7 & 0 & 1 & 1 & 0 & \\
\hline 8 & 0 & 1 & 1 & 1 & \\
\hline 9 & 1 & 0 & 0 & 0 & \\
\hline 10 & 1 & 0 & 0 & 1 & \\
\hline 11 & 1 & 0 & 1 & 0 & \\
\hline 12 & 1 & 0 & 1 & 1 & \\
\hline 13 & 1 & 1 & 0 & 0 & \\
\hline 14 & 1 & 1 & 0 & 1 & \\
\hline 15 & 1 & 1 & 1 & 0 & \\
\hline 16 & 1 & 1 & 1 & 1 & \\
\hline
\end{tabular}


The variables to be assessed in this research are:

1) Concentration of surfactant

2) Concentration of oil

3) $\mathrm{pH}$ of the solution

4) Particle size of the coal particles

The reason for choosing the concentration of surfactant as a variable is the surfactant is used for wetting or changing the surface chemistry of the coal. Different concentrations of the surfactant alter the selectivity and yield of the process. So the concentration of surfactant is a very important factor for the full study of the forth flotation process.

The concentration of oil is also an important factor for the same reason as the concentration of the surfactant. At very low concentration of oil the product yield will be low since less oil will wet the coal. At very high concentration of oil, more clay might appear in the float. So optimizing the value of oil is a important part of the study.

In the literature review, the importance of the surface chemistry of coal was discussed. In lignite coal the surface is oxidized in the form of carboxylic groups which react with metal-ions like sodium and calcium to form salts of the carboxylic acid. The presence of alkali and alkali earth metals reduces the floatability of the coal. They become hydrophilic like any other salt of an organic acid. To reverse this situation the coal is treated with a non-oxidizing acid. All the metal ions will ionize and hydrogen will replace them. This will turn the coal hydrophobic and therefore increase its floatability. That is the reason behind choosing the high and low values of $\mathrm{pH}$ as 3 and 5. The second reason is that the first surfactant DDA (do decyl amine) is only soluble at an acidic $\mathrm{pH}$.

Finally the particle size of the coal being treated is another critical variable in the whole process. The particle size can affect the overall separation that is attainable by the froth flotation process because large particles will not float. On the other hand very fine particle sizes are very difficult to obtain because the high percentage of water (approximately 30\%) causes the particles to stick together and choke the grinder. So particle sizing is a very important step in the process and hence included in the design of experiments. 


\subsection{Matrix of experiments:}

The first step for the design of experiments is the selection of the high and low values of the variables that are to be analyzed. In this section a high and a low value are selected for all four variables in the experimental matrix for conducting experiments.

The first variable is the particle size of coal. The particle size for efficient froth flotation must be small enough for doing froth flotation. For the other limit, the particle size must not be too fine because for a wet coal like Jewett lignite it is difficult to obtain very low particle sizes. Secondly, the distribution of the particle size must be narrow to ensure more homogeneity in the slurry. So the particle sizes considered in these experiments are 100-120 Mesh for the lower limit and $<200$ for the high limit.

The next variable considered is $\mathrm{pH}$ since the solubility of DDA (surfactant) is a function of $\mathrm{pH}$. This surfactant is not soluble at normal $\mathrm{pH}(\sim 7)$. At lower $\mathrm{pH}$ the surfactant is not only soluble but also mobile in the solution. So the $\mathrm{pH}$ limit that will be taken for DDA is 3 as low and 5 as high.

The concentration of DDA surfactant is selected as $0.5 \mathrm{gm} / \mathrm{Kg}$ of coal as the lower limit and $5 \mathrm{gm} / \mathrm{Kg}$ of coal as the higher limit. Since the surfactant is used in very small quantities, the high limit of $5 \mathrm{gm} / \mathrm{Kg}$ of coal might look high but the optimization equations will give the exact value of the surfactant for which the ash content can be minimized.

The lower limit of oil concentration is kept at $10 \mathrm{gm} / \mathrm{Kg}$ of coal and the higher limit is chosen to be $50 \mathrm{gm} / \mathrm{Kg}$ of coal. Again the optimization equations will give the exact amount of oil to be added in the slurry for minimum ash content.

The slurry concentration is kept constant throughout the experiments at $15 \%$ solids by weight. The rational is that at higher solid concentrations the viscosity will go up reducing the mixing of the surfactant and oil, so the ash rejection might not be very good.

As discussed above, both yield and selectivity are considered as important objectives. The data will be in terms of the dry weight of the coal in the float and the percentage of ash in the float. By doing this, the process can be analyzed on the basis of both yield and selectivity. 
The experiments were done according to the design matrix shown in Table 3.5. The float was collected, dried and weighed then a sample was taken out from it and was sent for proximate analysis. The calculations regarding the mass balance are also shown in the following section.

\subsubsection{Matrix of the experiments:}

The experiments were performed using the Design of Experiments matrix. The experimental data are presented below in Table 3.7. 
Table 3.6. Design of Experiments Matrix for DDA surfactant.

\begin{tabular}{|c|c|c|c|c|c|}
\hline & $\begin{array}{l}\text { Concentration of } \\
\text { DDA } \\
\mathrm{hi} / \mathrm{lo}=5 / 0.5(\mathrm{gm} / \mathrm{kg} \\
\text { of coal })\end{array}$ & $\begin{array}{l}\text { Concentration of } \\
\text { oil, } \\
\text { hi } / \mathrm{lo}=50 / 10(\mathrm{gm} / \mathrm{kg} \\
\text { of coal })\end{array}$ & $\begin{array}{l}\mathrm{pH}, \\
\mathrm{hi} / \mathrm{lo}=3 / 5\end{array}$ & $\begin{array}{l}\text { Particle size } \\
\text {,hi/lo=120/200(mesh } \\
\text { size) }\end{array}$ & $\begin{array}{l}\text { Coal back } \\
\text { from the } \\
\text { flotation } \\
\text { cell(dry)(gms) }\end{array}$ \\
\hline 1 & 0.5 & 10 & 2 & 120 & 21.6 \\
\hline 2 & 0.5 & 10 & 2 & 200 & 35.18 \\
\hline 3 & 0.5 & 10 & 4 & 120 & 27.1 \\
\hline 4 & 0.5 & 10 & 4 & 200 & 28.07 \\
\hline 5 & 0.5 & 50 & 2 & 120 & 28.7 \\
\hline 6 & 0.5 & 50 & 2 & 200 & 30.2 \\
\hline 7 & 0.5 & 50 & 4 & 120 & 24.84 \\
\hline 8 & 0.5 & 50 & 4 & 200 & 25.43 \\
\hline 9 & 5 & 10 & 2 & 120 & 49.16 \\
\hline 10 & 5 & 10 & 2 & 200 & 56.08 \\
\hline 11 & 5 & 10 & 4 & 120 & 44.91 \\
\hline 12 & 5 & 10 & 4 & 200 & 34.5 \\
\hline 13 & 5 & 50 & 2 & 120 & 41.76 \\
\hline 14 & 5 & 50 & 2 & 200 & 49.4 \\
\hline 15 & 5 & 50 & 4 & 120 & 39.73 \\
\hline 16 & 5 & 50 & 4 & 200 & 42.6 \\
\hline
\end{tabular}

The proximate analysis detects the amount of water, volatiles, fixed carbon and ash in the coal. From these results the ash content in the clean coal is found as well as the amount of combustible matter recovered from the froth flotation process. The raw data from proximate analysis is given below in Table 3.7 . 
Table 3.7 Proximate Analysis Results for DDA surfactant.

\begin{tabular}{|c|c|c|c|c|c|c|c|c|}
\hline $\begin{array}{l}\text { Sr. } \\
\text { No. }\end{array}$ & $\begin{array}{l}\text { Con. of } \\
\text { Surfactant } \\
\text { (gm/kg coal) }\end{array}$ & $\begin{array}{l}\text { Concentration } \\
\text { of oil (gm/kg } \\
\text { coal) }\end{array}$ & pH & PS & $\begin{array}{l}\text { Moisture } \\
\text { content } \\
(\%)\end{array}$ & $\begin{array}{l}\text { Volatiles } \\
(\%)\end{array}$ & $\begin{array}{l}\text { Ash } \\
(\%)\end{array}$ & $\begin{array}{l}\text { Fixed } \\
\text { Carbon } \\
(\%)\end{array}$ \\
\hline 1 & 0.5 & 10 & 2 & 120 & 43.5 & 23.34 & 14.84 & 19.45 \\
\hline 2 & 0.5 & 10 & 2 & 200 & 33.53 & 26.86 & 17.79 & 22.53 \\
\hline 3 & 0.5 & 10 & 4 & 120 & 7.75 & 38.41 & 20 & 34.84 \\
\hline 4 & 0.5 & 10 & 4 & 200 & 39.05 & 24.83 & 14.13 & 21.99 \\
\hline 5 & 0.5 & 50 & 2 & 120 & 26.23 & 34.1 & 14.84 & 25.92 \\
\hline 6 & 0.5 & 50 & 2 & 200 & 27.02 & 32.12 & 14.21 & 26.99 \\
\hline 7 & 0.5 & 50 & 4 & 120 & 26.75 & 33.23 & 14.51 & 26.17 \\
\hline 8 & 0.5 & 50 & 4 & 200 & 15.72 & 39.27 & 16.54 & 28.39 \\
\hline 9 & 5 & 10 & 2 & 120 & 25.4 & 30.56 & 17.07 & 25.91 \\
\hline 10 & 5 & 10 & 2 & 200 & 24.24 & 33.05 & 16.38 & 26.78 \\
\hline 11 & 5 & 10 & 4 & 120 & 27.31 & 31.56 & 15.26 & 25.53 \\
\hline 12 & 5 & 10 & 4 & 200 & 16.68 & 35.72 & 17.37 & 30.13 \\
\hline 13 & 5 & 50 & 2 & 120 & 12.77 & 38.23 & 18.21 & 30.64 \\
\hline 14 & 5 & 50 & 2 & 200 & 24.01 & 32.83 & 16.38 & 26.78 \\
\hline 15 & 5 & 50 & 4 & 120 & 22.88 & 35.69 & 14.16 & 27.27 \\
\hline 16 & 5 & 50 & 4 & 200 & 28.34 & 24.29 & 15.23 & 24.78 \\
\hline
\end{tabular}




\subsubsection{Experimental Data and procedure for the second surfactant:}

Similar experiments were performed using the second surtactant, TMAB, and the results are discussed in the following section.

The Design of Experiments for the second surfactant was done using the same frother, oil and at different $\mathrm{pH}$ values. The high and low $\mathrm{pH}$ values for this surfactant were kept at 7 and 5, the high and low concentrations for the surfactant were kept at 0.5 and $5 \mathrm{gm} / \mathrm{kg}$ of coal. The oil for the experiment was vegetable oil and its high and low values were 10 and $50 \mathrm{gm} / \mathrm{kg}$.

The froth flotation design of experiments was done for the full battery of tests and the samples were sent for proximate analysis, this time the calculations were done for both float and the slurry remaining in the vessel.

The results for the proximate analysis are given in Table 3.8: 
Table 3.8 Proximate analysis of the samples taken for froth flotation using TMAB as surfactant

\begin{tabular}{|c|c|c|c|c|c|c|c|c|}
\hline $\begin{array}{l}\mathrm{Sr} \\
\text { no. }\end{array}$ & $\begin{array}{l}\text { Conc. Of } \\
\text { surfactant }\end{array}$ & $\begin{array}{l}\text { Conc. } \\
\text { Of oil }\end{array}$ & $\mathrm{pH}$ & $\begin{array}{l}\text { Particle } \\
\text { size }\end{array}$ & $\begin{array}{l}\text { Moisture } \\
(\%)\end{array}$ & $\begin{array}{l}\text { Volatiles } \\
(\%)\end{array}$ & $\begin{array}{l}\text { Ash } \\
(\%)\end{array}$ & float $(\%)$ \\
\hline 1 & 0.5 & 10 & 5 & 120 & 14.67 & 35.35 & 19.07 & 30.93 \\
\hline 2 & 0.5 & 10 & 5 & 200 & 10.97 & 37.3 & 19.44 & 32.2 \\
\hline 3 & 0.5 & 10 & 7 & 120 & 27.73 & 29.91 & 16.69 & 25.68 \\
\hline 4 & 0.5 & 10 & 7 & 200 & 10.96 & 40.92 & 16.51 & 31.61 \\
\hline 5 & 0.5 & 50 & 5 & 120 & 25.63 & 35.25 & 16.62 & 24.75 \\
\hline 6 & 0.5 & 50 & 5 & 200 & 5.87 & 41.69 & 19.4 & 33.05 \\
\hline 7 & 0.5 & 50 & 7 & 120 & 12.23 & 29.18 & 19.21 & 29.38 \\
\hline 8 & 0.5 & 50 & 7 & 200 & 8.85 & 40.55 & 18.8 & 31.79 \\
\hline 9 & 5 & 10 & 5 & 120 & 7.18 & 38.54 & 23 & 31.29 \\
\hline 10 & 5 & 10 & 5 & 200 & 14.6 & 36.77 & 18.11 & 30.51 \\
\hline 11 & 5 & 10 & 7 & 120 & 27.8 & 31.2 & 16.9 & 24.97 \\
\hline 12 & 5 & 10 & 7 & 200 & 30.26 & 29.23 & 16.32 & 24.2 \\
\hline 13 & 5 & 50 & 5 & 120 & 24.26 & 36.05 & 15.84 & 23.85 \\
\hline 14 & 5 & 50 & 5 & 200 & 11.83 & 39.72 & 18.17 & 30.22 \\
\hline 15 & 5 & 50 & 7 & 120 & 7.13 & 42.83 & 19.1 & 30.44 \\
\hline 16 & 5 & 50 & 7 & 200 & 9.91 & 39.27 & 19.94 & 30.885 \\
\hline
\end{tabular}


The analysis of these experimental results is presented in Chapter 4. The actual examination of the analytical technique, results and conclusions of the experiments done in Chapter 3 are also discussed in Chapter 4. 


\section{Analysis of results and conclusions.}

\subsection{Results for froth flotation process for DDA and TMAB surfactants:}

The weight of the product coal which is recovered in froth flotation experiments is the wet weight To do exact calculations all the weights must be on dry or moisture-free basis. The initial amount of coal taken in all of the above experiment is $100 \mathrm{gm}$. It has $30 \%$ moisture by weight.

The first thing that is calculated is total mass recovered or the total product yield.

i. $\quad$ Total mass of sample initially taken $=100 \mathrm{gm}$

ii. Dry mass of sample $=($ Total Mass $) *\left(\frac{100-\text { Moisture content }}{100}\right)=70 \mathrm{gm}$

iii. Total weight of coal recovered $=\mathrm{m}_{1} \mathrm{gm}$

iv. Dry weight $\left(\mathrm{m}_{2}\right)=(m 1) *\left(\frac{100-\text { Moisture content }}{100}\right) \mathrm{gm}$

v. $\%$ coal recovered $=\frac{\mathrm{m} 2}{70} * 100 \%$

For ash content in any given sample on a dry basis:

i. Ash content in the proximate analysis $=\mathrm{m}_{1} \%$

ii. Ash content dry (in $\%)=\mathrm{m}_{1} * \frac{1}{100-\text { Moisture }} * 100$

iii. Mass of ash $=($ dry coal mass $) * \frac{a s h \% d r y}{100}$

Using the above relations the combustible matter recovery and the ash percentage in the coal were calculated. These results are shown in Tables 4.1 and 4.2. The values given in Table 4.1 are for DDA surfactant and the values in Table 4.2 are for TMAB surfactant. 
Table 4.1 Results from the calculations done for DDA surfactant.

\begin{tabular}{|c|c|c|c|c|}
\hline Sr. No. & $\begin{array}{l}\text { Ash } \\
\text { Content(dry)(gms) }\end{array}$ & $\begin{array}{l}\text { Total coal mass } \\
\text { recovered\%(Dry) }\end{array}$ & Ash \%(dry) & $\begin{array}{l}\text { Combustible } \\
\text { matter (dry) }\end{array}$ \\
\hline 1 & 5.62 & 30.85 & 26.02 & 22.83 \\
\hline 2 & 9.33 & 50.25 & 26.52 & 36.93 \\
\hline 3 & 5.86 & 38.71 & 21.62 & 30.34 \\
\hline 4 & 6.5 & 40.10 & 23.15 & 30.81 \\
\hline 5 & 7.49 & 41.0 & 26.09 & 30.30 \\
\hline 6 & 5.91 & 43.14 & 19.56 & 34.70 \\
\hline 7 & 4.86 & 35.48 & 19.56 & 28.54 \\
\hline 8 & 5.01 & 36.32 & 19.70 & 29.17 \\
\hline 9 & 11.39 & 70.22 & 23.16 & 53.96 \\
\hline 10 & 12.07 & 80.11 & 21.52 & 62.87 \\
\hline 11 & 8.86 & 64.15 & 19.72 & 51.50 \\
\hline 12 & 7.148 & 49.28 & 20.71 & 39.07 \\
\hline 13 & 8.85 & 59.65 & 21.19 & 47.01 \\
\hline 14 & 13.78 & 70.57 & 27.89 & 50.88 \\
\hline 15 & 7.83 & 56.75 & 19.71 & 45.57 \\
\hline 16 & 9.28 & 60.85 & 21.78 & 47.60 \\
\hline
\end{tabular}


Table 4.2 Results for ash in float and slurry for TMAB surfactant

\begin{tabular}{|r|r|r|r|r|r|r|r|r|}
\hline Sr no. & $\begin{array}{l}\text { Conc. of } \\
\text { surfactant }\end{array}$ & \multicolumn{1}{l|}{$\begin{array}{l}\text { Conc. } \\
\text { of oil }\end{array}$} & pH & \multicolumn{1}{l|}{ PS } & \multicolumn{1}{l|}{$\begin{array}{l}\text { coal } \\
\text { recovered }\end{array}$} & $\begin{array}{l}\text { ash(\%) } \\
\text { (float) }\end{array}$ & $\begin{array}{l}\text { ash\% } \\
\text { (slurry) }\end{array}$ & $\begin{array}{l}\text { coal } \\
\text { recovered(\%) }\end{array}$ \\
\hline 1 & 0.5 & 10 & 5 & 120 & 11.26 & 22.35 & 27.66 & 19.08 \\
\hline 2 & 0.5 & 10 & 5 & 200 & 9.79 & 21.84 & 30.17 & 16.59 \\
\hline 3 & 0.5 & 10 & 7 & 120 & 14.45 & 23.09 & 20.37 & 24.49 \\
\hline 4 & 0.5 & 10 & 7 & 200 & 7.56 & 18.54 & 20.15 & 12.81 \\
\hline 5 & 0.5 & 50 & 5 & 120 & 14.5 & 22.35 & 19.48 & 24.58 \\
\hline 6 & 0.5 & 50 & 5 & 200 & 10.54 & 20.61 & 19.91 & 17.86 \\
\hline 7 & 0.5 & 50 & 7 & 120 & 22.55 & 21.89 & 19.26 & 38.22 \\
\hline 8 & 0.5 & 50 & 7 & 200 & 14.7 & 20.63 & 19.86 & 24.92 \\
\hline 9 & 5 & 10 & 5 & 120 & 20.05 & 24.78 & 18.4 & 33.98 \\
\hline 10 & 5 & 10 & 5 & 200 & 28.78 & 21.21 & 19.32 & 48.78 \\
\hline 11 & 5 & 10 & 7 & 120 & 38.77 & 23.41 & 16.8 & 65.71 \\
\hline 12 & 5 & 10 & 7 & 200 & 28.59 & 23.4 & 22.52 & 48.46 \\
\hline 13 & 5 & 50 & 5 & 120 & 26.51 & 20.91 & 19.55 & 44.93 \\
\hline 14 & 5 & 50 & 5 & 200 & 30.59 & 20.61 & 19.62 & 51.85 \\
\hline 15 & 5 & 50 & 7 & 120 & 26.46 & 20.57 & 19.22 & 44.85 \\
\hline 16 & 5 & 50 & 7 & 200 & 30.63 & 22.13 & 22.08 & 51.92 \\
\hline
\end{tabular}

\subsection{Analysis of results:}

The analysis of these results is done by factoral analysis followed by an analysis of variance (ANOVA). This allows a correlation to be created for combustible matter recovery as well as ash content, and ultimately the value of the parameters that result in optimized (i.e., minimized) ash content.

The experimental matrix of results was solved using software called "design of experiments" (DOE). This particular software treats the data and fits them to an empirical correlation of a particular mathematical form which can be further optimized to predict 
conditions for maximum coal recovery and minimum ash content. Both of these calculations are done simultaneously and results are displayed as the values of the input variables that will give the best results. The input variables for the DOE analysis are $\mathrm{pH}$, particle size, concentration of surfactant and concentration of oil and the response of these variables optimized in the program are combustible matter recovery and ash percentage in the combustible matter recovered. The program performs ANNOVA testing on the data to check the accuracy of the convergence of the data points.

\subsection{Results of DOE analysis:}

Using the Design of Experiments program for calculation of a theoretical data point for which the ash percentage is minimum was performed. The results from the program did not converge i.e. in the ANNOVA testing of the data points the error margin was $532 \%$ for DDA surfactant and the error for the data for TMAB surfactant was more than $600 \%$. This means that the froth flotation process does not produce results that correlated with the variables or resemble any mathematical model. However looking at the 16 data points for both the experiments the lowest ash percentage that was achieved by DDA surfactant was $19.36 \%$ and for the TMAB surfactant this number was $18.54 \%$ ash.

\subsection{Conclusions for using conventional cleaning technique for cleaning Texas Jewett Lignite coal:}

It can be safely concluded that the Design of Experiment technique failed in generating a mathematical model for reduction in ash percentage using the froth floatation technique. The reason behind this is that the chemistry of lignite coal is very different than that of bituminous and sub-bituminous coal. Also the impurities in Texas Jewett Lignite coal are different than those of bituminous and sub-bituminous coal. In Texas lignite coal the primary impurity is clay which sticks to the coal and forms a composite particle, and since in froth flotation the coal particles are being floated using the surfactant there is no effective ash removal because the composite particle of coal and clay is not de-convoluted.

Since conventional coal cleaning techniques like gravity separations and froth flotation don't work on Texas Jewett lignite, a non conventional technique has to be developed to effectively de-ash the coal. In this new technique, efforts to de-convolute the coal and clay 
composite particle must be made. This can be done by targeting clays instead of coal, i.e. unlike in froth flotation where the surfactants were added to float the coal, in the new technique efforts are made to separate the clay particles from the coal particles. The details of this non conventional process are given in section 4.5.

\subsection{Non conventional cleaning techniques for cleaning Texas Jewett Lignite coal:}

In this technique clay dispersants are added to suspend the clay particles and at the same time an agglomerating agent is added to agglomerate the coal. The agglomerating agent chosen to carry out these experiments is cresylic acid. Cresylic acid is a chemical that is found in coal itself. It is also found in spent solvent solutions from where it can be obtained and used for the agglomeration and cleaning of coal. The basic principle is that cresylic acid is a hydrophobic chemical and it repels water. Since cresylic acid is a part of coal, it has an affinity towards organic compounds because they are also insoluble in water. So it attaches itself to coal and the agglomerate grows in size and falls out of the solution to the bottom of the vessel.

The agglomeration of coal is the just one part of the process. Cresylic acid being an organic compound has no affinity towards ash which is inorganic and inert. Also ash has a specific gravity greater than water so eventually it will fall out of the solution as well. If the ash falls out of the solution, it will not aid the separation of the coal so the ash must remain suspended while the coal is agglomerated. The clay rich water is then filtered to remove suspended ash for better separation. This can be done by using clay dispersant like the sodium salt of lignosulfonic acid.

The first experiment was done in a small beaker to test the above hypothesis. A small sample of coal was taken in a $500 \mathrm{ml}$ beaker and water was added to make the slurry. The sodium salt of lignosulfonic acid surfactant was then added and the solution stirred. After that cresylic acid was added, the solution was stirred again and allowed to stand overnight. The next morning samples were taken and sent for analysis. It was noted that, the beaker had two separated layers. The top layer was expected to be the inorganics while the coal had agglomerated and was settled to the bottom of the beaker. The muddy water was decanted and the coal was collected, filtered, and dried and sent for proximate analysis. 
The ash content in the separated coal sample was about $23 \%$ which indicates a poor separation. The reasons for having such a bad separation were the following:

1) Clay particles are denser than water. Even if a surfactant is used, the clay will fall out of the solution, with the agglomerated coal.

2) The application of surfactant was not proper because there was very little agitation, so the surfactant was not fully applied to the entire coal sample.

To improve upon both these problems the next experiment was done with a larger sample of $120 \mathrm{gm}$ which was suspended using an agitator with the RPM kept high at around 1700-1800. One gram of the surfactant was added to the mixture again without changing the set RPM. The mixture was agitated for another 10 minutes just to ensure that the surfactant is thoroughly mixed with the coal in the slurry. Then oil and cresylic acid were added and the agitator was stopped. The slurry was allowed to stand for 2-3 minutes and the liquid phase was decanted into another container and the coal agglomerates formed at the bottom of the vessel were collected. The same process was repeated again twice each time on the agglomerated coal without adding the surfactant or cresylic acid.

All the coal agglomerates were washed and filtered into a filtration funnel and a sample was taken from the coal and sent for proximate analysis. The water decanted from the vessels was filtered using a Buckner filter set up and house vacuum. Another sample from the filtrate was taken and was sent for proximate analysis.

The results from the proximate analysis are shown in the Table 4.3:

Table 4.3 Proximate analysis of samples for test run of cresylic acid and lignosulphonic salt as surfactant

\begin{tabular}{|c|c|c|c|}
\hline Sample & $\begin{array}{c}\text { Volatile } \\
\text { content\% (dry) }\end{array}$ & $\begin{array}{c}\text { Ash content\% } \\
(\text { dry })\end{array}$ & $\begin{array}{c}\text { Fixed carbon\% } \\
\text { content (dry) }\end{array}$ \\
\hline Agglomerates & 43.23 & 19.6 & 37.17 \\
\hline Rejects & 44.6 & 34.20 & 21.91 \\
\hline
\end{tabular}


These results show that the rejects have a higher percentage of ash. If the ratio of the ash in coal to the ash in the rejects ratio, it is almost twice as high. This means that this technique is selective and can achieve separation of clay from coal.

A series of experiments were performed using cresylic acid/sodium salt of lignio sulphonic acid for agglomeration/dispersion technique. All the details of these experiments are provided in Chapter 5. 


\section{Cresylic acid experiments}

A preliminary process was designed and experiments were conducted using agglomeration by cresylic acid. The process was based on first agglomerating coal by cresylic acid and then decantation of the remaining muddy water. The agglomerated coal after decantation was dried, weighed and sent for proximate analysis. The schematic diagram of the process is given below in Figure 5.1.

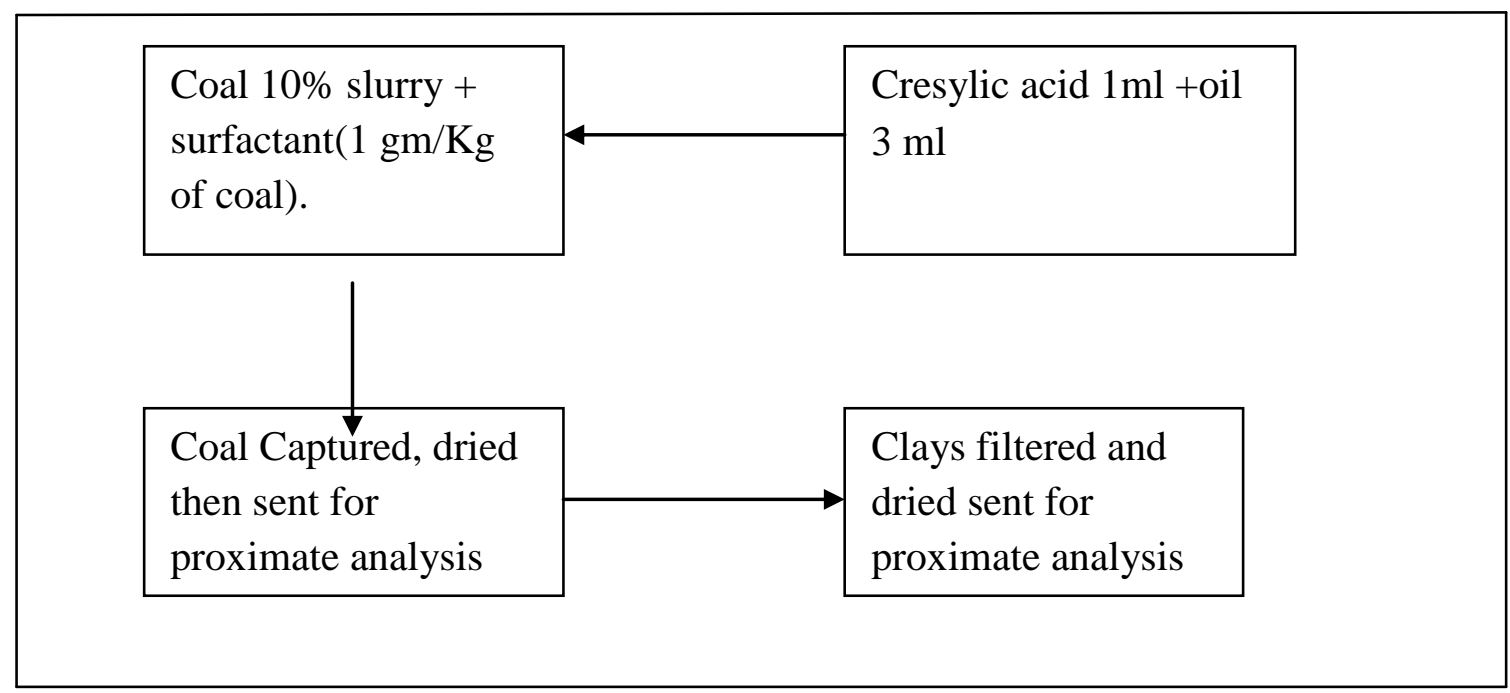

Figure 5.1 Protocol for cleaning coal using cresylic acid to agglomerate coal

The detailed procedure for doing these experiments is described below.

1) First $100 \mathrm{gm}$ of coal was weighed and made into $10 \%$ slurry in water.

2) The surfactant was the sodium salt of ligno sulphonic acid. The amount of surfactant was $1 \mathrm{gm} / \mathrm{Kg}$ of coal. The surfactant was thoroughly mixed with the coal using an agitator at 1200 RPM for 10 minutes.

3) Then $1 \mathrm{ml}$ cresylic acid along with $3 \mathrm{ml}$ of vegetable oil was added to agglomerate the coal.

4) The solution was left undisturbed for 9 minutes while the agglomerates settle. Then the muddy water was decanted into another beaker and the coal that remained in the original container was collected.

5) The settled coal was dried at $105^{\circ} \mathrm{C}$ for one hour and sent for proximate analysis. 
6) The rejects that were decanted from the starting container were filtered and dried at $105^{\circ} \mathrm{C}$ and sent for proximate analysis.

7) All the experiments were done at room temperature

A washing of coal was performed using the above protocol and the results were analyzed. The detailed results of the proximate analysis are shown in Tables 5.1, 5.2 and 5.3 also shown are the overall mass and ash balances.

Table 5.1. Results from a Single Pass with Cresylic Acid Washing, Agglomerate.

\begin{tabular}{|l|l|l|l|}
\hline Sample Id & Volatiles (\%) & Fixed Carbon (\%) & Ash (\%) \\
\hline 050710LigninCryAcidAGG 1 & 41.83 & 35.88 & 22.27 \\
\hline 050710LigninCryAcidAGG 2 & 42.23 & 35.52 & 22.23 \\
\hline 050710LigninCryAcidAGG 3 & 42.03 & 35.70 & 22.25 \\
\hline Average & 41.83 & 35.88 & 22.27 \\
\hline
\end{tabular}

Table 5.2. Results from a Single Pass with Cresylic Acid Washing, Rejects.

\begin{tabular}{|l|l|l|l|}
\hline Sample Id & Volatiles (\%) & Fixed Carbon (\%) & Ash (\%) \\
\hline 050710LigninCryAcid Rej 1 & 37.34 & 31.32 & 31.32 \\
\hline 050710LigninCryAcid Rej 2 & 36.73 & 31.84 & 31.42 \\
\hline 050710LigninCryAcid Rej 3 & 37.04 & 31.58 & 31.37 \\
\hline Average & 37.34 & 31.32 & 31.32 \\
\hline
\end{tabular}


Table 5.3 Mass and ash balance table for decantation process

\begin{tabular}{|c|c|c|c|c|c|}
\hline Sample & $\begin{array}{c}\text { Captured coal } \\
(\mathrm{dry})(\mathrm{gm})\end{array}$ & $\begin{array}{c}\text { Rejects } \\
(\mathrm{dry})(\mathrm{gm})\end{array}$ & $\begin{array}{c}\text { Total } \\
(\mathrm{grams})\end{array}$ & $\begin{array}{c}\text { Initial weight } \\
(\mathrm{dry})(\mathrm{gm})\end{array}$ & \% error \\
\hline Total mass & 53.62 & 19.82 & 73.42 & 70 & 4.88 \\
\hline Ash Mass & 11.48 & 6.22 & 17.7 & 18 & 1.66 \\
\hline
\end{tabular}

The yield from the first run of the coal through the process was $53.3 \mathrm{gm}$ out of $70 \mathrm{gm}$ of dry coal tabulated in Table 5.3. The percentage yield of the coal is $77 \%$, i.e. $77 \%$ of the combustible matter was recovered from the initial amount of coal added. The ash percent in the rejects is $31.32 \%$ (Table 5.2) whereas the ash percent in the agglomerates is $22.27 \%$ (Table 5.1). The selectivity of the separation is good but the absolute percentage of ash in the coal is still too high. So, a second run was performed using the same protocol described earlier. In the second run the product from the first run i.e. the agglomerated coal from the first run, was taken and run through the process another time for further reduction of ash. In the second run, the only difference is that in the first run the cleaned coal was taken as received from the mine and in the second run the coal was then taken was the cleaned coal in the first run. The results of the second run of coal cleaning are provided in Tables 5.4, 5.5 and 5.6.

Table 5.4. Results from Second run with Cresylic Acid Washing, Agglomerate.

\begin{tabular}{|c|r|r|r|}
\hline \multicolumn{1}{|c|}{ Sample Id } & Volatiles (\%) & Fixed Carbon (\%) & Ash (\%) \\
\hline 051410CRYAcidOilLig. AGG 1 & 46.71 & 33.05 & 20.23 \\
\hline 051410CRYAcidOilLig. AGG 2 & 43.81 & 36.13 & 20.04 \\
\hline 051410CRYAcidOilLig. AGG 3 & 44.45 & 35.05 & 20.49 \\
\hline Average & 44.94 & 34.74 & 20.25 \\
\hline
\end{tabular}


Table 5.5. Results from a Second run with Cresylic Acid Washing, Rejects.

\begin{tabular}{|c|r|r|r|}
\hline Sample Id & Volatiles (\%) & Fixed Carbon (\%) & Ash (\%) \\
\hline 051410CRYAcidOilLig.REJ 1 & 38.74 & 33.23 & 28.01 \\
\hline 051410CRYAcidOilLig.REJ 2 & 39.28 & 32.95 & 27.75 \\
\hline 051410CRYAcidOilLig.REJ 3 & 38.89 & 33.25 & 27.84 \\
\hline Average & 38.97 & 33.15 & 27.87 \\
\hline
\end{tabular}

Table 5.6 Mass and ash balance for the second run with cresylic acid washing

\begin{tabular}{|c|c|c|c|c|c|}
\hline Sample & $\begin{array}{c}\text { Captured coal } \\
(\mathrm{dry})(\mathrm{gm})\end{array}$ & $\begin{array}{c}\text { Rejects } \\
(\mathrm{dry})(\mathrm{gm})\end{array}$ & $\begin{array}{c}\text { Total } \\
(\mathrm{grams})\end{array}$ & $\begin{array}{c}\text { Initial weight } \\
(\mathrm{dry})(\mathrm{gm})\end{array}$ & \% error \\
\hline Total mass & 43.6 & 9.7 & 53.3 & 53.62 & 0 \\
\hline Ash Mass & 8.5 & 2.53 & 11.03 & 11.5 & 4.08 \\
\hline
\end{tabular}

In the second run, results for coal in Table 5.4 show that the ash percentage is $20.25 \%$ in the clean coal and that ash percentage is $28 \%$ in the rejects. The yield of the second run as mentioned in Table 5.6 is 43.6 gm. However the percentage yield of the coal is calculated by taking the initial coal as the reference i.e. $70 \mathrm{gm}$ of coal, because the second run is a part of the overall cleaning process and the yield must be calculated by taking the initial amount of coal as a reference point. The yield in the second run was $62.3 \%$ calculated on the basis of total dry coal. The second run showed a further decrease in the ash and so the collected agglomerated coal was run through the process a third time. The coal did agglomerate, proving that cresylic acid is not required in every step of the washing to form agglomerates. The results from third washing are provided below in Tables 5.7, 5.8 and 5.9. 
Table 5.7 Results from a Third Pass with Cresylic Acid Washing, Agglomerate.

\begin{tabular}{|l|r|r|r|}
\hline Sample Id & Volatiles (\%) & Fixed Carbon (\%) & Ash (\%) \\
\hline 052110CryacidLignin AGG 1 & 43.35 & 37.62 & 19.02 \\
\hline 052110CryacidLignin AGG 2 & 42.95 & 38.07 & 18.97 \\
\hline 052110CryacidLignin AGG 3 & 43.28 & 38.24 & 18.47 \\
\hline Average & 43.19 & 37.98 & 18.82 \\
\hline
\end{tabular}

Table 5.8. Results from a Third Pass with Cresylic Acid Washing, Rejects.

\begin{tabular}{|l|r|r|r|}
\hline Sample Id & Volatiles (\%) & Fixed Carbon (\%) & Ash (\%) \\
\hline 052110CryacidLignin REJ 1 & 41.38 & 35.04 & 23.57 \\
\hline 052110CryacidLignin REJ 2 & 40.92 & 35.20 & 23.86 \\
\hline 052110CryacidLignin REJ 3 & 40.89 & 35.43 & 23.67 \\
\hline Average & 41.06 & 35.22 & 23.70 \\
\hline
\end{tabular}

Table 5.9 Mass and Ash balance for third run of Cresylic acid washing

\begin{tabular}{|c|c|c|c|c|c|}
\hline Sample & $\begin{array}{c}\text { Captured coal } \\
(\mathrm{dry})(\mathrm{gm})\end{array}$ & $\begin{array}{c}\text { Rejects } \\
(\mathrm{dry})(\mathrm{gm})\end{array}$ & $\begin{array}{c}\text { Total } \\
(\mathrm{grams})\end{array}$ & $\begin{array}{c}\text { Initial weight } \\
(\mathrm{dry})(\mathrm{gm})\end{array}$ & \% error \\
\hline Total mass & 33.9 & 8.6 & 42.5 & 43.6 & 2.52 \\
\hline Ash Mass & 6.43 & 2.06 & 8.49 & 8.5 & 0 \\
\hline
\end{tabular}

The ash percentage of the clean coal after the washing was performed for the third time using the same process shown in Figure 5.1 was reduced to $18.82 \%$ as shown in Table 5.7. However the ash percent in the rejects is $23 \%$ as shown in Table 5.8. The yield of this process is $33.9 \mathrm{gm}$. The percentage yield based on the initial $70 \mathrm{gm}$ of coal is $42.42 \%$. After analyzing each 
run separately the analysis of the cleaning as a whole was done. The results of each individual step were tabulated in Table 5.10.

Table 5.10 Data from the experiments done with the cresylic acid protocol.

\begin{tabular}{|c|c|c|}
\hline Number of Experiments & Ash $(\%)$ & Coal Recovered (grams) \\
\hline 0 ( Initial condition) & 28 (Initial Condition ) & 70 ( Initial Condition) \\
\hline 1 & 22.25 & 53.62 \\
\hline 2 & 20.25 & 43.6 \\
\hline 3 & 18.82 & 33.9 \\
\hline
\end{tabular}

The first observation was that the ash percentage in the rejects drops progressively as more and more cleaning runs were performed, i.e. when the cleaning procedure described in Figure 5.1 is repeated in series taking the product of the previous run as the starting coal for the subsequent run, the ash that is rejected decreases progressively. This behavior is shown in Figure 5.2. The decrease is a weak exponential function and decreases as more and more runs are performed on the same coal in series. Thus the regression equation predicts the number of experiments that are needed in order to get an ash percentage below $10 \%$ is 8 runs. This is too high for any process to be economical.

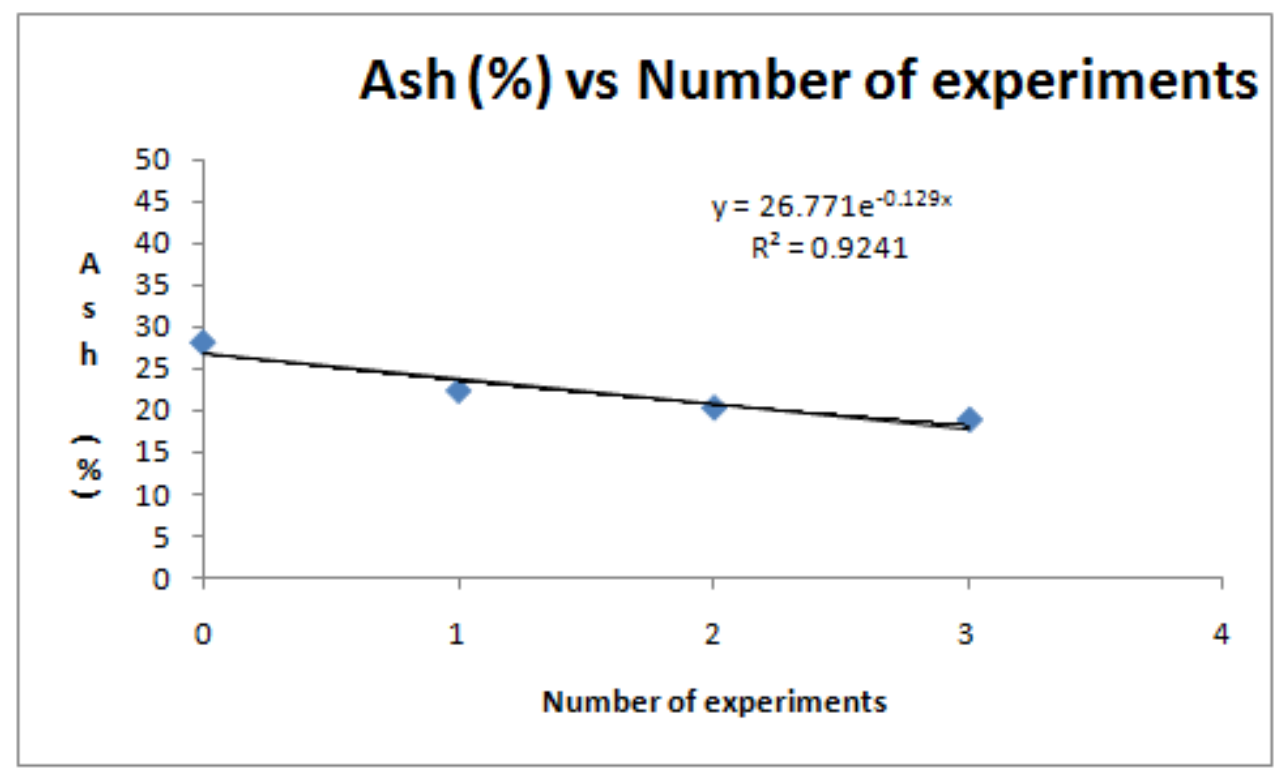

Figure 5.2 Ash(\%) vs Number of experiments for cresylic acid agglomeration method 
Similar observations were made for the yield in the agglomerated clean coal that is collected and measured. The yields are decreasing progressively as shown in Figure 5.3, and the equation of the line is $y=0.2444 x+9.9185$. According to this equation if the goal is to achieve an ash percentage below 10\%, the amount of coal that can be recovered at that ash percentage is $.334 \mathrm{gm}$ which makes the yield to be $0.48 \%$. In other words it is not possible from this process to obtain an ash percentage that is below $10 \%$.

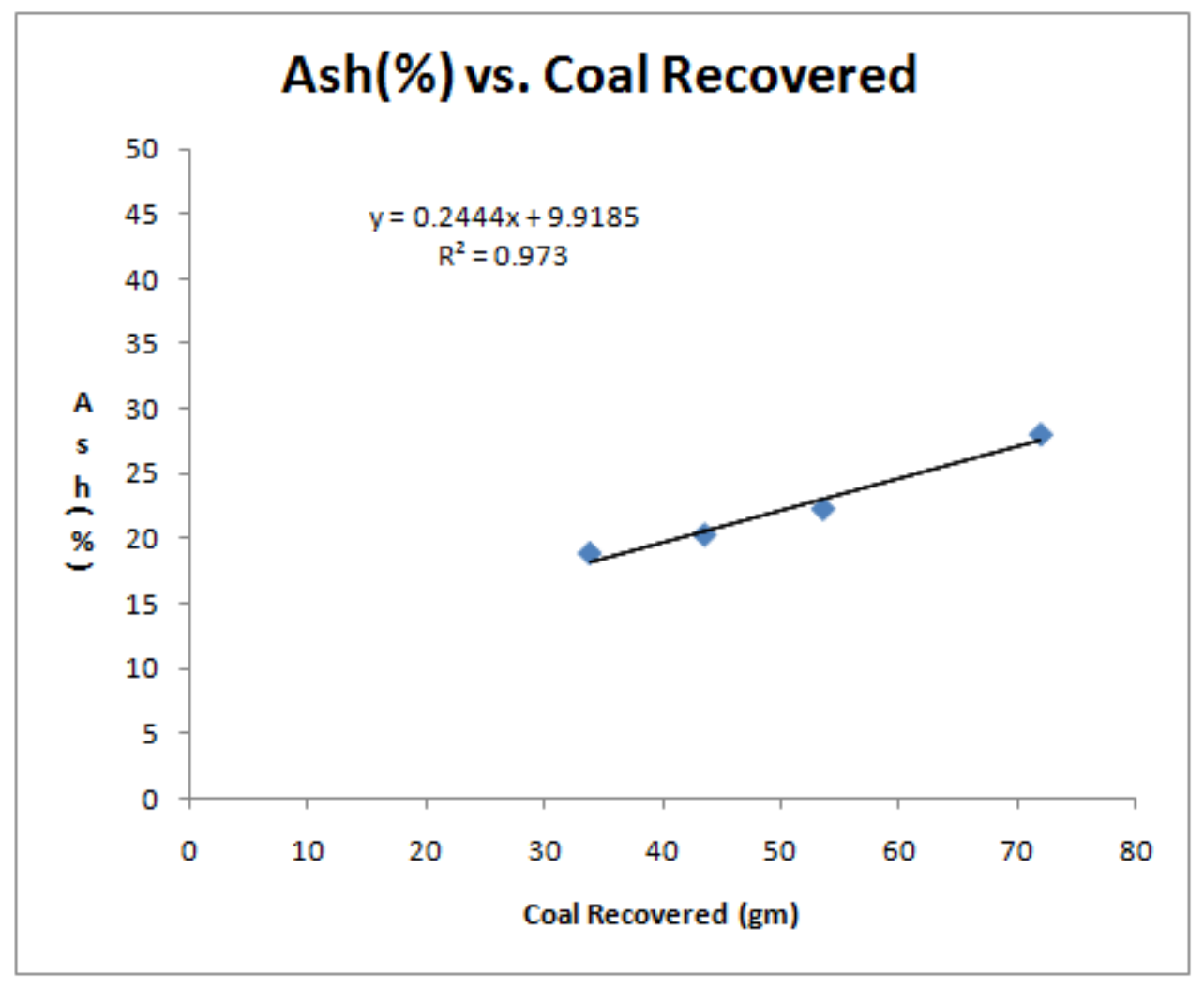

Figure 5.3 Ash (\%) vs Coal Recovered for Cresylic acid agglomeration method

Calculating the number of experiments and yields at $10 \%$ ash level by interpolation of data, it is safe to say that there must be some key changes in the process to make it achieve the goals. One such key change is that the process for separating the clays is decantation which is not proving to be effective. Another technique that was proposed was particle size separation. The details of the next procedure are given in the Section 5.2. 


\subsection{Separations using Particle size:}

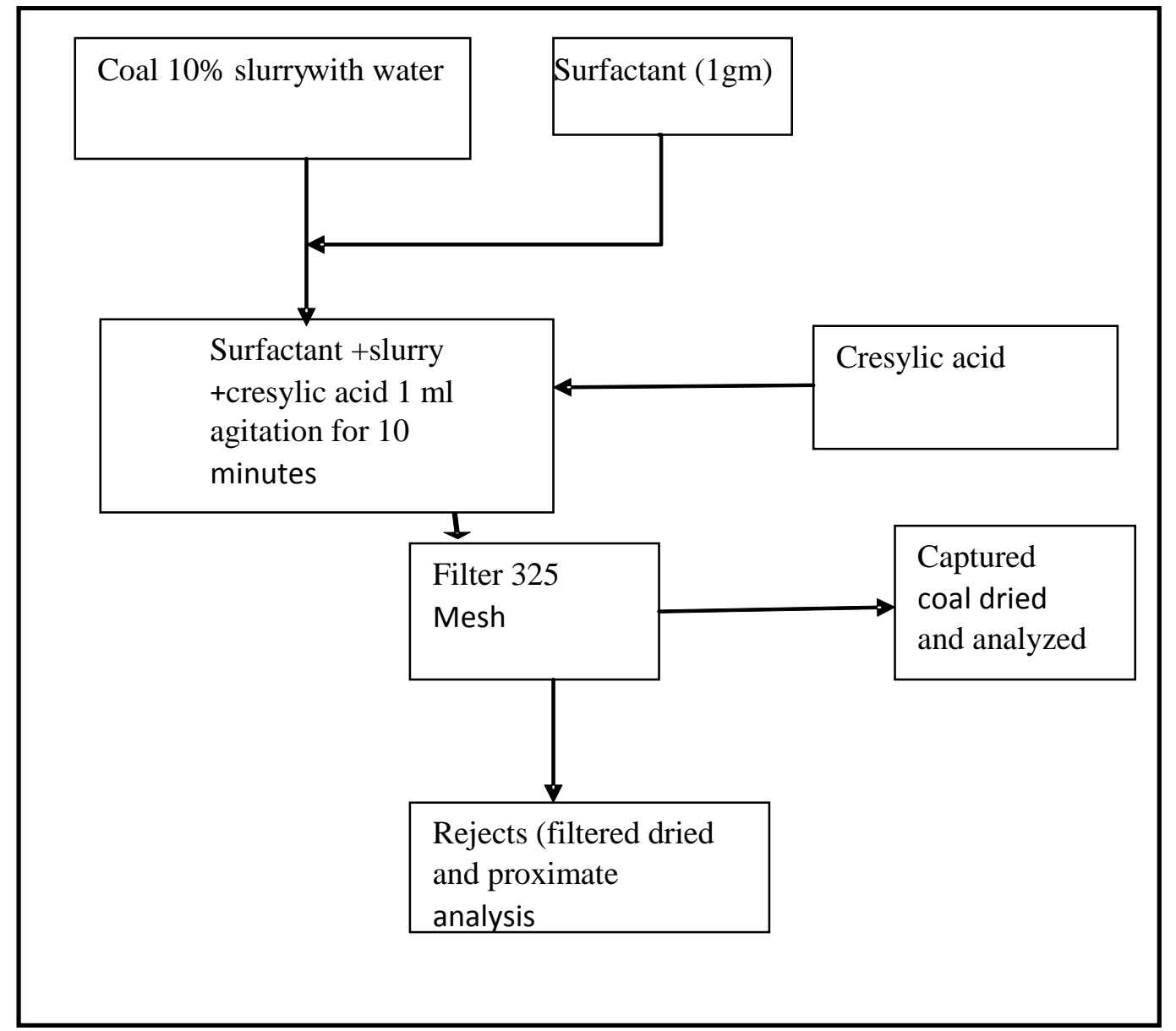

Figure 5.4 Particle size separation protocol for coal cleaning processes.

\subsubsection{Principle:}

In the process shown in Figure 5.4, instead of decanting the rejects, the whole slurry is run through a 325(25 Microns) Mesh screen. The agglomerated coal is trapped in the sieve and the clays having a smaller particle size fall through the sieve. Typical particle size for clay ranges from 3-7 Microns, ${ }^{[35]}$ and the coal that is being used here is $65-75$ Microns. So, all the coal will be captured by the sieve and the clays will be rejected. With this process improvement, another round of coal cleaning was done. 


\subsubsection{Procedural details:}

1) The next experiment was done with a sample of $100 \mathrm{gm}$ and slurried to $10 \%$ by weight with water at room temperature using an agitator for 10 minutes. $1 \mathrm{gm} / \mathrm{Kg}$ of coal surfactant (sodium salt of lingo-sulphonic acid) is added to this slurry and the mixture was agitated thoroughly. The RPM was kept at around 1700-1800. The mixture was agitated for another 10 minutes just to ensure that the surfactant was thoroughly mixed with the coal in the slurry.

2) Then the whole mixture was passed through a 325 Mesh (47 Micron) screen and all the agglomerated coal was captured by the sieve and the clays that are much smaller in size are allowed to pass through.

3) Meanwhile the water containing the ash (rejects), coal and the surfactant was again passed through the 325 Mesh screen and, the coal captured by the 325 mesh screen is added to the coal that was captured previously using the same mesh size screen in step 2. The rejects are filtered in a separate funnel, dried at $105^{\circ} \mathrm{C}$ for one hour and sent for proximate analysis. A Buchner filter setup and house vacuum were used to perform filtration and a drying oven was used to dry the sample at $105^{\circ} \mathrm{C}$.

4) All the coal agglomerates were washed and filtered into a filtration funnel and dried for 1 hour at $105{ }^{\circ} \mathrm{C}$. Then a sample was taken from the coal and sent for proximate analysis.

These results in Tables 5.11, 5.12 and 5.13 shows that the particles suspended in the water have a higher percentage of ash. The coal-to-ash ratio in the rejects is high because most of the volatile matter in the rejects and the agglomerates is cresylic acid i.e. the cresylic acid added to agglomerate coal is sticking to the coal and thereby increasing the volatile content in the coal and the ash. The results show that the volatiles recorded in the proximate analysis of the second run were $51.4 \%$ as compared to more general $38-45 \%$ volatiles that are recorded for Jewett Lignite coal time and again.

The major change in the protocol is that the suspended ash is not decanted from the slurry but filtered out. Since the particle size of clay is smaller than that of coal, the clay particles will go directly through the sieve and coal will be captured by the sieve. The results of the run done using the above described protocol are given in Tables 5.11, 5.12 and 5.13 
Table 5.11 Results for Particle size separation method, Agglomerated Coal.

\begin{tabular}{|l|r|r|r|}
\hline Sample Id & Volatiles (\%) & Fixed Carbon (\%) & Ash (\%) \\
\hline 0527CRYAcidOilLigninAggSiV 1 & 42.95 & 37.35 & 19.69 \\
\hline 0527CRYAcidOilLigninAggSiV 1 & 43.20 & 37.17 & 19.62 \\
\hline Average & 43.54 & 36.98 & 19.47 \\
\hline
\end{tabular}

Table 5.12. Results for Particle size separation method, Rejects.

\begin{tabular}{|l|r|r|r|}
\hline Sample Id & Volatiles (\%) & Fixed Carbon (\%) & Ash (\%) \\
\hline 0527CRYAcidOilLigninRejSiV 1 & 43.69 & 21.53 & 34.76 \\
\hline 0527CRYAcidOilLigninRejSiV 2 & $45 . .01$ & 21.03 & 33.95 \\
\hline Average & 45.09 & & 33.90 \\
\hline
\end{tabular}

Table 5.13 Ash balance and mass balance for the particle size separation method first run

\begin{tabular}{|c|c|c|c|c|c|}
\hline Sample & $\begin{array}{c}\text { Captured coal } \\
(\text { dry })(\mathrm{gm})\end{array}$ & $\begin{array}{c}\text { Rejects } \\
(\mathrm{dry})(\mathrm{gm})\end{array}$ & $\begin{array}{c}\text { Total } \\
(\mathrm{grams})\end{array}$ & $\begin{array}{c}\text { Initial weight } \\
(\mathrm{dry})(\mathrm{gm})\end{array}$ & $\%$ error \\
\hline Total mass & 52 & 19 & 71 & 70 & 1.42 \\
\hline Ash Mass & 9.5 & 7 & 16.5 & 18 & 8.33 \\
\hline
\end{tabular}

The yield from the first run using a sieve is $52 \mathrm{gm}$ of coal. The percentage yield from the first run using a sieve was $74.28 \%$ taking the initial dry weight as the basis for calculating the yield.. In Tables 5.11 and 5.12 the ash percentages in coal and rejects are $19.47 \%$ and $33.9 \%$ respectively. From these results the selectivity of the process was confirmed but the absolute value of the ash in the coal was still not very low. The reason is the coal formed a cake on the screen and the water containing the dispersed ash could not go through the sieve, trapping the ash particles in the coal cake. To avoid this problem more water was used for the filtration and 
the sample was repeatedly washed to remove all the clays trapped inside the filter cake. The second washing of the coal was performed using the coal captured from the first washing of coal and running it through the same procedure described in Figure 5.4. The results from the second washing of the product from the first washing are shown in Tables 5.14, 5.15 and 5.16.

Table 5.14. Results of the Second Pass of particle size separation method first pass, coal.

\begin{tabular}{|l|c|c|c|}
\hline Sample Id & Volatiles (\%) & Fixed Carbon (\%) & Ash (\%) \\
\hline 061110CRYLigAGG2 1 & 48.78 & 35.59 & 15.62 \\
\hline 061110CRYLigAGG2 2 & 46.41 & 36.06 & 17.51 \\
\hline 061110CRYLigAGG2 3 & 46.07 & 36.33 & 17.58 \\
\hline Average & 47.09 & 35.99 & 16.90 \\
\hline
\end{tabular}

Table 5.15. Results of the Second Pass of particle size separation method first pass, Rejects.

\begin{tabular}{|ll|c|c|c|}
\hline Sample Id & & Volatiles (\%) & Fixed Carbon (\%) & Ash (\%) \\
\hline 061110CRYLigREJ2 & 1 & 57.61 & 22.29 & 20.09 \\
\hline 061110CRYLigREJ2 & 2 & 57.33 & 22.42 & 20.24 \\
\hline 061110CRYLigREJ2 & 3 & 56.87 & 23.12 & 19.99 \\
\hline Average & 57.27 & 22.61 & 20.10 \\
\hline
\end{tabular}


Table 5.16 Mass and ash balance of second washing using the Particle size separation method

\begin{tabular}{|c|c|c|c|c|c|}
\hline Sample & $\begin{array}{c}\text { Captured coal } \\
(\mathrm{dry})(\mathrm{gm})\end{array}$ & $\begin{array}{c}\text { Rejects } \\
(\mathrm{dry})(\mathrm{gm})\end{array}$ & $\begin{array}{c}\text { Total } \\
(\mathrm{grams})\end{array}$ & $\begin{array}{c}\text { Initial weight } \\
(\mathrm{dry})(\mathrm{gm})\end{array}$ & $\%$ error \\
\hline Total mass & 43.6 & 8.3 & 51.9 & 52 & 0 \\
\hline Ash Mass & 7.36 & 1.66 & 9.02 & 9.5 & 5.05 \\
\hline
\end{tabular}

The ash percentage after performing the second washing was further reduced to $16.90 \%$ as described in Table 5.14. However the ash percentage in the rejects also dropped from 33.90\% to $20.1 \%$ after the second washing of coal as described in the Table 5.15. The yield after the second washing of the coal is $43.6 \mathrm{gm}$ and the percentage yield of coal after the second run is $62.28 \%$. Since the ash percentage is still high, a third round of washing was again performed on the coal using the product of the second washing. The procedure remained the same as described in Figure 5.4 and the results of the third washing are described in the Tables 5.17, 5.18 and 5.19.

Table 5.17. Results for third pass of Particle size separation method, agglomerates.

\begin{tabular}{|l|r|r|r|}
\hline Sample Id & \multicolumn{1}{|l|}{ Volatiles (\%) } & \multicolumn{1}{|l|}{ Fixed Carbon (\%) } & \multicolumn{1}{|c|}{ Ash (\%) } \\
\hline 061110CRYLigAGG2 1 & 49.51 & 35.89 & 14.59 \\
\hline 061110CRYLigAGG2 2 & 48.69 & 36.92 & 14.38 \\
\hline 061110CRYLigAGG2 3 & 49.41 & 36.19 & 14.38 \\
\hline Average & 49.20 & 36.33 & 14.45 \\
\hline
\end{tabular}


Table 5.18. Results for third pass of Particle size separation method, Rejects.

\begin{tabular}{|ll|r|r|r|}
\hline Sample Id & & Volatiles (\%) & Fixed Carbon (\%) & Ash (\%) \\
\hline 061110CRYLigREJ3 & 1 & 44.37 & 34.47 & 21.15 \\
\hline 061110CRYLigREJ3 & 2 & 43.81 & 34.82 & 21.35 \\
\hline 061110CRYLigREJ3 & 3 & 44.24 & 34.75 & 20.99 \\
\hline Average & & 44.14 & 34.68 & 21.17 \\
\hline
\end{tabular}

Table 5.19 Mass and ash balance of third washing using the Particle size separation method

\begin{tabular}{|c|c|c|c|c|c|}
\hline Sample & $\begin{array}{c}\text { Captured coal } \\
(\mathrm{dry})(\mathrm{gm})\end{array}$ & $\begin{array}{c}\text { Rejects } \\
(\mathrm{dry})(\mathrm{gm})\end{array}$ & $\begin{array}{c}\text { Total } \\
(\mathrm{grams})\end{array}$ & $\begin{array}{c}\text { Initial weight } \\
(\mathrm{dry})(\mathrm{gm})\end{array}$ & \% error \\
\hline Total mass & 37.2 & 4.2 & 41.4 & 43.6 & 5.05 \\
\hline Ash Mass & 4.37 & 0.80 & 5.17 & 5.05 & 2.4 \\
\hline
\end{tabular}

The results of third washing show a further decrease in the ash percentage of coal. The ash level was reduced to $14.45 \%$ as described in Table 5.17 and in the rejects stream the ash percentage is $21.17 \%$. After the analysis of individual steps of washing the coal a total assessment was made combining the data from all the three runs using the particle size separation process. These results are tabulated in the Table 5.20.

Table 5.20 Data from the experiments done with the Particle size separation protocol

\begin{tabular}{|c|c|c|}
\hline Number of Experiment & Ash (\%) & Coal Recovered (grams) \\
\hline 0 ( Initial condition) & 28 (Initial Condition ) & 72 ( Initial Condition) \\
\hline 1 & 19.59 & 52 \\
\hline 2 & 16.9 & 43.6 \\
\hline 3 & 14.45 & 37.2 \\
\hline
\end{tabular}




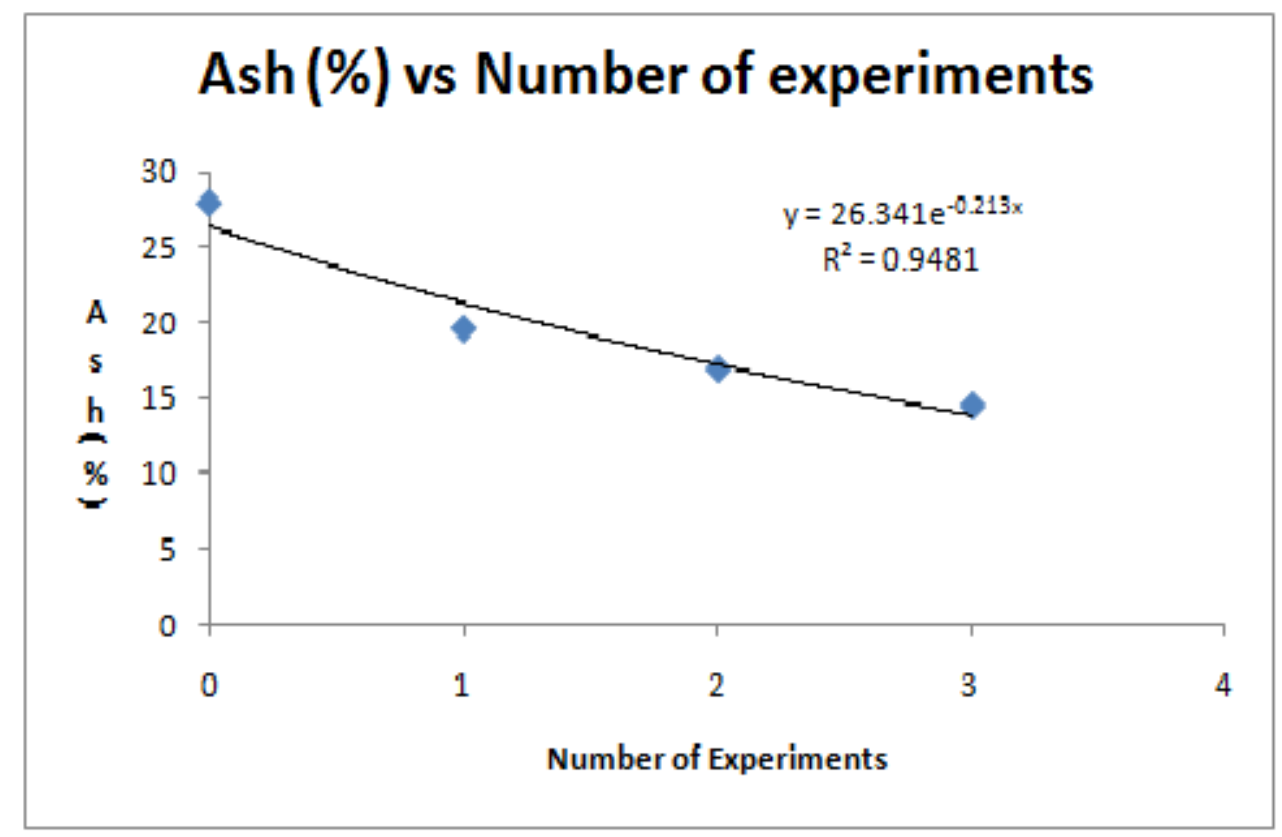

Figure 5.5 Ash(\%) vs No. of experiments for Particle size separation method

The Figure 5.5 of Ash(\%) vs the number of experiments shows a diminishing result of ash rejected as the number of runs is incresed. The number of runs that need to be made for the ash percentage to be $10 \%$ can be calculated using the regressing equation. This number turned out to be 5. This is clearly an improvement from the decantation method. Also the the coal collected after the thrid run has an ash percentage of $14.45 \%$ as compared to $18.85 \%$ ash in the coal collected after the third run of the decantation mehtod. This clearly suggests that the particle size separation method is better than the decantation method.

The coal yield after the third run is $37.2 \mathrm{gm}$, giving overall percentage coal yield of $53.14 \%$. This is a small improvement from the $48 \%$ yield of coal using the decantation process. Also as described in the Figure 5.6 the yield of coal at $10 \%$ ash if calculated by interpolation comes out to be $26.18 \mathrm{gm}$ and the percentage yield is $37 \%$ which is higher that $0.4 \%$ coal using the decantation method. 


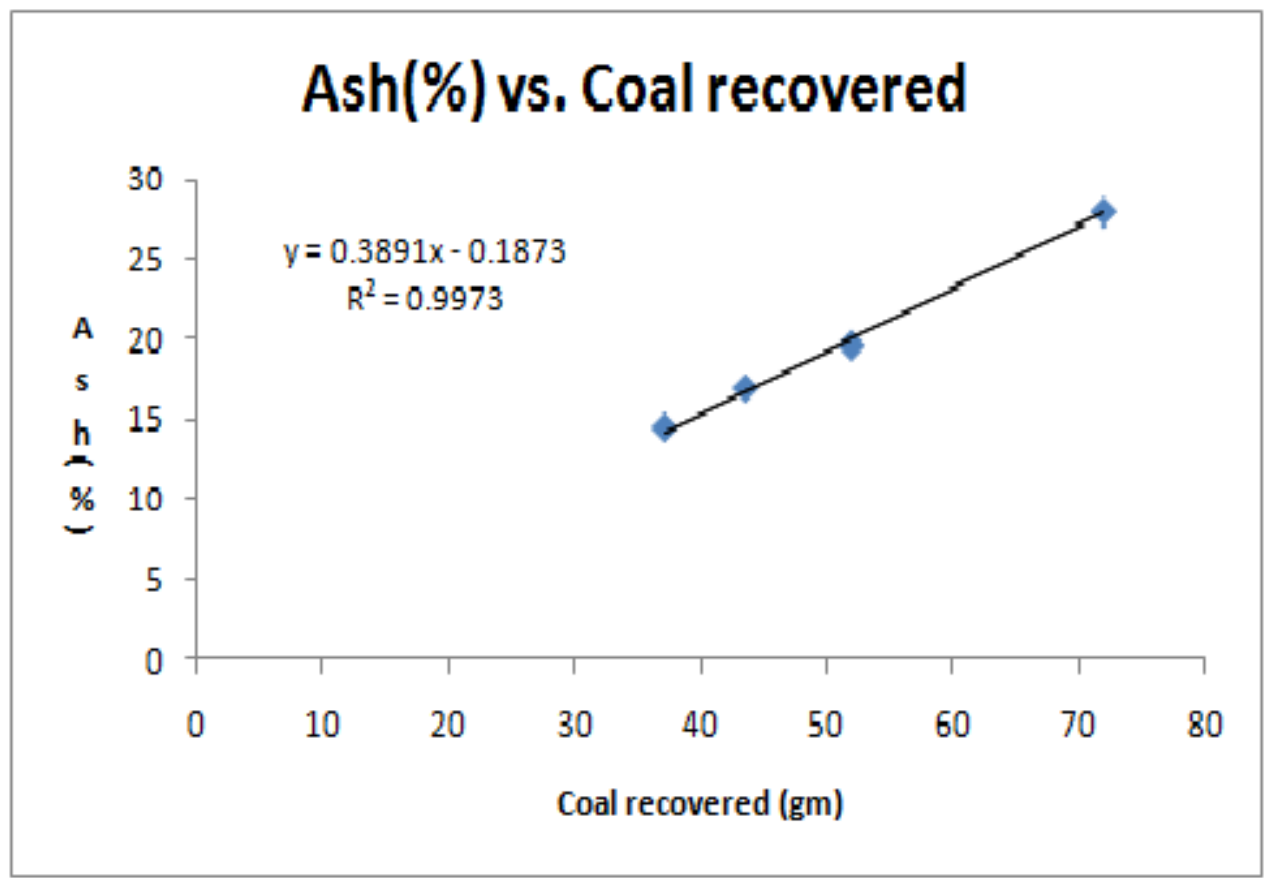

Figure 5.6 Ash (\%) vs. Coal recovered for Particle Size separation method

The changes that have been made in the process have produced better results. The new process can be compared with the decanted process. The selectivity and yields are the parameters by which the two processes can be compared. In Section 5.3 both of the processes are compared. 


\subsection{Comparison between particle size separation method and decantation method:}

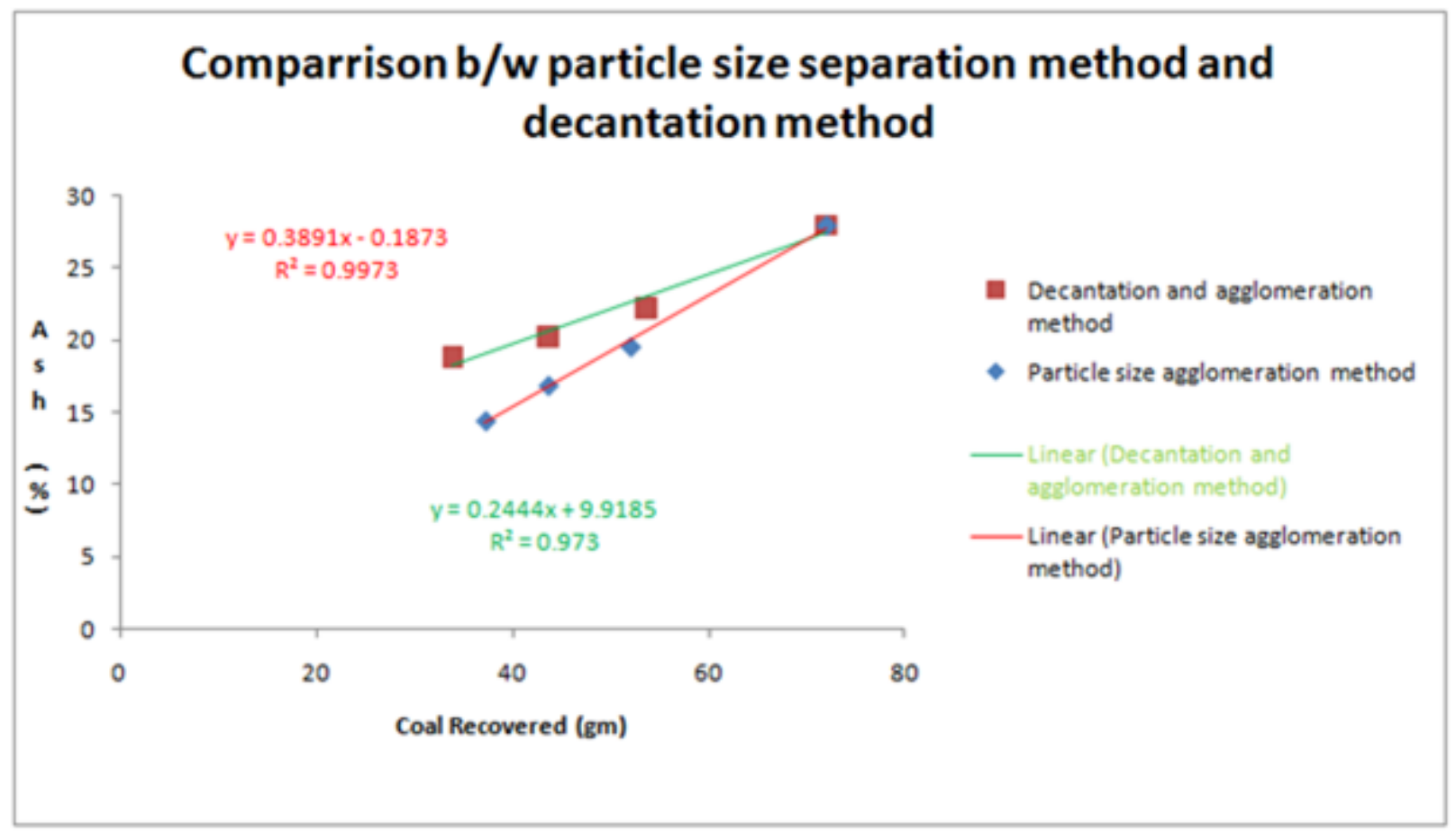

Figure 5.7 Comparrison between particle size separation method and decantation method

The comparison between the decantation method and the particle size separation method using a 325 Mesh sieve is shown in Figure 5.7. The effectiveness of the process is shown in the slope of the line; if the slope is higher it means that the ash removed per gram of coal recovered is high. And if the ash removed per gram of rejects is high this means that the process is very effective. In Figure 5.7 it is shown that the slope of the line of the particle size separation method is larger than the slope of decantation and agglomeration method. Thus the particle size separation method is clearly more effective than the decantation method.

The ash percent in the coal after performing the cleaning for the third time on the same sample using the particle size separation method is $14.45 \%$ as shown in Table 5.17. Since the goal is to obtain a $10 \%$ ash level, additional changes must be made to the process. The effectiveness of the surfactant to suspend clay in the water depends upon the effectiveness of agitation. Agitation can be enhanced using ultrasound. Thus one more step has to be included in the coal cleaning process, the use of ultrasound for effective agitation. This in turn should help in 
making the suspension of clays easier. The details of the experiments performed using ultrasound as an addition to the particle size separation process are given in Section 5.4.

\subsection{Refined protocol for the washing of coal:}

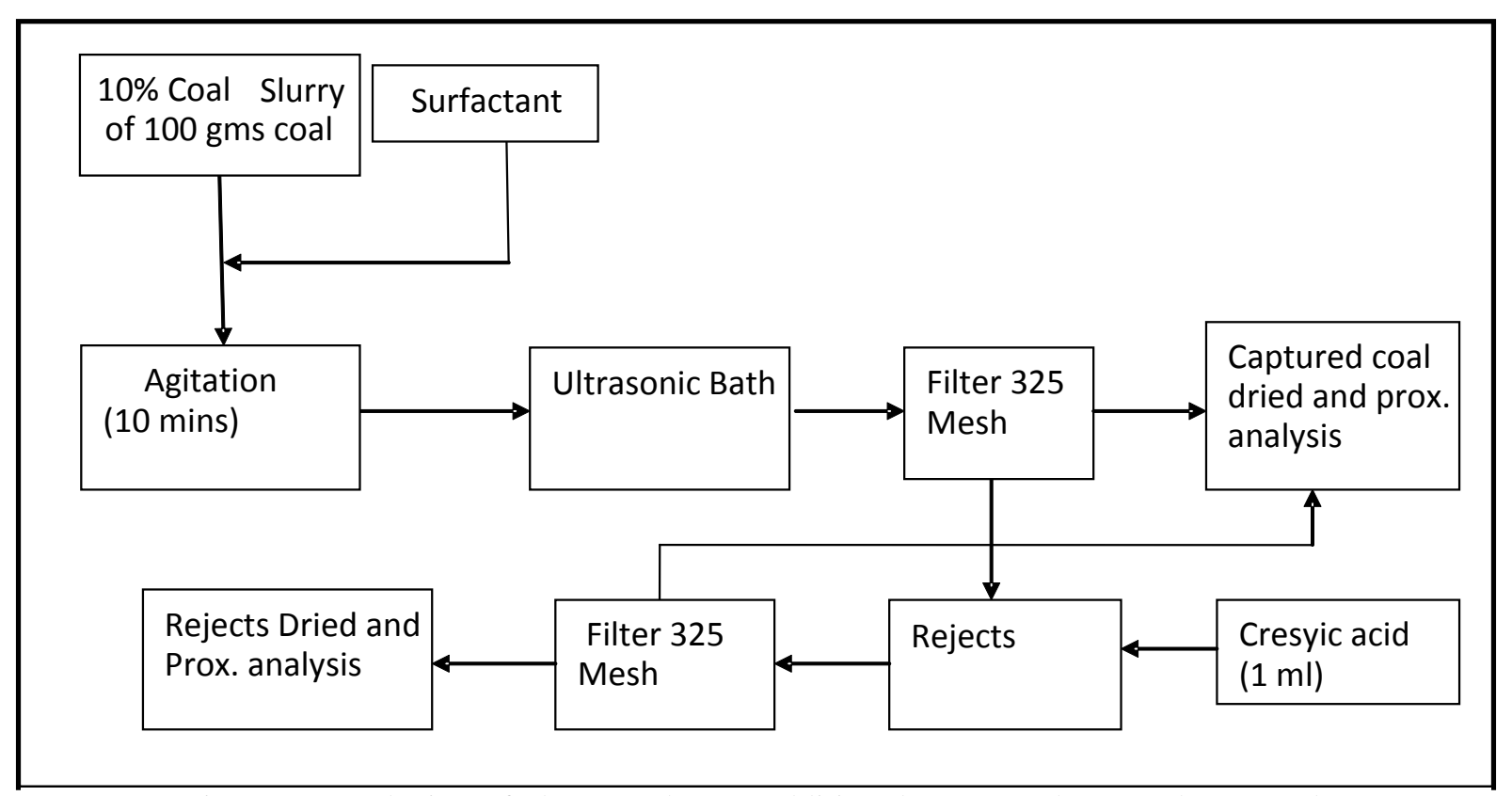

Figure 5.8 Inclusion of ultrasound as an additional step to enhance ash removal.

The above flow chart in Figure 5.8 describes the coal cleaning process that was used to clean lignite. A slurry of $10 \%$ coal in water is mixed with $1 \mathrm{gm} / \mathrm{kg}$ of coal surfactant and agitated for ten minutes. It was then put in an ultrasonic bath of $215 \mathrm{~W}$ at room temperature for one hour. The slurry is then filtered through a 325 mesh screen and the captured coal was collected. Cresylic acid was added to the rejects and then the mixture was again run through the 325 mesh screen. The remaining coal was filtered and the rejects that pass through the 325 Mesh screen were separated using a Buchner funnel. After filtration the rejects were dried at atmospheric pressure and $105^{\circ} \mathrm{C}$ for one hour and sent for proximate analysis. The coal that was captured in both the filter runs (first run and through 325 Mesh and second run with agglomeration using cresylic acid) was also collected, dried and sent for proximate analysis.

The experiments were done using the above mentioned protocol and the experimental results are tabulated below in Tables 5.21 to 5.23. To test the efficacy of ultrasound, two experiments were conducted simultaneously keeping all the other parameters constant. One 
sample was subjected to ultrasound and other was not. The former experiment performed using ultrasound is called (US) and the latter experiment is called the control experiment (CE). Both the experiments were performed simultaneously. The results of these experiments are given in Tables 5.21 to 5.26 .

Table 5.21. Results of the Control Experiment (CE), Agglomerated Coal.

\begin{tabular}{|l|r|r|r|}
\hline Sample Id & \multicolumn{1}{|l|}{ Volatiles (\%) } & \multicolumn{1}{|l|}{ Fixed Carbon (\%) } & \multicolumn{1}{|c|}{ Ash (\%) } \\
\hline 061810CRYLigCE AGG 1 & 42.61 & 34.17 & 23.20 \\
\hline 061810CRYLigCE AGG 2 & 41.63 & 35.21 & 23.158 \\
\hline 061810CRYLigCE AGG 3 & 42.84 & 34.12 & 23.03 \\
\hline Average & 42.36 & 34.50 & 23.13 \\
\hline
\end{tabular}

Table 5.22. Results of the Control Experiment (CE), Rejects.

\begin{tabular}{|ll|r|r|r|}
\hline Sample Id & & \multicolumn{1}{|l|}{ Volatiles (\%) } & Fixed Carbon (\%) & Ash (\%) \\
\hline 061810CRYLigCERej 1 & 34.27 & 29.99 & 35.73 \\
\hline 061810CRYLigCERej 2 & 34.40 & 30.47 & 35.12 \\
\hline 061810CRYLigCERej 3 & 35.39 & & 35.14 \\
\hline Average & & 34.69 & 29.45 & 35.33 \\
\hline
\end{tabular}


Table 5.23 Mass and ash balance for the control experiment (CE)

\begin{tabular}{|c|c|c|c|c|c|}
\hline Sample & $\begin{array}{c}\text { Captured coal } \\
(\mathrm{dry})(\mathrm{gm})\end{array}$ & $\begin{array}{c}\text { Rejects } \\
(\mathrm{dry})(\mathrm{gm})\end{array}$ & $\begin{array}{c}\text { Total } \\
(\mathrm{grams})\end{array}$ & $\begin{array}{c}\text { Initial weight } \\
(\mathrm{dry})(\mathrm{gm})\end{array}$ & \% error \\
\hline Total mass & 59.45 & 13.41 & 72.84 & 70 & 4.05 \\
\hline Ash Mass & 13.87 & 4.08 & 17.95 & 18 & 0 \\
\hline
\end{tabular}

The results for the experiments performed using the ultrasound are in Table 5.24 to 5.26.

Table 5.24 Results for the Ultrasonic treatment of coal, Agglomerated Coal.

\begin{tabular}{|c|c|c|c|}
\hline Sample ID & Volatiles(\%) & Fixed Carbon $(\%)$ & $\operatorname{Ash}(\%)$ \\
\hline 2010618 Cry Lig/US/AG & 42.12 & 37.36 & 20.52 \\
\hline
\end{tabular}

Table 5.25. Results for the Ultrasonic Treatment, Rejects.

\begin{tabular}{|l|r|r|r|}
\hline Sample Id & \multicolumn{1}{|l|}{ Volatiles (\%) } & Fixed Carbon (\%) & \multicolumn{1}{|l|}{ Ash (\%) } \\
\hline 061810CRYLigUSRej 1 & 34.81 & 29.90 & 35.27 \\
\hline 061810CRYLigUSRej 2 & 35.24 & 30.23 & 34.51 \\
\hline 061810CRYLigUSRej 3 & 35.10 & 30.58 & 34.31 \\
\hline Average & 35.05 & 30.24 & 34.70 \\
\hline
\end{tabular}

Table 5.26 Mass and ash balance for the Ultrasound experiment (US)

\begin{tabular}{|c|c|c|c|c|c|}
\hline Sample & $\begin{array}{c}\text { Captured coal } \\
(\mathrm{dry})(\mathrm{gm})\end{array}$ & $\begin{array}{c}\text { Rejects } \\
(\mathrm{dry})(\mathrm{gm})\end{array}$ & $\begin{array}{c}\text { Total } \\
(\mathrm{grams})\end{array}$ & $\begin{array}{c}\text { Initial weight } \\
(\mathrm{dry})(\mathrm{gm})\end{array}$ & \% error \\
\hline Total mass & 58.71 & 16.42 & 75.13 & 70 & 7.14 \\
\hline Ash Mass & 11.34 & 5.74 & 17.11 & 18 & 5.0 \\
\hline
\end{tabular}


The results of both the experiments show consistency in the percentage of ash in the rejects. Because the same chemicals and method are being used, the consistency in the ash percentage of the rejects was expected. This proves that the protocol being used for cleaning the Jewett Lignite produces consistent and reproducible results.

However the ash percentage in the coal is $3 \%$ lower in the experiment using ultrasound as compared to the control experiment. The effect of ultrasound on the ash rejection is not very profound, but since the aim is to get the highest purity, ultrasonic agitation is incorporated in the protocol and all the subsequent experiments will be performed with the use of ultrasound.

The yield from the experiments was $87 \%$ for the control experiment and $84 \%$ for the experiment using the ultrasound. Since the absolute value of ash in the sample is still high, a second run was performed and in this run instead of using a 325 mesh screen, a 230 mesh screen was used to make the suspended clays and the surfactant go through the filtration step more easily. The results of this run are tabulated below in Tables 5.27-5.30.

Table 5.27. Results with Ultrasonic Treatment, $2^{\text {nd }}$ washing Agglomerated Coal.

\begin{tabular}{|l|r|r|r|}
\hline Sample Id & Volatiles (\%) & Fixed Carbon (\%) & Ash (\%) \\
\hline $07142^{\text {nd }}$ Run US 1 & 47.08 & 42.63 & 10.28 \\
\hline $07142^{\text {nd }}$ Run US 2 & 46.56 & 41.71 & 11.71 \\
\hline Average & 46.82 & & 42.17 \\
& & & 11.00 \\
\hline
\end{tabular}


Table 5.28. Results with Ultrasonic Treatment, Second run, Rejects.

\begin{tabular}{|c|c|c|c|}
\hline Sample Id & Volatiles (\%) & Fixed Carbon (\%) & $\operatorname{Ash}(\%)$ \\
\hline $07142^{\text {nd }}$ Run US REJ 1 & 41.73 & 33.22 & 25.03 \\
\hline $07142^{\text {nd }}$ Run US REJ 2 & 41.14 & 32.96 & 25.89 \\
\hline Average & 41.44 & 33.09 & 25.46 \\
\hline
\end{tabular}

Table 5.29 mass and ash balance for Ultrasonic Treatment, Second Trial

\begin{tabular}{|c|c|c|c|c|c|}
\hline Sample & $\begin{array}{c}\text { Captured coal } \\
(\mathrm{dry})(\mathrm{gm})\end{array}$ & $\begin{array}{c}\text { Rejects } \\
(\mathrm{dry})(\mathrm{gm})\end{array}$ & $\begin{array}{c}\text { Total } \\
(\mathrm{grams})\end{array}$ & $\begin{array}{c}\text { Initial weight } \\
(\mathrm{dry})(\mathrm{gm})\end{array}$ & \% error \\
\hline Total mass & 34.65 & 23.57 & 58.22 & 58.71 & 0 \\
\hline Ash Mass & 3.81 & 5.89 & 9.7 & 10.89 & 10.09 \\
\hline
\end{tabular}

It should be noted that the ash percentage in the agglomerated coal dropped to $11 \%$. This is a significant improvement in the process. Not only is the ash percentage lower than before but also it is achieved in two steps instead of three.

Table 5.30 Data from the experiments done with the Particle size separation protocol with Ultrasound.

\begin{tabular}{|c|c|c|}
\hline Number of experiments & Ash $(\%)$ & Coal Recovered (grams) \\
\hline 0 ( Initial Conditions) & 28 ( Initial Conditions) & 70 ( Initial Conditions) \\
\hline 1 & 20.52 & 58.71 \\
\hline 2 & 11 & 34.65 \\
\hline
\end{tabular}




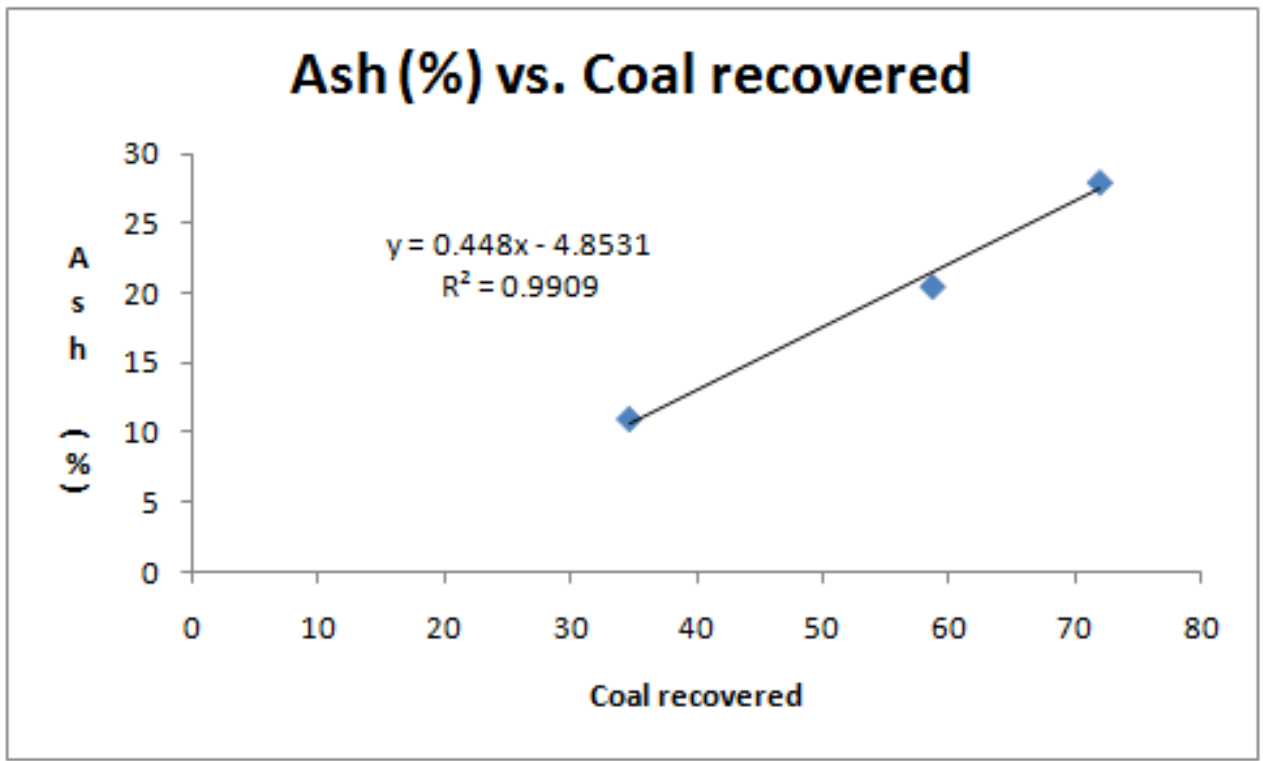

Figure 5.9 Ash (\%) vs. Coal recovered for particle size separation method with ultrasound

In the graph shown in Figure 5.9 the ash percentage vs. coal recovered is a straight line, this behavior has been found in all the previous experiments. The amount of coal recovered at any ash level can be calculated by the regression equation $y=0.448 x-4.853$. The amount of coal recovered at $10 \%$ ash is $33.15 \mathrm{gm}$. The percentage yield of coal at $10 \%$ theoretically is going to be $47.3 \%$. 


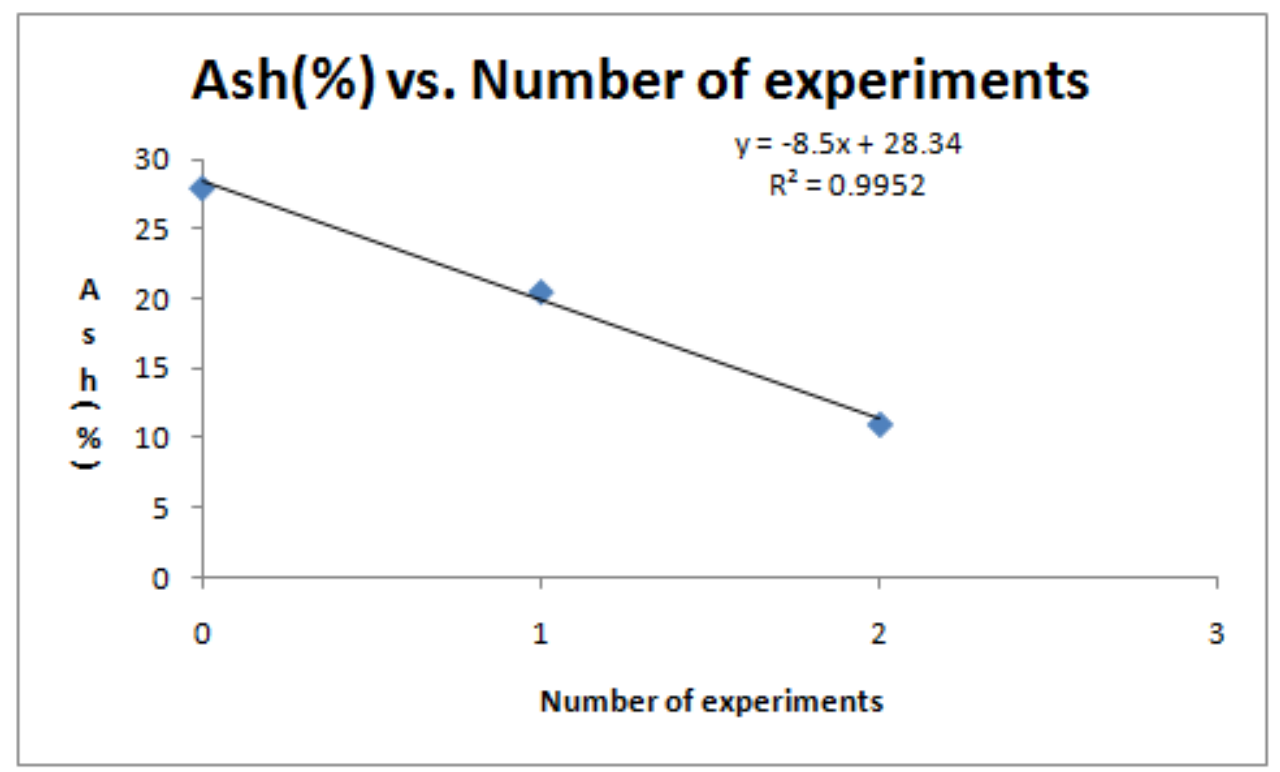

Figure 5.10 Ash (\%) vs number of experiments for Particle size separation method with ultrasound

From the plot of data in Figure 5.10 the ash percentage vs. the number of runs is a straight line as opposed to the exponentially decreasing curve observed in the previous runs. Using the ultrasound makes the ash removal in one step a linear function. This is the major advantage of using the ultrasound. This is the same reason why the yield observed at the target ash percentage of $10 \%$, which is calculated using the regression line, is higher in the experiment in which ultrasound was used. The effectiveness of ultrasound is discussed in the following Section 5.4.2. 


\subsubsection{Effect of ultrasound:}

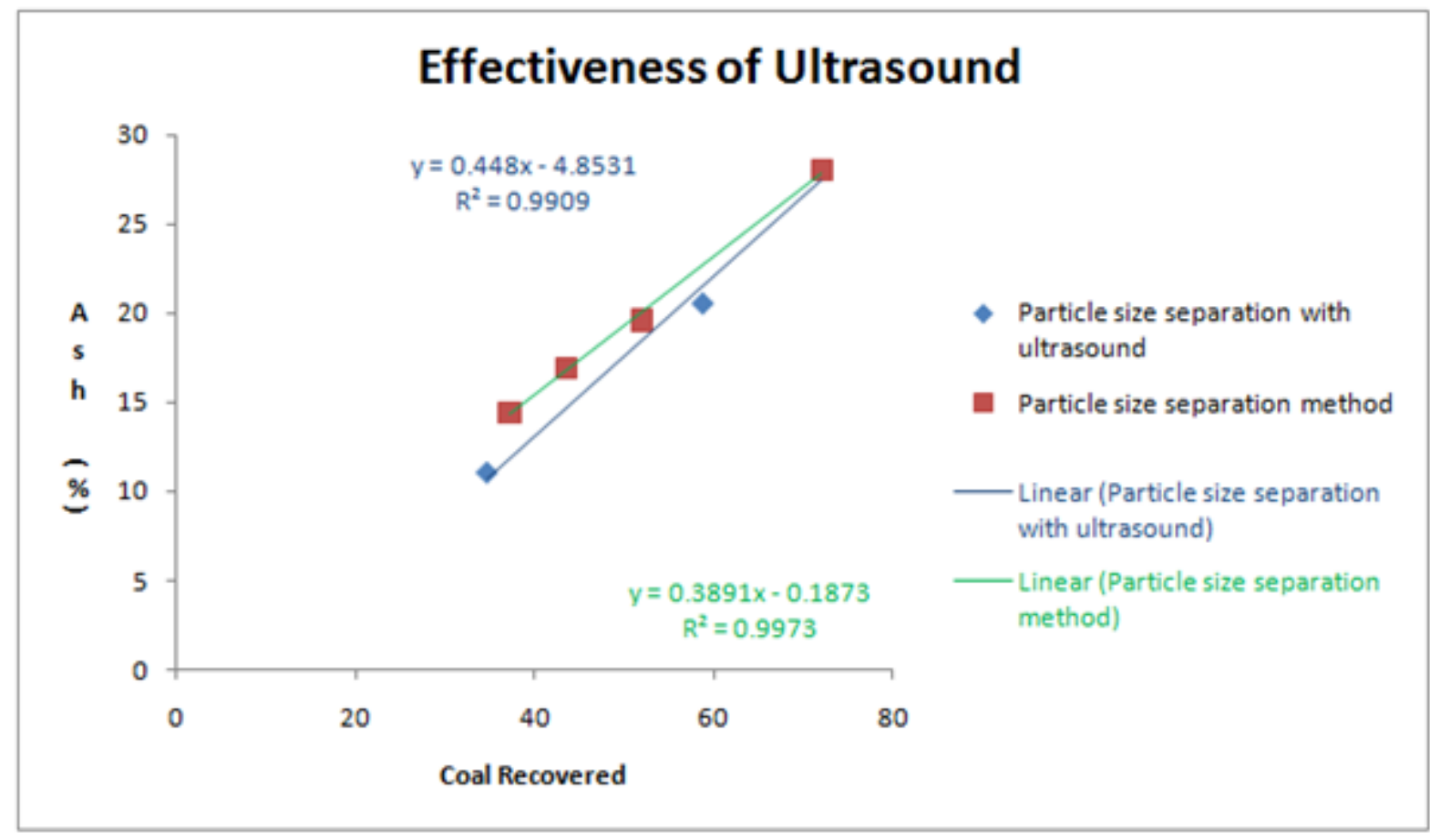

Figure 5.11 Graph showing comparrison between experiments with and w/o ultrasound

The data generated by experiments performed using the ultrasound at room temperature and $216 \mathrm{~W}$ for one hour are not significantly different from the data generated without using the ultrasound in the terms of slope and yields. However the major difference lies in the fact that only two steps were required to bring the ash percentage down to $11 \%$ using ultrasound as opposed to performing three steps without the use of ultrasound with the end result of $14.45 \%$. So, it is safe to conclude that better agitation, while not increasing the yield by orders of magnitude, still makes the protocol more effective by lessening the number of washings to be performed on the same sample of coal. Also ultrasound increases the ash rejection in each step of the washing.

The ash content is seen to be reduced in the number of experiments that are performed using various techniques. However the goal of obtaining coal with $10 \%$ ash has not been achieved yet. This might be attributed to the fact that during the particle size separation step a filter cake forms on the sieve and restricts the flow of suspended clay particles through the sieve. This problem was resolved by using 230 Mesh sieve instead of 325 Mesh screen for the filtration step. 
Also to increase the yield of the process, a larger particle size of coal was used. The particle size of the coal was increased to 65 to 100 Mesh. This allowed enough porosity in the filter cake to make the flow of clay particles easier. The size of coal particles at 65 to 100 Mesh is between 250 to 150 Microns, whereas the size of clay particle is 2-5 Microns. The particle size separation method with ultrasound was performed on a coal sample of 65 to 100 Mesh and the results are provided in Tables 5.31 to 5.33.

Table 5.31. Results of the 65-100 Mesh coal, Agglomerated Coal.

\begin{tabular}{|l|r|r|r|}
\hline Sample Id & Volatiles (\%) & Fixed Carbon (\%) & \multicolumn{1}{|l|}{ Ash (\%) } \\
\hline 061810CRYLigCE AGG 1 & 42.61 & 34.17 & 12.15 \\
\hline 061810CRYLigCE AGG 2 & 41.63 & 35.21 & 13.09 \\
\hline 061810CRYLigCE AGG 3 & 42.84 & 34.12 & 12.23 \\
\hline Average & 42.36 & 34.50 & 12.51 \\
\hline
\end{tabular}

Table 5.32. Results of the 65-100 Mesh coal, Rejects.

\begin{tabular}{|ll|r|r|r|}
\hline Sample Id & Volatiles (\%) & Fixed Carbon (\%) & Ash (\%) \\
\hline 061810CRYLigCERej 1 & 34.27 & 29.99 & 35.73 \\
& & 34.40 & 30.47 & 35.12 \\
\hline 061810CRYLigCERej 2 & 35.39 & 29.45 & 35.14 \\
\hline 061810CRYLigCERej 3 & 34.69 & 29.97 & 35.33 \\
\hline Average & & & \\
\hline
\end{tabular}


Table 5.33 Mass and ash balance for cleaning of 65-100 Mesh coal

\begin{tabular}{|c|c|c|c|c|c|}
\hline Sample & $\begin{array}{c}\text { Captured coal } \\
(\mathrm{dry})(\mathrm{gm})\end{array}$ & $\begin{array}{c}\text { Rejects } \\
(\mathrm{dry})(\mathrm{gm})\end{array}$ & $\begin{array}{c}\text { Total } \\
(\mathrm{grams})\end{array}$ & $\begin{array}{c}\text { Initial weight } \\
(\mathrm{dry})(\mathrm{gm})\end{array}$ & $\%$ error \\
\hline Total mass & 37.23 & 36.2 & 73.41 & 70 & 4.87 \\
\hline Ash Mass & 4.65 & 13.03 & 17.68 & 18 & 1.8 \\
\hline
\end{tabular}

Since larger particle size was used to perform this run, the agglomerates that formed after the addition of cresylic acid were bigger and had enough space between them for clays to pass through the filter cake and the sieve. This resulted in enhancing the efficacy of the process and $12.51 \%$ ash level was reached in a single step.

\subsection{Incorporation of Float Sink for removing rock ash.}

The ash formed after the ashing step of the proximate analysis was red in color, indicating the presence of iron. The basic assumption on which whole process was designed was that all the inorganic material was aluminum silicates. However, since the presence of iron was suspected, another float sink step was added to the process. The coal agglomerates that were captured by the sieve after the clay removal process were dried and a float sink step was performed. The density of liquid media was chosen to be 1.7 as average coal density is less that 1.6 and iron oxides and pyrites have a density of $5.3 \mathrm{~g} / \mathrm{cm}^{3[42]}$. By performing this step all the heavy impurities of iron sink to the bottom and the coal floats on the top. After performing the clay removal step to the coal whose results are shown in Table 5.33, 37.23 gm of coal was then recovered. This coal was further cleaned by using float sink. Since clays stick to coal macerals and have a comparable density to the coal, the float sink step is only effective after the clay has been removed from the coal macerals. Taking the coal cleaned in the clay removal step given in Table 5.33, a float sink step was performed. The results of the float sink step are provided in Table 5.34. 
Table 5.34. Results float sink performed on coal previously cleaned using the clay removal step.

\begin{tabular}{|c|c|c|c|}
\hline Sample ID & Volatiles(\%) & Fixed Carbon (\%) & $\operatorname{Ash}(\%)$ \\
\hline 2010618 Cry Lig/US/AG & 45.12 & 39.38 & 11.18 \\
\hline
\end{tabular}

The weight of coal recovered after the float-sink step was $35 \mathrm{gm}$. This makes the overall yield to be $50 \%$. The amount of material that fell at the bottom was too small for a proximate analysis and was unrecoverable. But the proximate analysis of the float is given in Table 5.34.The final protocol which was used to clean coal is described in Figure 5.12.

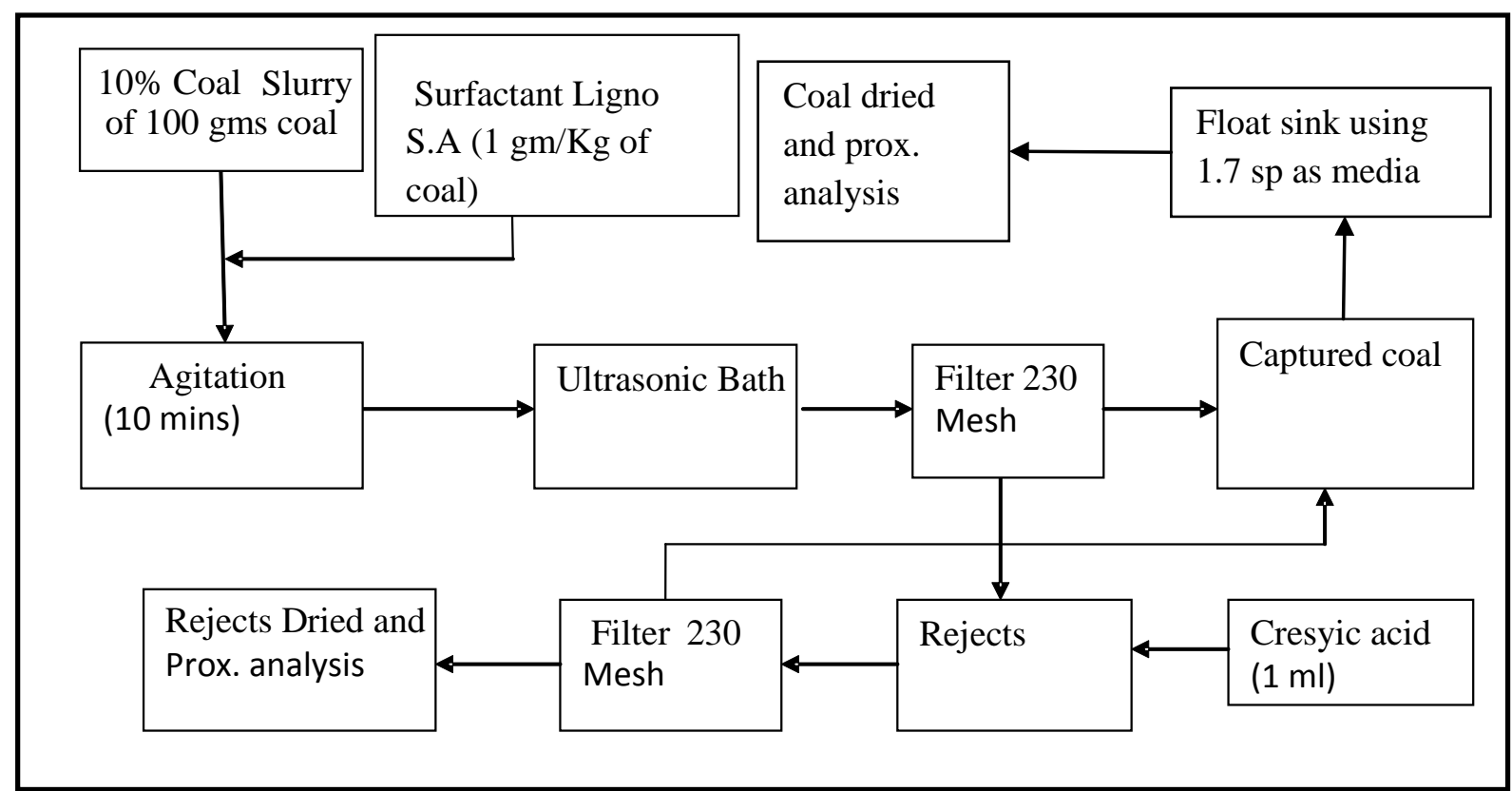

Figure 5.12 Revised protocol developed for coal cleaning

The process described above is the final protocol developed for cleaning of Texas lignite coal using the combination of particle size separation, assisted by ultrasound and float sink as the basis of separating inorganic compounds like clay and metal oxides such as iron oxide from coal. Using the above protocol the ash was reduced to $11.18 \%$ starting from $28 \%$. 


\subsubsection{Description of the Revised Protocol for cleaning coal.}

The process described in Figure 5.12 targets two different kinds of impurities. The first half of the process is the clay removal step. Since clay sticks to the coal macerals because they hold moisture and are wet, in the first half of the process the clay is suspended using the sodium salt of lingo-sulphonic acid and the coal is agglomerated using cresylic acid as an agglomerating agent. The separation occurs when the slurry is mixed thoroughly by agitation and followed by ultrasound and is poured over a 230 Mesh screen (65 Microns). The clay particles being small in size (about 2-5 microns) pass through the pores of the sieve and the coal is captured over the sieve in the form of a filter cake. After the clay is removed, the next part of the process described in Figure 5.12 separates out heavy impurities like rock ash by a simple float sink process. The density of the medium is 1.7 since the average density of lignitic coal is about 1.6. The heavy impurities containing iron oxides and pyrites sink to the bottom and the clean coal floats on the top. These can then easily be separated by decantation. The coal which is in the top fraction is separated, filtered, and dried at $105^{\circ} \mathrm{C}$ and atmospheric pressure for one hour and sent for proximate analysis.

\subsection{DevourX Coal Grinding:}

DevourX LLC has recently developed a process to grind coal to a very small particle size at low cost. The machine uses a very powerful engine to create a very highly turbulent vortex at the center of an air duct. Coal or some other friable material may be fed directly into the air tunnel and due to the strong eddy currents of the turbulent air is crushed to a very small particle size. Because coal is much stronger in compression than in shear or tension, it perhaps should not come as a surprise that it can be reduced to the -100 to -200 average mesh size in such a machine.

The DevourX machine can be used to increase the efficacy of the particle size separation process for two reasons. First, the machine crushes the coal to a very small size so that the separation between coal and clay may be enhanced for processes that depend on the surface area of the particles. Secondly, crushing coal by shear forces separate the coal macerals, which are often in the range of micron size, which helps in removing the clay that is fused with coal in the 
coal shale. Another advantage of using this machine is the moisture content of the coal decreases significantly because of the very high air flow rate through the machine.

The next section describes experiments which were carried out using the particle size separation process on Jewett Lignite coal which was ground using DevourX machine.

\subsection{Cleaning lignite coals that were ground using DevourX process using the process described in figure 5.12 .}

The process described in Section 5.5.1 and in Figure 5.12 was used to carry out cleaning of coal (Jewett lignite and San Miguel lignite coal) which was crushed using DevourX grinding process. The conditions described in Figure 5.12 are kept the same. The results, calculation of yield and other calculations for the clay removal step and the float sink step are done separately. All the results and calculations are given in Tables 5.35 to 5.40.

\subsubsection{Results for coal cleaning process performed on Texas Jewett lignite which was ground using DevourX.}

The process described in Figure 5.12 was used to clean DevourX Texas Jewett lignite coal. The details of the process were kept the same; the results of the run are provided in the tables below.

Table 5.35 Results for DevourX coal, cleaned by clay removal process

\begin{tabular}{|c|c|c|c|}
\hline Sample Id & Volatiles (\%) & Fixed Carbon (\%) & Ash (\%) \\
\hline Devx Lignite cleaning 1 & 41.77 & 45.23 & 12.98 \\
\hline Devx Lignite cleaning 2 & 42.29 & 45.19 & 12.51 \\
\hline Devx Lignite cleaning 3 & 42.54 & 44.52 & 12.93 \\
\hline Average & 42.20 & 44.98 & 12.81 \\
\hline
\end{tabular}


Table 5.36 Results for DevourX coal rejects, cleaned by clay removal process

\begin{tabular}{|c|c|c|c|}
\hline Sample Id & Volatiles (\%) & Fixed Carbon (\%) & Ash (\%) \\
\hline Devx Lignite cleaning rej 1 & 27.85 & 29.90 & 42.24 \\
\hline Devx Lignite cleaning rej 2 & 27.61 & 29.87 & 42.51 \\
\hline Devx Lignite cleaning rej 3 & 27.51 & 29.66 & 42.82 \\
\hline Average & 27.66 & 29.81 & 42.52 \\
\hline
\end{tabular}

The mass balance for the clay removal step for DevourX lignite is provided in Table 5.39. The coal that was recovered in the clay removal step was taken and float sink was performed on it. The results from the float sink step and the calculation of yields are provided in Tables 5.37 to 5.40 .

Table 5.37 Results for DevourX coal rejects, cleaned by float sink process

\begin{tabular}{|c|c|c|c|}
\hline Sample Id & Volatiles (\%) & Fixed Carbon (\%) & Ash (\%) \\
\hline Devx Lignite cleaning float 1 & 47.85 & 43.90 & 9.28 \\
\hline Devx Lignite cleaning float 2 & 47.61 & 43.87 & 9.87 \\
\hline Devx Lignite cleaning float 3 & 47.51 & 43.66 & 9.59 \\
\hline Average & 47.66 & 43.81 & 9.52 \\
\hline
\end{tabular}

Table 5.38 Results for DevourX coal rejects, cleaned by float sink process

\begin{tabular}{|c|c|c|c|}
\hline Sample Id & Volatiles (\%) & Fixed Carbon (\%) & Ash (\%) \\
\hline Devx Lignite cleaning sink 1 & 37.85 & 39.90 & 23.05 \\
\hline Devx Lignite cleaning sink 2 & 37.61 & 39.87 & 23.48 \\
\hline Devx Lignite cleaning sink 3 & 37.51 & 39.66 & 23.73 \\
\hline Average & 37.66 & 39.81 & 23.42 \\
\hline
\end{tabular}


The yields of the two different steps are provided in Tables 5.39 and 5.40. The DevourX lignite was run through the clay removal step, and the clays were separated out as rejects. The coal was then agglomerated captured and dried at $105{ }^{\circ} \mathrm{C}$.

Table 5.39 Mass Balance for the clay removal step.

\begin{tabular}{|c|c|c|c|c|}
\hline Sample & $\begin{array}{c}\text { Captured Coal } \\
(\text { dry })(\text { grams })\end{array}$ & $\begin{array}{c}\text { Rejects (dry) } \\
\text { (grams) }\end{array}$ & $\begin{array}{c}\text { Total (dry) } \\
\text { (grams) }\end{array}$ & \% error (\%) \\
\hline Total Mass & 62.33 & 22.67 & 85 & 1.39 \\
\hline Ash Mass & 7.41 & 11.59 & 19 & 2.98 \\
\hline
\end{tabular}

Yield for the clay removal step $=62.3 / 85^{*} 100=73.5 \%$.

After the clay removal process, float sink was performed on the coal that was recovered from the clay removal step, the results of which are give in Table 5.40.

Table 5.40 Mass Balance for the float sink step

\begin{tabular}{|c|c|c|c|c|}
\hline Sample & $\begin{array}{c}\text { Captured Coal } \\
(\text { dry })(\text { grams })\end{array}$ & $\begin{array}{c}\text { Rejects(dry) } \\
(\text { grams })\end{array}$ & $\begin{array}{c}\text { Total(dry) } \\
\text { (grams) }\end{array}$ & \% error $(\%)$ \\
\hline Total Mass & 51.92 & 12.37 & 63.29 & 1.44 \\
\hline Ash Mass & 4.48 & 2.84 & 7.53 & 2.29 \\
\hline
\end{tabular}

Yield for Float sink step $=50.92 / 63.29 * 100=80.4 \%$

The total yield of both the processes was calculated to be, $59.91 \%$

\subsubsection{Results for coal cleaning process performed on San Miguel lignite.}

San Miguel lignite was tested keeping all the conditions of the process described in the Figure 5.12 constant. The result of the experiment is provided below. The starting ash percentage of San Miguel coal is $32 \%$. 
Table 5.41 Results for SM coal, cleaned by clay removal process

\begin{tabular}{|c|c|c|c|}
\hline Sample Id & Volatiles (\%) & Fixed Carbon (\%) & Ash (\%) \\
\hline SM Lignite cleaning 1 & 43.85 & 34.27 & 21.86 \\
\hline SM Lignite cleaning 2 & 43.18 & 34.04 & 22.76 \\
\hline SM Lignite cleaning 3 & 43.90 & 34.76 & 21.33 \\
\hline Average & 43.64 & 34.36 & 21.98 \\
\hline
\end{tabular}

Table 5.42 Results for SM coal rejects, cleaned by clay removal process

\begin{tabular}{|c|c|c|c|}
\hline Sample Id & Volatiles (\%) & Fixed Carbon (\%) & Ash (\%) \\
\hline SM Lignite cleaning rej 1 & 35.44 & 23.58 & 40.96 \\
\hline SM Lignite cleaning rej 2 & 30.65 & 19.61 & 49.72 \\
\hline SM Lignite cleaning rej 3 & 36.31 & 23.49 & 40.19 \\
\hline Average & 34.13 & 22.23 & 43.63 \\
\hline
\end{tabular}

Table 5.43Results for SM coal, cleaned by float sink process

\begin{tabular}{|c|c|c|c|}
\hline Sample Id & Volatiles (\%) & Fixed Carbon (\%) & Ash (\%) \\
\hline SM Lignite cleaning float 1 & 52.13 & 36.06 & 11.81 \\
\hline SM Lignite cleaning float 2 & 51.86 & 36.93 & 11.18 \\
\hline SM Lignite cleaning float 3 & 52.49 & 36.07 & 11.42 \\
\hline Average & 52.17 & 36.35 & 11.47 \\
\hline
\end{tabular}


Table 5.44 Results for SM coal rejects, cleaned by float sink process

\begin{tabular}{|c|c|c|c|}
\hline Sample Id & Volatiles (\%) & Fixed Carbon (\%) & Ash (\%) \\
\hline SM Lignite cleaning sink 1 & 39.48 & 27.46 & 33.04 \\
\hline SM Lignite cleaning sink 2 & 39.30 & 27.44 & 33.24 \\
\hline SM Lignite cleaning sink 3 & 39.51 & 26.79 & 33.69 \\
\hline Average & 39.43 & 27.23 & 33.32 \\
\hline
\end{tabular}

The yields were calculated based on the results of proximate analysis results and are provided in Tables 5.45 and 5.46 .

Table 5.45 Mass Balance for the clay removal step.

\begin{tabular}{|c|c|c|c|c|}
\hline Sample & $\begin{array}{c}\text { Captured } \\
\text { Coal(dry) (grams) }\end{array}$ & $\begin{array}{c}\text { Rejects(dry) } \\
\text { (grams) }\end{array}$ & $\begin{array}{c}\text { Total(dry) } \\
\text { (grams) }\end{array}$ & Error (\%) \\
\hline Total Mass & 49.24 & 35.67 & 85 & 2.89 \\
\hline Ash Mass & 11.00 & 15.66 & 28 & 1.23 \\
\hline
\end{tabular}

Yield for the clay removal step $=49.44 / 85^{*} 100=58.29 \%$.

Table 5.46 Mass Balance for the float sink step

\begin{tabular}{|c|c|c|c|c|}
\hline Sample & $\begin{array}{c}\text { Captured Coal } \\
\text { (dry) (grams) }\end{array}$ & $\begin{array}{c}\text { Rejects(dry) } \\
\text { (grams) }\end{array}$ & $\begin{array}{c}\text { Total(dry) } \\
\text { (grams) }\end{array}$ & Error (\%) \\
\hline Total Mass & 30.28 & 19.16 & 49.44 & 1.11 \\
\hline Ash Mass & 3.38 & 6.42 & 11 & 1.93 \\
\hline
\end{tabular}

Yield for Float sink step $=30.28 / 49.44 * 100=61.24 \%$.

The total yield of both the processes was calculated to be, $35.62 \%$.

The results that are shown in Tables 5.46 and 5.40 suggest that DevourX and San Miguel coal can be cleaned using the protocol described in Figure 5.12. All the yields are for the clay 
removal steps are in the Tables 5.45 and 5.39. The inorganic content in the San Miguel coal has more heavy impurities like iron oxide and pyrites. However the purity of the coal comes at the price of the yield. But it is demonstrated in the Sections 5.6.1 and 5.6.2 that lignites other than the Jewett Lignite can be cleaned by the process developed during this research work and shown in Figure 5.12. 


\section{Conclusions and future work:}

\subsection{Conclusions:}

Based on the results obtained by repeated runs using the particle size process the following conclusions can be drawn in compliance with the research objectives that are mentioned in Sections 1.1 and 1.2.

1) A bench scale set up was built to perform various cleaning processes on coal, such as froth flotation, clay removal process, agglomeration of coal and float sink processes.

2) It was shown that conventional cleaning techniques typically used for bituminous and sub-bituminous like froth flotation and heavy media separation cannot be used for lignitic type coals.

3) A new process was developed that suspends clays in the slurry and agglomerates coal simultaneously. The effectiveness of this process was tested on three different kinds of coals, namely the Jewett lignite, Jewett lignite ground using DevourX process and San Miguel lignite also ground using DevourX process. This process is described in Figure 6.1 .

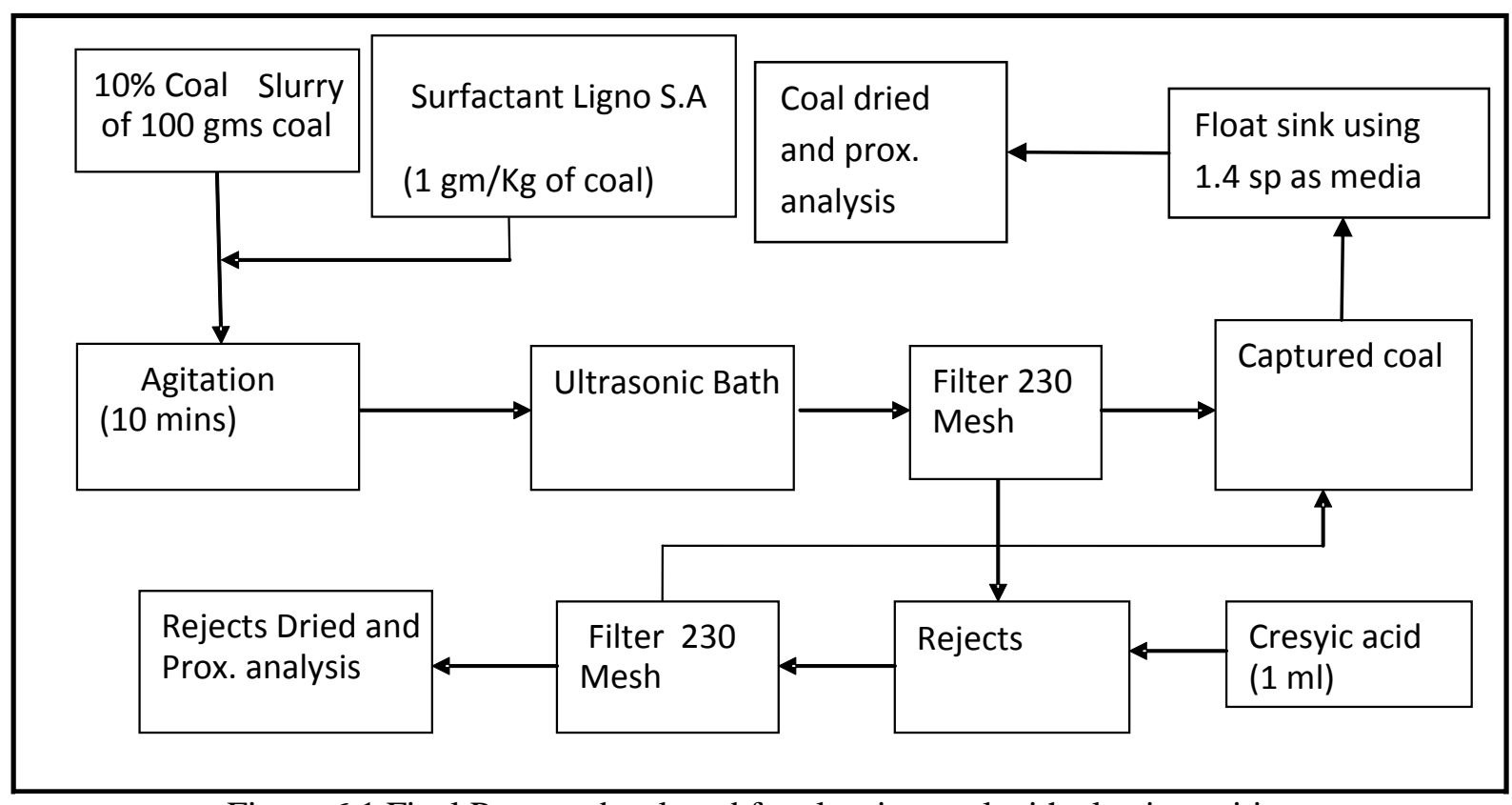

Figure 6.1 Final Process developed for cleaning coal with clay impurities 
4) Jewett lignite was cleaned using this process and lowest ash percentage attained for Jewett lignite was $11.87 \%$ ash with $49 \%$ yield.

5) DevourX crushing of coal enhances the process shown in Figure 6.1 as the ash percentage in the Jewett lignite coal was lowered to $9.52 \%$ with a yield of $59 \%$.

6) San Miguel lignite was cleaned by this process with the yields of $30 \%$ and the lowest ash percentage obtained was $11 \%$. The lower yields can be attributed to the fact that the process was not optimized for cleaning San Miguel Coal. Although a proof of concept was done showing that the San Miguel Coal, when put through the DevourX process, can be cleaned through the process demonstrated in Figure 6.1.

\subsection{Recommendations for future work:}

Based on the results of this thesis work a few recommendations for future work are listed below.

1) Using a Zeta meter to measure the exact surface charges, the process should be optimized by measuring the change in surface charges of the particles of coal at different concentrations of the surfactant.

2) For more effective separation between the suspended clay particles and agglomerated coal, it is recommended that a cyclone separator be used to recover all the coal fines to improve the yield of the process.

3) Testing of more effective agglomerating agents is recommended. A few agglomerating agents that can be used are naphthenic acid, block co-polymer surfactants, diesel fuel etc.

4) Testing of more effective dispersing agents containing a sodium cation and a large inert anion is recommended.

5) The water reduction effect of cresylic acid as an agglomerating agent should be studied in detail, and must be compared with the water loss of the "as-received" coal under the same conditions. 


\section{References}

1. AIE S. T., Scale effects in laboratory and pilot-plant reactors for trickle-flow processes, Oil \& Gas Science and Technology. 1991, 46, 501-515.

2. Aong C., Schobert H., Non-fuel uses of coals and synthesis of chemicals and materials, Fuel, 1996, Page 724-736.

3. A Jubert k., Stevens G., Masudi H., "A Study of Coal Formation,"

http://www.osti.gov/bridge/servlets/purl/32536-0e81BL/webviewable/ (1987)

4. Smith, Duane. "Mining America: The Industry and the Environment, 1800-1980." Lawrence, KS: University Press of Kansas. Page 210 (May 1993).

5. "Coal Mining." World Coal. World Coal Institute. 10 Mar. 2009 Page 57.

6. Sumboko Murti, S Sakashini, "Molecular Composition of coal liquids characterized by Gas Chromatography with atomic emissions detector."

www.anl.gov/PCS/.../45_4_WASHINGTON\%20DC_08-00_0860.pdf (1995)

7. U.S. Energy Information Administration. 2008. "World Coal Production" Most Recent Estimates1980-2007 (October2008).

http://www.eia.doe.gov/emeu/international/coalproduction.html [accessed 11-2-08].

8. Technology Status Report 010, “Coal Liquefaction”, Cleaner Coal Technology Programme, Department of Trade and Industry, (October 1999)

9. Osborne D.G. "Coal Preparation Technology", Chapter 2 Classification and properties, page 67. (1992).

10. Osborne D.G., "Coal Preparation Technology." Chapter 2 Classification and properties, page 79. (1992).

11. Schobert H., "Coal: The Energy Source of the Past and Future.” American Chemical Society, Washington D.C. (1987).

12. Schobert H., "The Geochemistry of Coal." Chem 1 supplement, Fuel Science Program, Pennsylvania State University. (1984)

13. “Coal Analytical Methods.” Blackwell Scientific Press, Page number 134. (1984). 
14. Robbins G. A., R. A. Winschel, C. L. Amos,"Agglomeration of low rank coal as pretreatment for direct coal liquefaction." Consolidation coal company, R\&D department.(1991)

15.Magean L., WVU Analytical Labs, College of Engineering and Mineral Resources.

16. Van Krevelen D.W., Coal: "Typology-Chemistry-Physics-Constitution" Elsevier Scientific Publishing Company, Amsterdam. (1981)

17. "Production of Carbon Products Using a Coal Extraction Process." U.S. Department of Energy National Energy Technology Laboratory, Final Report, (September 11, 2002 to August 31, 2004.)

18. Katakdaunde M, "Performance Study in the Hydrotreatment of Coal with Coal-Derived Solvents", Thesis, Department of Chemical Engineering, West Virginia University. Page 117. (2004)

19. Winans Randall E., John C. Crelling, "Argonne National Laboratory Southern Illinois University Chemistry and Characterization of Coal Macerals." American Chemical Society. Division of Fuel chemistry page 216. IV. Series. (May 08, 1984.)

20. Gray Daniel P., Petrographic Analysis of coal. Koppers. (February 04, 2009.)

21 Coal Preparation Plant Emission Tests, Consolidation Coal Company, Bishop, West Virginia, EMB Report 72-CCL-19A, U. S. Environmental Protection Agency, Research Triangle Park, NC, February 1972.

22. Hall, B.E., Halliburton Services, "A New Technique for Generating In-Situ Hydrofluoric Acid for Deep Clay Damage Removal.", Journal of Petroleum Technology, Volume 30 Number 9,1978

23. Lutterell G.L., R.Q. Honaker, D.I. Phillips, :Enhanced gravity separators: New method for cleaning coal fines.” Dept. of Mining Engineering Virginia Pole technique Institute, Blacksburg, Va. Page 3. (January 03, 1997)

24. Lutterell G.L., R.Q. Honaker, D.I. Phillips, "Enhanced gravity separators: New method for cleaning coal fines" Dept. of Mining Engineering Virginia Pole-technique Institute, Blacksburg Va. Page 5. (January 03, 1997) 
25. Xia Liuyin, Hong Zhong, Guangyi Liu, Zhiquang Huang. "Flotation separation of aluminum silicates from diaspore by a Gemini Cationic collector." Page 74-83 International Journal Mineral Processing. (2009)

26. M. Polat, H. Polat, S Chander. "Physical and Chemical Interactions in Coal Flotation." International Journal of Mineral Processing. Page 199-203 (2003).

27. Vanangamudi M. and T.C. Rao, "Development of an index for the floatability of Indian coal fines" (1999)

http://www.sciencedirect.com/science?_ob=ArticleURL\&_udi=B6VDR-47XF5XT-

7W\&_user=10\&_coverDate=12/31/1989\&_rdoc=1\&_fmt=high\&_orig=search\&_origin=search \&_sort=d\&_docanchor $=\&$ view $=c \& \_s e a r c h S t r I d=1445752351 \& \_r e r u n O r i g i n=$ google $\& \_a c c t=C 0$ 00050221\&_version=1\&_urlVersion=0\&_userid=10\&md5=658df5b1478e6e93c75a09ba4d651e a6\&searchtype $=\mathrm{a}$

28. Bhagvatula Abhijit. "Hydrogenation of naphthalene and coal tar distillate over ni/mo/al2o3 catalyst in a trickle bed reactor" Thesis, Department of Chemical Engineering, West Virginia University. Page 29 (2009)

29. Peirce, C. S., A Theory of Probable Inference, Studies in Logic, Little, Brown, and Company. Page 126-181, (Reprinted 1983, John Benjamins Publishing Company)

30. Vasconcellos Stephan R, Langhorne, Phuong-Thao Luong, Treverse. "Flocculation of Coal Fines with electrolytes and polyelectrolytes". US Patent 4906386 (1984)

31. Ding Kejian, Janusz S. Laskowski. "Coal Reversr Flotation Part II: Cleaning of subbituminous coal. Minerals Engineering.” Page Number 79-86 (2006)

32. Ding Kejian, Janusz S. Laskowski, "Coal Reversr Flotation Part II: Separation of mixture of sub-bituminous coal and gangue materials.” Minerals Engineering, Page 72-78. (2005)

33. Turunc Umit, "Methods for dewatering coal and mineral concentrates". US Patent Number 5089142. Turunc et al ( 1992).

34. Kamada S, Blackmore P.F., Kubota T. "Coal treatment for ash removal and agglomeration". US Patent 4331447 (1982) 
35. Guggenheim Stephen; Martin, R. T. "Definition of clay and clay mineral: Journal report of the AIPEA nomenclature and CMS nomenclature committees", Clays and Clay Minerals. Page 255-256.(1995)

36. Stevens E. D, M. L. de Lucia, and P. Coppens. "Experimental observation of the Effect of Crystal Field Splitting on the Electron Density Distribution of Iron Pyrite". Inorganic Chemistry. Page 813. (1980). 